\title{
»TÜRCK IST MEIN NAHM IN ALLEN LANDEN...« KUNST, PROPAGANDA UND DIE WANDLUNG DES TÜRKENBILDES IM HEILIGEN RÖMISCHEN REICH DEUTSCHER NATION
}

\author{
ZSUZSA BARBARICS* \\ (Pécs)
}

\begin{abstract}
Die Zielsetzung des vorliegenden Aufsatzes ist, anhand von Ergebnissen der Geschichtswissenschaft, der Germanistik und anderer Disziplinen und durch Anwendung derer Methoden die Wandlung des Türkenbildes, als Teil frühneuzeitlicher Wandlungsprozesse im Heiligen Römischen Reich Deutscher Nation zu rekonstruieren. Der Hauptakzent liegt auf der Analyse frühneuzeitlicher Flugblätter und Flugschriften als Indikatoren dieses Wandlungsprozesses und der Darstellung des Wandlungsprozesses in seinen Zusammenhängen. Neben der erwähnten interdisziplinären Annäherung liegt das Novum der Arbeit darin, daß sie versucht, auch jener Frage nachzugehen, inwieweit die kaiserliche Propaganda durch den Einsatz verschiedener Medien zu dieser Wandlung, die als eine vollständige inhaltliche Umdeutung zu bewerten ist und sich in allen Bereichen menschlichen Lebens erkennen läßt, beigetragen hat.
\end{abstract}

Key words: Türkenbild, Erbfeind, Medien, Flugschriften, Flugblätter, Propaganda, Türkenfurcht, Türkenmode

\section{Die Entstehung der Türkenfurcht in den Erbländern}

Der Kampf der Christenheit gegen die Osmanen ${ }^{1}$ hat zwangsweise zur Herausbildung des Türkenbildes geführt. Die ungarischen Könige wurden seit 1365 mit dem Vorstoß des Osmanischen Reiches auf der Balkanhalbinsel konfrontiert und mußten in ihrer Außenpolitik auf die Bewältigung der Türkengefahr einen großen Wert legen. ${ }^{2}$ Wegen ihrer geographischen Lage waren unter den Ländern der Habsburger die

${ }^{*}$ Zsuzsa Barbarics, Universität zu Pécs, Lehrstuhl für Geschichte des Mittelalters und der Frühen Neuzeit, 7624 Pécs, Rókus u. 2.

${ }^{1}$ Im Rahmen dieser Arbeit kann an dieser Stelle der Aufstieg des Osmanischen Reiches nicht ausführlich dargestellt werden. Im weiteren werde ich mich auf die Konfrontation der Erbländer mit den Osmanen beschränken. Weiterführende Fachliteratur zur Geschichte des Osmanischen Reiches siehe: Inalcik (1973); Itzkowitz (1980); Matuz (1986); Heppner (1986, pp. 145-154).

${ }^{2}$ Der vor kurzem verstorbene ungarische Historiker, Ferenc Szakály, hat in einem seiner Aufsätze die Phasen der Auseinandersetzung des Ungarischen Königtums mit den Osmanen behandelt, wobei er die wichtigsten Schlachten im Gegensatz zu früheren Arbeiten unter ganz neuen 
Steiermark, Kärnten und die Krain am meisten den Einfällen der Türken ausgesetzt. Dies hatte zur Folge, daß die ersten Konturen des Türkenbildes in diesen Ländern entstanden sind. In diesem Zusammenhang stellen sich gleich mehrere Fragen: Wann ist die Türkenfurcht in den erwähnten Herzogtümern erschienen? Ist die direkte Konfrontation mit dem Feind zur Herausbildung eines Feindbildes unbedingt notwendig oder genügt es, wenn die Bevölkerung über ihn nur bestimmte Informationen erhält? Wenn wir diese Fragen beantworten, bekommen wir ein annäherndes Bild davon, wann und wie sich das Türkenbild im Habsburgerreich herausgebildet hat. ${ }^{3}$

Die Daten der zeitgenössischen »Geschichtsschreiber « (Valvasor, Unrest, Santonio, Dlugos) helfen uns meistens nicht weiter, weil sie oft von solchen Ereignissen berichten, die gar nicht stattgefunden haben. Einige von ihnen behaupten zum Beispiel, die Türken hätten bereits nach der Schlacht bei Nikopolis (1396) die Steiermark angegriffen. ${ }^{4}$ Karl Teply weist zwar darauf hin, daß bei der berühmten Schlacht von 1396 in der Kreuzzugsarmee auch österreichische Ritter und Knechte anwesend waren. ${ }^{5}$ Wir wissen jedoch bereits, daß die ersten osmanischen Streifscharen die östliche Grenze des Habsburgischen Reiches zwischen 1408 und 1426 erreichten. ${ }^{6}$ In der österreichischen Historiographie gab es lange Zeit keinen Konsens darüber, wann der Beginn der konkreten Konfrontation der Erbländer mit den Osmanen zu datieren ist. Nach Dorothea Wiesenberger wurden die Herzogtümer Kärnten, die Steiermark und die Krain vom ersten Türkeneinfall im Jahre 1469 heimgesucht, dem bis 1493 weitere umfangreiche und folgenschwere Einfälle folgten. ${ }^{7}$ Für dieses Datum spricht auch die Tatsache, daß die erste Maßnahme zur Bewältigung der Türkengefahr in dem erwähnten Jahr getroffen wurde: Kaiser Friedrich III. hat im Jahre 1469 den SanktGeorg-Ritterorden als Vorhut der Türkenabwehr gegründet. ${ }^{8}$ Nächstdem schrieb er am 4. Juni 1474 einen gemeinsamen Landtag für die Steiermark, Kärnten und Krain auf den 29. Juni 1474 aus, wo der Probst Andre von Seckau zusammen mit den Prä-

Gesichtspunkten betrachtet hat. Dabei weist er oft auch auf die Rolle der Erbländer hin. Anlaß dazu bietet die Tatsache, daß Sigismund (1387-1437 ungarischer König) am 31. Mai 1433 zum Kaiser des Heiligen Römischen Reiches Deutscher Nation gekrönt wurde. Dazu detaillierter siehe seinen Aufsatz: Szakály (1979, pp. 65-111).

${ }^{3}$ Der Begriff »das Türkenbild im Habsburgerreich« wurde mit Absicht verwendet, weil die anderen Länder des Heiligen Römischen Reiches Deutscher Nation die in den Erbländern entstandenen Vorstellungen von den Türken einfach nur »fertig« übernommen haben. Die Erklärung dafür ist, daß sie der Gefahr nicht direkt ausgesetzt waren und deswegen keine eigenen Erfahrungen mit dem Erbfeind machen konnten. Aus diesem Grund werden demnächst ausschließlich die Türkeneinfälle in die Steiermark, Kärnten und in die Krain untersucht.

${ }^{4}$ Voje (1992, p.10).

${ }^{5}$ Teply ist der Meinung, daß diese Schlacht indirekt als erste österreichisch-türkische Begegnung betrachtet werden könnte. Trotzdem äußert er sich so, daß die eigentliche Geburtsstunde des Türkenschrecks in den Erbländern mit der Eroberung Bosniens (1463) begann, weil die Türken von hier aus zahlreiche Einfälle nach Krain, Kärnten und in die Steiermark organisierten. Vgl. Teply (1983a, p. 26).

${ }^{6}$ In dieser Periode war nur das slowenische Gebiet von den Türkeneinfällen betroffen, die noch sporadischen Charakter hatten und deren Hauptzweck damals nur der Raub war. Die Steiermark blieb von 1408 bis 1426 noch verschont. Vgl. Voje (1992, p. 12); Simoniti (1991, p. 295).

${ }^{7}$ Wiesenberger (1986, pp. 181-183).

${ }^{8}$ Kocadoru (1990, p. 109). 
laten, den Herren vom Adel und den Vertretern der Stände aller drei Länder die Aufgabe hatten, zu beraten, wie die Einbrüche der Türken abgewehrt werden könnten. ${ }^{9}$ Die Türkenabwehr stellte ebenfalls während der Regierungszeit von Maximilian I. eines der wichtigsten Probleme dar. Der Kaiser plante sogar mehrere Kreuzzüge gegen die Türken, die aber von ihm nie verwirklicht wurden. ${ }^{10}$

Seit Ende des 15. Jahrhunderts ist unter den zwei wichtigsten Themen auf den Landtagen und Reichstagen das eine immer das Problem der Türkenabwehr gewesen. Mit dem Beginn der Reformation erschien es oft mit konfessionellen Fragen verbunden. Da der Kaiser für die Führung der Türkenkriege auf die Geldzahlungen der Stände angewiesen war, bewegten die protestantischen Stände den katholischen Herrscher oft mit Verweigerung der Zahlung der Türkenhilfe zu religiösen Konzessionen. ${ }^{11}$ Die tiefverwurzelte Türkenfurcht entsprach jedoch auch den Interessen des kaiserlichen Hofes, dessen politische Propaganda den manipulativen Einsatz der Türkenfurcht aufwies. Dies war besonders für die Zeit des Befreiungskrieges gegen die Türken charakteristisch. Weiter unten wird noch ausführlich von der politischen Propaganda des Kaiserhofes im Zusammenhang mit der Herausbildung und Verbreitung des Türkenbildes die Rede sein. Der Hinweis auf ihre Rolle war an dieser Stelle wichtig, um zeigen zu können, daß das im Rahmen dieser Arbeit behandelte Thema eine interdisziplinäre Annäherung erfordert und aus diesem Grund unter mehreren Aspekten untersucht werden muß.

\section{Charakteristika des Türkenbildes bis zu den achtziger Jahren des 17. Jahrhunderts}

\section{II.1. Die Anfänge...}

Der kometenhafte Aufstieg des Osmanischen Reiches mochte dem christlichen Europa unerklärlich und unheimlich erscheinen. Von Anfang an suchte man nach den

\footnotetext{
${ }^{9}$ Auf diesem Landtag wurde beschlossen: die Wochenpfennigsteuer wird eingeführt, Söldner müssen bestellt und an der Grenze so verteilt werden, daß die Türken nicht wieder überraschend und unbemerkt das Land angreifen können. Steiermärkisches Landesarchiv Graz, U 7508.

${ }^{10}$ Dazu ausführlicher siehe: Wiesflecker (1986). Wiesflecker und seine Schüler vertreten die Ansicht, daß sich Maximilian I. in der Türkenabwehr als Schirmherr der Christenheit betrachtet habe und er nur durch die Verhältnisse an der Verwirklichung seiner Konzeption verhindert worden sei. Im Gegensatz dazu ist Rudolf Buchner der Meinung, daß es dem Kaiser um kaum anderes als um den im Hinblick auf die Anliegen seines Hauses erwünschten Propagandaeffekt gegangen sei. $\mathrm{Zu}$ den zwei verschiedenen Beurteilungen des Kaisers in bezug auf die Türkenabwehr siehe: Teply (1983b, p. 27).

${ }^{11}$ Dies geschah zum ersten Mal auf dem Reichstag von Speyer im Jahre 1526. Dieses Datum ist in der Geschichte des Kampfes gegen die Osmanen von großer Bedeutung. Die verlorene Schlacht bei Mohács bedeutet gleichzeitig das Ende des Ungarischen Königtums. Mit dem Argument der Türkengefahr werden Luther und dadurch dem Protestantismus die ersten Konzessionen zugeteilt. Vgl. Vocelka (1977, pp. 14-27). Zu den Reichstagen detaillierter siehe: Aulinger (1980).
} 
Gründen seines Erfolges und wollte immer mehr Informationen über den unbekannten Feind erwerben. Die Angst und das Interesse waren der Ausgangspunkt für die Herausbildung des Türkenbildes. Das war ebenfalls für die Erbländer charakteristisch. Dieser Gedankengang wird noch deutlicher, wenn wir dem im April 1488 in Straßburg entstandenen Werk Pronosticatio Aufmerksamkeit schenken. Der Verfasser, Johannes Lichtenberger (ein berühmter Astrologe seiner Zeit) hat es in der Tradition der mittelalterlichen Pseudoprophetien geschrieben. Dem Grundriß der osmanischen Geschichte folgt darin die für uns wichtige Prophezeiung, daß die Osmanen fast alle Länder in Europa erobern und bis ins Herz des Heiligen Römischen Reiches Deutscher Nation, nach Köln, vorstoßen würden, wo sie in einer eschatologischen Endschlacht endlich besiegt werden könnten. 1527 wurde die Pronosticatio ins Deutsche übersetzt. Diese deutsche Ausgabe mit der Einleitung von Martin Luther fand damals und auch später eine weite Verbreitung. ${ }^{12}$ Was mochte im Kopf der Menschen des deutschsprachigen Raumes vorgehen, als ihnen der Inhalt dieser Prophezeiung bekannt wurde? Waren sie doch nicht in Sicherheit? Diese Fragen können wir aus dieser geschichtlichen Entfernung nicht mehr hundertprozentig beantworten. Wir können uns davon nur Vorstellungen machen, was die Türkenfurcht, die eigentlich für die Entstehung des Türkenbildes verantwortlich ist, für die Menschen im 15-17. Jahrhundert bedeuten konnte.

Es wäre trotz allem ein großer Fehler, wenn wir annehmen würden, daß die Osmanen die ersten Repräsentanten des Türkenbildes gewesen waren. Sie waren nur Fortsetzer jenes Türkenbildes, welches das christliche Europa im 11. Jahrhundert von einem anderen Türkenvolk, den Seldschuken geschaffen hatte. Das bedeutet jedoch nicht, daß die Feindbilder von den zwei verschiedenen Völkern völlig identisch sind und in ihren Charakteristika keine Unterschiede aufweisen. Aber der Grundgedanke ist in beiden Fällen der gleiche. Es ist gar kein Zufall, daß die Osmanen auch Ende des 17. Jahrhunderts als »Erbfeinde der Christenheit« bezeichnet wurden. Die Wurzeln dieser Vorstellung sind im 11. Jahrhundert zu finden. Urban II. hat nämlich auf dem Konzil von Clermont am 27. November 1095 die gesamte Christenheit zum heiligen Krieg gegen die Türken aufgerufen. In seiner Rede äußerte er sich über die Eroberer Jerusalems wie folgt:

"... sie immer tiefer eindrangen in das Land dieser Christen, haben sie diese siebenmal in der Schlacht besiegt, haben eine grosse Anzahl von ihnen getötet und gefangengenommen, haben die Kirchen zerstört und das Land verwüstet... $\ll^{13}$

Diese Worte sind für uns von großer Bedeutung, weil sie während der nächsten sieben Jahrhunderte in den Berichten über die Osmanen, besonders in den Flugschriften und Zeitungen, immer wieder auf die gleiche Weise erscheinen, d.h. sie werden einfach wiederholt. Auf dem Konzil von Clermont wurden sowohl die Araber als auch die Türken als »Feinde der Christenheit« bezeichnet, was darauf hindeu-

\footnotetext{
${ }^{12}$ Köhbach (1992, p. 2).

${ }^{13}$ Diese Rede des Papstes Urban II. wird nach Yüksel Kocadoru zitiert: Kocadoru (1990, p. 29). 
ten kann, daß die Anfänge doch nicht im 11. Jahrhundert, sondern noch früher zu suchen sind. Trotz der gleichen Bezeichnung handelt es sich hier um zwei verschiedene Feindbilder. Der Araber als Feind war nämlich in Europa nicht neu. Diese Vorstellung existierte seit der Eroberung der Iberischen Halbinsel durch die Arabern. Der Türke als Feind erschien jedoch zum ersten Mal auf dem Konzil von Clermont. Aus diesem Grund ist das Jahr 1095 die Geburtsstunde des Türken-Feindbildes im Abendlande. $^{14}$

\section{II.2. Das Türkenbild im Habsburgerreich}

»Die Türken kommen! « ${ }^{15}$ ließ sich fast 300 Jahre lang oft die Warnung hören, von deren Bedeutung für die Einwohner der Erbländer das Landplagenbild an der Südseite des Grazer Domes sehr viel verrät. Neben der visuellen Darstellung der Einfälle der Türken im August 1480 erklärt die Inschrift dieses Landplagenbildes sie als Strafe Gottes für die Sünden der Menschen, indem der Türkeneinfall neben der Heuschreckenplage und der Pest unter den drei als göttliche Strafgerichte empfundenen Heimsuchungen erwähnt wird. ${ }^{16}$ Wir würden uns irren, wenn wir nach diesem Beispiel die Schlußfolgerung ziehen würden, daß von den Türken nur diese einzige Vorstellung existiert hätte. In diesem Fall wären alle weiteren Untersuchungen unnötig.

Um das Gegenteil beweisen zu können, muß an dieser Stelle angedeutet werden, daß es von dem »Erbfeind der Christenheit « nie ein einheitliches Bild gab. Für die Richtigkeit dieser Äußerung sprechen auch die zwei verschiedenen Bedeutungen des indogermanischen Wortes »ghostis (der Fremde)《. Es wurde sowohl für die Bezeichnung eines Gastes als auch eines Feindes verwendet. ${ }^{17}$ Eine Erklärung für dieses Phänomen kann die Beobachtung liefern, daß es nämlich immer von der konkreten Situation und den Eigenschaften der sich mit »dem Fremden« konfrontierenden Gemeinschaft abhängt, ob der Fremde positiv oder negativ beurteilt wird. Die zwei Deutungen sind meistens zusammen vertreten, aber in einem bestimmten Kontext wird das eine oder das andere hervorgehoben und nimmt dadurch eine dominierende Rolle an. Diese Dualität ist das grundlegende Charakteristikum des Türkenbildes. Es muß jedoch bereits jetzt vorausgeschickt werden, daß fast 300 Jahre lang die negative Konnotation dominierte. Wie kann eine solche Feststellung begründet werden? Wir dürfen nicht vergessen, daß die »Begegnung « mit dem Osmanischen Reich nicht nur eine militärische Auseinandersetzung bedeutete. Das christliche Europa (und darin auch das Heilige Römische Reich Deutscher Nation) stand einem Staatsgebilde gegenüber, von dessen Kultur und Religion nur geringe Kenntnisse zur Verfügung standen. Der Reiz, der von der fremdartigen Welt der Osmanen ausging, übte seit der Re-

${ }^{14}$ Ebd. (pp. 2-32).

${ }^{15}$ Zitiert nach: Bauer (1982, p. 7).

${ }^{16}$ Köhbach (1992, p. 2).

${ }^{17}$ In den verschiedenen etymologischen Wörterbüchern stehen unter dem Lemma »ghostis« die folgenden Erklärungen: ghostis, lat. hostis, Fremdling, Feind, Kriegsfeind, lat. hospes, Fremder, Fremdling, Gast, Gastfreund. Vgl. Kluge (1989, p. 300); Pokorny (1989, p. 453). 
naissance eine Wirkung auf Europa aus. Aus der von uns untersuchten Region hatten nur wenige die Möglichkeit, sich »freiwillig « ${ }^{18}$ das Reich des »türkischen Kaisers" mit eigenen Augen anzuschauen. Aus diesem Grund ist es völlig verständlich, daß neben der Angst auch eine Art Neugier vorhanden war. Dadurch lassen sich die zwei wichtigsten Charakteristika des Türkenbildes erklären: die Stereotypisierung und die Europäisierung. ${ }^{19}$ Bei der Untersuchung der genannten Begriffe erbietet sich die Erklärung des letzteren als die leichtere Aufgabe.

\section{II.2.1. Das als »europäisch« gekleidete Osmanische Reich}

Wie es oben bereits angedeutet wurde, konnten unter den Einwohnern der Steiermark, Kärnten und Krain nur wenige behaupten, daß sie über die im Osmanischen Reich herrschenden Verhältnisse »originelle«, mit eigenen Augen erlebte Erfahrungen verfügen. Die geographische Entfernung, die Gefahren, die eine Fahrt in die Heimat des »Erbfeindes« nach den Berichten von Reisenden mit sich bringen konnte, haben dazu wesentlich beigetragen, daß nur einige Abenteuerlustige den Mut hatten, eine solche Reise anzutreten. Selbst für sie war diese Welt mit den fremden Sitten, der Religion, Sprache und Kleidung völlig fremd, aber gleichzeitig auch faszinierend. Aus der Verschiedenheit der zwei Kulturen ergab sich das Problem, daß im Reich der Türken auch Phänomene existierten, die in Europa gar nicht vorhanden waren. Für die Bezeichnung dieser Phänomene mußten entweder neue Wörter geschaffen werden oder man konnte den Versuch unternehmen, diese Begriffe mit vorhandenen Elementen des Wortschatzes zu erklären. Diese Erklärung mit eigenen Kategorien kommt öfter vor: der osmanische Sultan wird z.B. als türkischer Kaiser, der Mufti als oberster Priester bezeichnet. Der Grund dafür ist, daß von den Türken trotz der zahlreichen Reisebeschreibungen und Berichte nicht genügend Informationen vermittelt wurden. Dies ist jedoch nicht nur für die schriftlichen Quellen charakteristisch, sondern auch für die Medien, die mit visuellen Informationen operierten. Davon zeugen die zahlreichen Darstellungen, auf denen die Türken in europäischer Kleidung erscheinen und europäische Gesichtszüge tragen. Die große Anzahl von Quellen dieser Art zeugt davon, daß sich die Menschen trotz Angst und Gefahr für die fremdartige Welt des Islams interessierten.

Sehr früh, bereits vom Beginn der Expansion der Osmanen und der Entdeckung des Buchdrucks erschienen viele Werke verschiedener Art (Bücher, Flugblätter, Neue Zeitungen usw.) als Antwort auf die große Nachfrage für Informationen über die Geschichte des Osmanischen Reiches. ${ }^{20}$ Daß dieses Interesse auch in den achtziger Jahren des 17. Jahrhunderts nicht geringer war, beweisen die Werke von Jo-

${ }^{18}$ Bei den großen Feldzügen der Türken wurden viele Einwohner der Herzogtümer Steiermark, Kärnten und Krain in die Sklaverei abgeschleppt. Unter ihnen befanden sich nicht nur Angehörige des steirischen, Krainer und Kärntner Adels, sondern auch einfache Menschen. Einige von ihnen wurden aus der türkischen Gefangenschaft freigekauft, aber die meisten kehrten in ihre Heimat nie wieder zurück. Dazu ausführlicher siehe: Voje (1992, p. 12).

${ }^{19}$ Grothaus (1985, p. 70).

${ }^{20}$ Vocelka (1988, pp. 29-30). Beispiele für die am frühesten entstandenen Werke über das Osmanische Reich: Tardy (1977), und Fügedi (1976).

Acta Orient. Hung. 54, 2001 
hann Christoph Wagner aus Augsburg, die 1685 bzw. 1687 veröffentlicht wurden. ${ }^{21}$ Wenn wir darüber nachdenken, da $\beta$ seit dem ersten Einfall der Osmanen mehr als 200 Jahre vergangen waren, stellt sich die Frage, wieviel Kenntnisse die Bevölkerung des deutschsprachigen Gebietes bis zur zweiten Hälfte des 17. Jahrhunderts über die Osmanen erworben hatte, wenn damals noch Werke solcher Art verkauft werden konnten. Man darf es ebenfalls nicht außer acht lassen, daß die erwähnten Werke in Augsburg gedruckt wurden. Obwohl der Ort der Veröffentlichung außerhalb der Erbländer liegt, gelten ihre Inhalte für das ganze Heilige Römische Reich Deutscher Nation. Es wurde oben bereits darauf hingewiesen, daß die anderen Länder die Vorstellungen über die Türken von den österreichischen Ländern übernommen hatten. Sie waren nämlich der Türkengefahr nie direkt ausgesetzt, und aus diesem Grund war dort die Türkenfurcht nur als ein Phänomen vorhanden, das nicht durch das Erlebnis der konkreten Konfrontation hervorgerufen wurde. Trotzdem verspricht der Verfasser auf der Titelseite beider Werke eine ausführliche Beschreibung Ungarns und des Türkischen Reiches. Der Haupttitel ist in beiden Fällen der gleiche: "DELINATIO PROVINCIARUM PANNONIAE ET IMPERII TURCII IN ORIENTE«. Der Untertitel des Werkes von $1687^{22}$ kündigt die Darstellung der gesamten Geschichte des Osmanischen Reiches an: »Ein historische Beschreibung Deß Ottomanischen oder Turkischen Reichs. Ursprung und Wachstum/ desselben gegen vielen Landern/ sonderlichen aber gegen ermeldtem Königreich Ungarn / bißhero außgeubten Tirrannischen Feind- und Gewalthatigkeiten. (...) Anjetzo aufs neue ubersehen/corrigiert/ und vermehrt mit einem auß-Furlichen Bericht/von dem Religion/ und denen Turkischen Hecten/ wie solche von/Der Machometischen Religion/ und denen Turkischen Hecten/wie solche von Busbetio/Della Balle und Ricaut beschrieben Werden.«

Die Verwendung des Wortes »corrigiert« kann neben einem Hinweis auf die Umarbeitung der »Delinatios« aus dem Jahre 1685 andeuten, daß es dem Autor bewußt war, daß durch die Medien der damaligen Zeit von den Osmanen auch Vorstellungen verbreitet wurden, die der Wahrheit nicht entsprachen. Aus diesem Grund betont er, daß seine Informationen aus Reisebeschreibungen stammen, die auf eigenen Erfahrungen der Verfasser ${ }^{23}$ basieren: »Dem curiosen Leser zu lieb und Nachricht/ Belustigung Und Nutzen/ aus den bewahrtesten Historieen schreiben/ solcher Lander durch-Gereisten eigener Erfahrung/ und in offenen Druck gegeben ReißBeschreibungen/ besten Fleisses.« Der Kupferstich auf der ersten Seite erleichtert

${ }^{21}$ Beide Werke befinden sich in der Handschriftensammlung der Grazer Universitätsbibliothek unter der Signatur: RARA I, II. 26332.

${ }^{22}$ Wagner Norimberg, Johann Christoph, DELINATIO PROVINCIARUM PANNONIAE ET IMPERII TURCII IN ORIENTE: Oder Grundrichtigen Beschreibung deß ganzen Aufgangs/ sonderlich aber deß hochloblichen Königreichs UNGARN und der ganzen TURCKEN/ ec. ANDEREN THEIL. Inhaltend Ein historische Beschreibung Deß Ottomanischen oder Turkischen Reichs. Ursprung und Wachstum/ desselben gegen vielen Landern/ sonderlichen aber gegen ermeldtem Königreich Ungarn/ bißhero außgeubten Tirrannischen Feind- und Gewaltthatigkeiten, Augsburg, Gedruckt und verlegt durch Jacob Koppmayer/ Anno M. DC. LXXXVII., Universitätsbibliothek Graz, RARA 1, II. 26332.

${ }^{23}$ Er beruft sich auch auf konkrete Personen wie Busbetio, Della Balle und Ricaut. Ebd. 
die geographische Orientierung der Leser in bezug auf die Abstammung und Heimat der Türken. Vier Kontinente sind dargestellt: Europa, Asien, Amerika und Afrika. In der Mitte des Bildes mit der Inschrift »Asia» sitzt eine Figur in »türkischer" Kleidung, die in die Richtung der im Hintergrund dargestellten Schlacht schaut und auch mit der Hand in diese Richtung zeigt. Der Darstellung des Islams und des Verwaltungssystems im Osmanischen Reich widmet Wagner ein ganzes Kapitel. Die Beschreibung ist überraschenderweise in beiden Fällen positiv und erweckt im Leser den Eindruck, daß die geschilderten Verhältnisse in seiner Heimat vielleicht als Vorbild betrachtet werden sollten. Denken wir nur daran, wie schwach die Zentralmacht während der Regierungszeit von Leopold I. war! Auch der Wunsch der katholischen Kirche wird hier zum Ausdruck gebracht: der »Muffti« hat nämlich in der islamischen Welt ein so hohes Ansehen und eine so große Macht, daß der »Groß-Turck« (der Sultan) die Richtigkeit seiner Entscheidungen nie in Frage stellt. $^{24}$

In der DELINATIO aus $1685^{25}$ bietet Wagner neben dem Bericht über die Kriegsereignisse des vorliegenden Jahres eine Beschreibung der Geschichte des Osmanischen Reiches und eine Darstellung seiner Einwohner, Tiere, Pflanzen und alle Besonderheiten, die die Europäer immer noch faszinierten. ${ }^{26}$ Bei der Vorstellung des Sultans hebt er hervor, daß seine Informationen von zwei Dienern am »Turckischen Hof« stammen, die ihm ihre Erfahrungen persönlich erzählt hätten. Danach sei der »Turckische Kayser« ein Monarch, der seine Untertanen wie Sklaven behandelt. Sie folgen seinen Befehlen so gehorsam, als wenn sie von Gott selbst stammen würden. Seine Macht ist zwar als tyrannisch zu bezeichnen, man kann jedoch darin einige »Fehler« entdecken: die Janitscharen und »das gemeine Volk« haben nämlich ein gewisses Mitspracherecht. Aus diesem Grund verfügt der Sultan über keine »absolute« Macht, was den Verhältnissen im Osmanischen Reich des 17. Jahrhunderts entspricht. Dieses Werk ist ein Beweis dafür, daß der Islam auch zur damaligen Zeit aus religiöser Sicht verschieden beurteilt wurde. Auf die Ansicht der katholischen Kirche wurde schon oft hingewiesen. Im Gegensatz dazu hat die muslimische Konfessionspolitik die Anhänger der Reformation fasziniert. Man hoffte sogar, die osmanische Macht würde dem verhaßten Papsttum ein Ende bereiten. Von dieser Meinung zeugt der Spruch: »lieber türkisch als papistisch $\aleph^{27}$. Auch Wagner scheint der Meinung zu sein, daß die Christen den Islam und seine Ausübung als Vorbild betrachten sollten. In bezug auf die Religion der Türken erscheint wieder die bereits erwähnte Dualität. »Der oberste Priester« (der Mufti) genießt nach Wagner ein sehr hohes Ansehen, da es in der Welt keinen anderen gibt, bei dessen Empfang der Sultan zur

\footnotetext{
${ }^{24}$ Wagner (1687, pp. 129-138).

${ }^{25}$ Wagner, Norimberg, Johann Christoph, DELINATIO PROVINCIARUM PANNONIAE ET IMPERII TURCII IN ORIENTE. Eine Grundrichtige Beschreibung deß ganzen Aufgangs/sonderlich aber deß Hochloblichen KONIGREICHS UNGARN und der ganzen TURCKEN, Augsburg, Gedruckt und verlegt durch Jacob Koppmayer/ Anno M. DC. LXXXV., Universitätsbibliothek Graz, RARA 1, II. 26332 .

${ }^{26}$ Ebd. (pp. 119-154).

${ }^{27}$ Köhbach (1992, p. 2).

Acta Orient. Hung. 54, 2001
} 
Begrüßung aufsteht. Die Parallele zum Verhältnis zwischen Kaiser und Papst ergibt sich in diesem Fall ganz offensichtlich.

Diese exemplarischen Beispiele erlaubten einen kurzen Einblick in die Vorstellungen des Okzidents vom Osmanischen Reich, wonach die dort herrschenden Verhältnisse oft sehr »europäisch« erscheinen.

\section{II.2.2. Die Stereotype}

Das Türkenbild des Habsburgerreiches kann mit einem Mosaik verglichen werden, das sich aus zahlreichen Details zusammenstellt. Die im vorigen Kapitel geschilderten Charakteristika bilden jedoch nur einen sehr kleinen Teil dieses Mosaiks, da hauptsächlich die negativen Merkmale die dominierende Rolle gespielt haben. An dieser Stelle möchte ich auf die eingangs gestellte Frage antworten, ob die direkte Konfrontation mit dem Feind zur Herausbildung eines Feindbildes unbedingt notwendig ist oder es genügt, wenn die Menschen nur bestimmte Informationen von ihm erhalten. Der Brief von Aeneas Silvius Piccolomini, dem späteren Papst Pius II. an Papst Nikolaus V. kann dabei zur Hilfe gerufen werden. Der Ort und die Zeit der Entstehung des erwähnten Briefes sind für uns von großer Bedeutung. Aeneas Silvius Piccolomini hat ihn nämlich am 12. Juli 1453 in Graz geschrieben. Danach befinden wir uns zeitlich im Jahr der Eroberung Konstantinopels, die 16 Jahre vor dem ersten Türkeneinfall in die Steiermark stattgefunden hat.

»Was für eine schreckliche Nachricht wird heutzutage aus Konstantinopel mitgebracht? Mir zittern die Hände, wenn ich darüber schreibe, meine Seele ist entsetzt, und solange meine Empörung mir verbietet, zu schweigen, vom Schmerz kann ich kein Wort sagen. Unglückliche Christenheit! Italien, Deutschland, Frankreich, Hispanien blühen, und wir lassen es zu - oh Schmerz! -, daß Konstantinopel von den türkischen Weichlingen erobert wird!" « Anscheinend verfügt er über ganz genaue Informationen: »nach drei Anstürmen hat er die Stadt erobert, ihre Einwohner über die Klinge springen lassen, die Priester mit grausamen Folterungen zu Tode gequält, ohne Rücksicht auf Geschlecht oder Alter, angeblich wurden mehr als 40000 Menschen getötet! Die Stadt, die seit Constantinus länger als 1100 Jahre bestanden hat, und noch nie in die Hände der Ungläubigen gefallen ist, ist in diesem unglücklichen Jahr Opfer der Verheerung der Türken geworden! (...) Mohamed ist schon unter uns, der Türke ist uns auf dem Halse; das Schwarze-Meer ist für uns schon geschlossen, der Don unzugänglich; die Walachen haben sich bequemt, den Türken zu dienen. Von dort wird der Schwert der Türken zuerst unter die Ungarn, dann unter die Deutschen hineindringen... « Diese Vision wiederholt sich in der Prophezeiung von Lichtenberger, die jedoch bereits nach dem ersten Türkeneinfall (1469) im Jahre 1488 formuliert wurde. Aber Piccolomini hofft: »daß es bald soweit kommen wird, daß der Türke seine Zügellosigkeit bereut und das Christentum sich verklärt. « ${ }^{28}$ Dieser Wunsch geht erst nach dem Ende des Großen Türkenkrieges (1683-1699) in Erfüllung. Bis dahin bleiben die Charakteristika des Türkenbildes konstant und der »Erb-

\footnotetext{
${ }^{28}$ Übersetzt von Zsuzsa Barbarics. Der Originaltext in ungarischer Sprache stammt aus: Boronkai (1980, p. 39).
} 
feind der Christenheit« wird immer auf die gleiche Weise als »grausam, blutdürstig, tyrannisch und teuflerisch « bezeichnet. Diese Attribute gehören zum Kanon jener Stereotype ${ }^{29}$ die zur Bezeichnung der Osmanen angewandt wurden. Sie spiegeln die Mentalität der Einwohner des deutschsprachigen Gebietes wider, die in den verschiedenen Urteilen und Vorurteilen ihren Ausdruck findet. Die Dualität gehört ebenfalls zu den Hauptcharakteristika der Stereotype, da in ihnen sowohl Fremdbilder als auch Selbstbilder fixiert sind. ${ }^{30}$ Wenn wir annehmen, daß sich das eigentliche Erkenntnisinteresse auf historische Typisierungen und Stilisierungen von Kommunikation richtet, ${ }^{31}$ dann bestünde die Hauptfunktion der Stereotypisierung darin, die Welt fremder Kulturen und ihrer Vertreter leichter verständlich zu machen. Das Problem liegt jedoch darin, daß es sich öfters um ungerechtfertigte Verallgemeinerungen mit emotionalem und wertendem Charakter handelt. Hinsichtlich der verbalen Stereotype vertreten die meisten Linguisten die Ansicht, daß ihre Entstehung unabhängig von direkten Erfahrungen mit Angehörigen der Gruppen, auf die sie sich beziehen, möglich ist. ${ }^{32}$ Diese Feststellung unterstützt auch unsere Hypothese, die mit Hilfe des oben zitierten Briefes von Aeneas Silvius Piccolomini belegt wurde. Aufgrund dessen reichen die durch die Kanäle der Kommunikation vermittelten Informationen aus, um ein Feindbild ins Leben rufen zu können. Damit wird es eigentlich erklärt, warum die Stereotype so zählebig und immun gegenüber allen Veränderungen sind, die ihren Inhalt vielleicht modifizieren und gleichzeitig widerlegen könnten. ${ }^{33}$ Der Begriff der Tradition nach Michel Foucault scheint ebenfalls diese Aussage zu unterstützen: »er zielt darauf ab, eine Menge gleichzeitig sukzessiver und identischer (oder zumindest analoger) Phänomene ein besonderes zeitliches Statut zu geben; er gestattet, die Streuung der Geschichte in der Form des Gleichen erneut zu denken; er gestattet, den allem Beginn eigenen Unterschied zu beschränken, um ohne Unterbrechung in der unbegrenzten Bestimmung des Ursprungs zurückzugehen; dank seiner kann man die Neuigkeiten auf einem Hintergrund der Permanenz isolieren (...) «. ${ }^{34}$ Laut Zielsetzung dieses Aufsatzes möchte ich den letzteren Gedanken widerlegen, wobei die Untersuchung der kaiserlichen Propaganda erforderlich ist. Es stellt sich natürlich die Frage, wie sich Stereotype mit der kaiserlichen Propaganda in Verbindung setzen

\footnotetext{
${ }^{29}$ Statt Stereotyp hätten wir auch die Ausdrücke wie Klischee, Topoi, Vorurteil, Image verwenden können, weil die begriffliche Unterscheidung bzw. Abgrenzung dieser Denk- und Kategorisierungsschemata besonders schwierig und problematisch ist. Ihr Hauptmerkmal ist, daß sich in ihnen die Erfahrungen und Reflexionen von Jahrhunderten kristallisieren. Vgl. Koller (1998, p. 1).

${ }^{30} »$ Nicht die Fixierung des Menschen in der Stereotypie eines Bildes, eines Fremdbildes und des davon erzeugten Selbstbildes, ist kulturprägend, sondern nur die Möglichkeit, dem Bild zu entgehen und lebendig zu bleiben, schafft humane Kultur.« Vgl. Ebd. (p. 3).; In sozialpsychologischen Studien wird den ethnischen und nationalen Stereotypen die Funktion der Stärkung des Wir-Gefühls einer Gruppe zugeschrieben, die ein schwaches Ich-Gefühl hat. Diese Feststellung gilt ebenfalls für das gesamte Heilige Römische Reich Deutscher Nation, dessen Einwohner bis 1683 davon überzeugt waren, daß die Türken unbesiegbar sind und es gar nicht möglich ist, sie aus Europa zu vertreiben. Vgl. Ebd. (p. 8).

${ }^{31}$ Vgl. Linke (1998, p. 140).

${ }^{32}$ Vgl. Wenzel (1978, p. 40); Koller (1998, p. 2).

${ }^{33}$ Koller (1998, pp. 1-7).

${ }^{34}$ Foucault (1997, p. 33). 
lassen. Das folgende Zitat liefert dafür die Erklärung: »Mit Stereotypen werden Angehörige bestimmter Gruppen diskriminiert, mit Stereotypen wird Propaganda getrieben, werden Feindbilder aufgebaut und ggf. in kriegerische Aktivitäten umgesetzt. $\ll^{35}$ Nach dieser Auffassung sind Stereotype als Mittel und Produkt der kaiserlichen Propaganda anzusehen. Dies läßt sich auch vom Türkenbild behaupten. Der kaiserliche Hof wollte es nämlich mit allen Mitteln erreichen, daß die Türkenfurcht im Bewußtsein der Untertanen ständig anwesend ist. Obwohl die Beschreibung der Initiativen und Mechanismen dieser Propaganda in einem folgenden Kapitel erfolgt, muß bereits jetzt darauf hingewiesen werden, daß die von ihr verwendeten Klischees wesentlich dazu beigetragen haben, daß unter den Merkmalen des Türkenbildes jahrhundertelang die negativen Eigenschaften dominierten.

Nach dieser theoretischen Einleitung wollen wir nun konkret prüfen, was für Eindrücke und Vorstellungen für das Bild der Türken unter den Einwohnern der Erbländer bestimmend waren. Bevor wir mit dieser Untersuchung beginnen, müssen wir uns darüber Gedanken machen, in welcher Art von Quellen sich das Türkenbild des Menschen im 15-17. Jahrhundert rekonstruieren läßt. Haben die Werke der zeitgenössischen Autoren seine Entstehung beeinflußt? Die Chronik des österreichischen 》Geschichtsschreibers« Jakob Unrest gibt die Antwort auf diese Frage. Er ist der erste unter den Chronisten seiner Zeit, ${ }^{36}$ der über den Türkeneinfall im Jahre 1469 berichtet: »Sy (die Türken) vienngen yeden mann, alt und chindt haben sy getodt (...), die kind an die zewn gespiest (...), frawen in den kindlpetten verfuert, die kirchen all verprannt und perawbt... ${ }^{37}{ }^{37}$ Der Vergleich mit der Rede des Papstes Urban II. auf dem Konzil von Clermont und mit dem Brief von Aeneas Silvius Piccolomini macht uns darauf aufmerksam, daß die »Erbfeinde der Christenheit« in allen drei Fällen auf die gleiche Weise dargestellt worden sind. Wenn wir noch hinzufügen, daß auch die späteren »Geschichtsschreiber« der Steiermark, Kärnten und der Krain die Chronik von Unrest als wichtigste Quelle benutzt und seine Sätze immer wieder wortwörtlich zitiert haben, ${ }^{38}$ kann die einseitig negative Schilderung der Türken gar nicht überraschend vorkommen. Maximilian Grothaus hebt in seinen Aufsätzen ${ }^{39}$ hervor, daß das Türkenbild der Adels- und Volkskultur bis zum Beginn des Großen Türkenkrieges (1683-1699) kaum Unterschiede aufweist. Erst von diesem Zeitpunkt an läßt sich eine neue Erscheinung beobachten, sie fangen nämlich an, unterschiedliche Merkmale, Eigenschaften anzunehmen. Bis dahin waren sowohl auf dem Lande als auch in den Städten die zerstörenden Streifscharen und die grausamen Einfälle für das

\footnotetext{
${ }^{35}$ Koller (1998, p. 5).

${ }^{36}$ Die Namen von Valvasor, Santonio und Dlugos können hier beispielsweise angeführt werden. Am Anfang dieses Aufsatzes wurde schon auf ihre Rolle hingewiesen.

${ }^{37}$ Zitiert nach: Kocadoru (1990, p. 111).

${ }^{38}$ Das Werk von Manfred Straka »Im späten Mittelalter, GRENZLAND STEIERMARK« kann als Beispiel angeführt werden, weil seine Sätze manchmal wirklich wortwörtlich mit der Beschreibung von Unrest übereinstimmen: »Sie (die Türken) fingen und töteten jung und alt, spießten Kinder auf Zäune (...), vergewaltigten Frauen im Kinderbette, notzüchtigten Frauen und Jungfrauen zu Tode, beraubten und verbrannten Kirchen.« Zitiert nach Ebd.; Das gleiche Phänomen läßt sich auch bei Megiser und Valvasor beobachten. Vgl. Wiesenberger (1986, p. 181).

${ }^{39}$ Vgl. Grothaus (1985, pp. 67-89) und Grothaus (1983, pp. 63-87).
} 
Türkenbild der verschiedenen Gesellschaftsschichten ausschlaggebend. Diese Erlebnisse sind in den Türkensagen ${ }^{40}$ der Erbländer immer noch lebendig. Unabhängig davon, ob sich die Geschichte, die erzählt wird, in der Steiermark, Kärnten oder in der Krain abspielt, fallen die Türken ins Land ein, sie rauben, plündern, zünden Dörfer an und hinterlassen überall nur Qual, Seuchen und Hungersnot. Es genügte damals nur die bloße Erwähnung der Akinçis, um die Bevölkerung in Panik zu versetzen. Sie wurden in den Quellen als »Renner und Brenner«, »Senger und Brenner« oder als »Sackmann«, »Sackleute« bezeichnet. Dies läßt sich auf die für sie charakteristische Kriegführung zurückführen. Die Begriffe »Sackmann«, »Sackleute« gehen auf das mittelhochdeutsche Wort »sakman « = Troßknecht zurück. ${ }^{41}$ Hinsichtlich der Sagen taucht jedoch immer wieder die Frage auf, ob man sie als historische Quellen verwenden kann und die in ihnen dargestellten Ereignisse der historischen Wahrheit entsprechen. Trotz aller Einwände darf man sie nicht beiseite setzen, weil sie in eine von der Historiographie bisher als Peripherie behandelte Sphäre führen, in die Welt des »gemeinen Mannes«. Ohne seine Anteilnahme wäre nämlich die Türkenabwehr nie möglich gewesen. Diese Sagen sind besonders für die Mentalitätsgeschichte von großer Bedeutung. Ihre Titel verraten sehr viel von ihrem Inhalt: »Das Türkenkreuz«, »Die Blutgasse«, »Die mißhandelte Großmutter«, »Der erblindete Pascha«, usw. Diese exemplarischen Beispiele weisen eindeutig darauf hin, daß sie ebenfalls Repräsentanten des negativen, von Stereotypen bestimmten Türkenbildes sind, das nach meiner Hypothese bis zu den achtziger Jahren des 17. Jahrhunderts keine großen Änderungen erfährt. Eine Hypothese muß jedoch mit Hilfe von Quellen belegt werden. Eine Chronik aus dem 17. Jahrhundert scheint die Richtigkeit der Hypothese zu beweisen. Sie berichtet über den Einfall der Türken im Jahre 1480. Ihr Verfasser hat sie anhand von mündlichen Erzählungen und einigen schriftlichen Aufzeichnungen geschaffen. Günter Jontes ist jedoch der Meinung, daß die ersteren die größere Rolle gespielt haben. ${ }^{43}$ Dies zeugt davon, daß die Qualen früherer Jahrhunderte in der Erinnerung der Bevölkerung tiefe Spuren hinterlassen haben. In dieser Chronik erscheinen wieder die bereits aus der Rede von Papst Urban II., dem Brief von Aeneas Silvius Piccolomini und der Chronik von Unrest bekannten Bilder: »Darauf in dem 1480. Jahr, 7. Augusti, seint die Türkhen heimblich vnnd verstollner Weiss in dass Landt khommen, vnnd dass Steymarch mit Raub vnnd Prandt ohn alle Verschonung erbärmlich verhört vnd zerstört, haben die Gottheüser verbrent, das heilige Sacrament aussgeworffen, mit Füessen darauf getretten, in Kirchen vil gottlosen besen Fäuel vnnd Muetwillen getriben, Prüster verbrennt, die Weibsbilder geschenndt, vil Man, Weib vnd Kühndt mit Khötten hinwekh gefriert, khaines Menschen verschont. Es war Niemandt sicher weder in Alben noch Pergen es lagen allenthalben vil totter Leyber der menschen vnnd Vich, vnnd Niemandt war vorhanndten, der solliche begraben thette;

${ }^{40} \mathrm{Zu}$ den Türkensagen ausführlicher siehe: Brunner (1986); Petzold (1993); Bauer (1982).

${ }^{41}$ Vgl. Wiesenberger (1986, p. 181).

${ }^{42} \mathrm{Im}$ Rahmen dieser Arbeit können die Türkensagen ausführlicher nicht behandelt werden. Aus diesem Grund sind nur einige Beispiele angeführt worden. Vgl. Bauer (1982); Petzold (1993, pp. 148-162).

${ }^{43}$ Vgl. Jontes (1983, p. 2).

Acta Orient. Hung. 54, 2001 
thaills seint von Hundten vnnd Wölffen verzört worden, thailss in die Prunen geworffen vnnd verschnitt wordten, vnnd war ein sollicher Gestannkh, dass die vbrigen Menschen khaum bleiben mechten. Ess khamb auch der Sterb, wegen des Schröckhen vnd Geschray vnnd Gestannkh, dass etliche Heüsser ganzz öd vnnd lähr waren. Ess war auch ein grosse Theurung vnd Hungers - Noth, dass manicher Hausswürth in 4 Woche khain Bissen Broth het, vnnd erschlug jährlich das Wetter Wein vnd Getraydt; die Wein waren fast sauer vnnd theuer; war auch lannge Zeit khain Fridt in Lanndt, dan die Unngern waren auch auf vnnd heten Besazungen in Lanndt, Markh, vnnd Schlösser, die dass Lanndt mit Raub vnnd Pranndt verderbten... In diesem Ellendt mit den Türcken hat Gott genediglkich dises Gotthauss behüet, alss die Türkhen auf dem Leitendorfferischen Feldt gewesen, ist die Abbtissin mit dem Convent mit brinnenten Kherzen khnüenter auf sanct Lamprecht zu der Capelln ganngen. Darauf haben die Türkhen, alss sie vber Muhr haben sezen wollen, gesechen mit blosen Schwerdern auf dem Tach sizen die Patronan desselbigen Khirchls, alls sanct Lambertum, sanctum Balsium, s. Georgium vnnd sanct Oswaldum, vnnd so offt sie haben wollen vber die Muhrr sezen, haben sie nach ihnen geschlagen, darüber vnzahlbare Vül ersoffen, vnnd also durch gnedige Beschüzung dieser vier Heiligen dass Gottshauss vor diesen bluetgirigen hundten unverletzt erhalten worden «. ${ }^{44}$

In diesem Zitat sind alle Greueltaten angeführt, die von den Türken nach der Erinnerung der Bevölkerung immer wieder verübt worden sind. Sie sind heute in Österreich auf Darstellungen zahlreicher Votivbilder zu sehen. In einigen Fällen - ähnlich wie in den Sagen - greifen die Menschen zu Waffen und vertreiben die »türkisch « gekleideten Gegner. ${ }^{45}$

Nach der zitierten Chronik haben die Türken Kirchen niedergebrannt, das heilige Sakrament hinausgeworfen und mit Füßen getreten. Neben diesen Bildern wird oft darüber berichtet, daß die Türken die Kirchen und Kapellen als Pferdestall benutzten und die geweihten Hostien mit den Tieren verfütterten. ${ }^{46}$ In diesem $\mathrm{Zu}$ sammenhang kommt es gar nicht überraschend vor, daß die Inschrift des Landplagenbildes der Grazer Domkirche die Türkeneinfälle zu den Zornesäußerungen Gottes rechnet. Nach der Meinung der Zeitgenossen galt der Türkenkrieg als Strafe Gottes für das allgegenwärtige, unsittliche und sündhafte Leben und Treiben. Man war sich darüber einig, daß die Bewältigung der Türkengefahr nicht allein mit militärischen Maßnahmen zu erreichen sei. Es mußte auch gegen den moralischen Verfall der Menschen vorgegangen werden. Um dieses Ziel verwirklichen zu können, wurde 1542 eine »Policeyordnung« für die Steiermark und Krain erlassen. Sowohl Ferdinand I. als auch die Stände waren der Meinung, daß zuerst der erfolgreiche innere Kampf gegen »Unglauben« und Sünde die Menschen zur Gegenwehr gegen die »Geißel Gottes«, die Türken befähige. Die Gründung der Bruderschaft vom goldenen

\footnotetext{
${ }^{44}$ StLa., SpA. Leoben, Sch. 178. H. 1034.

${ }^{45}$ Solche Votivbilder finden wir z.B. in Klosterneuburg, Mariazell und im Kloster von Settensstetten. Vgl. Göllner (1978, pp. 137-170).

${ }^{46}$ Die Ungarn haben übrigens während der Zeit der Streifzüge das gleiche getan und nach dem Großen Türkenkrieg (1683-1699) wurden die Dschamis und Türbes in Pferdeställe und Lagerhäuser verwandelt.
} 
Kreuz (1558) in den Herzogtümern Steiermark und Krain war deswegen ebenfalls ein Bestandteil der Landesdefension, weil es unter anderem zu ihrem Aufgabenbereich gehörte, die Durchsetzung der Policeyordnung zu ermöglichen und damit gleichzeitig die Türkengefahr zu bewältigen. ${ }^{47}$ Die oben geschilderte Auffassung ist insofern völlig verständlich, da im Leben der Menschen der Reformation und Gegenreformation die Religion von besonders großer Bedeutung war. Davon zeugen die »Türkenpredigten«, Prozessionen, Wallfahrtsorte und »Türkenglocken«. Die letzteren haben ebenfalls die Angst des Volkes vor den Osmanen zum Ausdruck gebracht und sind zum Symbol der Volksnot geworden. In den weit entfernten Ländern des Heiligen Römischen Reiches Deutscher Nation wurde die Türkengefahr eine Zeit lang unterschätzt. Erst 1566 (nach der Schlacht von Szigetvár) wurde ihre Bedeutung auf dem Reichstag zu Augsburg erkannt und wurden die erforderlichen Maßnahmen gegen sie getroffen. Herzog Christoph von Württemberg ließ kurz danach die ersten Türkenglocken läuten. In Österreich wurden die Glocken in derselben Zeit nach der Verordnung Herzog Ferdinands von Österreich geläutet, um Gott zu bitten, dem christlichen Heer zum Sieg zu verhelfen. ${ }^{48}$ Ein Eintrag im Domkapitelprotokoll von Münster zeigt, daß vom 22. Januar 1594 an die Glocken mittags auch dort geläutet wurden. ${ }^{49}$ Diese Tatsache beweist, daß die Türkenfurcht auch in den von den Erbländern weit entfernt liegenden Ländern im Norden anwesend war.

Die Türkennot hoffte man auch mit Hilfe von Schutzpatronen überwinden zu können. Da die Herzogtümer Steiermark, Kärnten und Krain der Gefahr direkt ausgesetzt waren, ist hier ihre Anzahl viel größer als in den anderen Ländern der Habsburger. Der bekannteste war der hl. Michael, aber im 16-17. Jahrhundert waren auch andere Schutzpatronen von großer Bedeutung, deren Aufgabe war, die Krieger zu schützen: wie zum Beispiel St. Florian, ${ }^{50}$ St. Stephan, St. Katharina und St. Johann Baptist. Einige Madonnendarstellungen sind ebenfalls auf die Türkenfurcht bezogen, auf denen Maria mit dem Halbmond dargestellt ist. Das symbolisiert die Wunderkraft Marias, den Halbmond zu brechen und damit die Macht der Osmanen zu mindern. ${ }^{51}$ In den Sagen und Legenden entscheidet oft ihr Eingriff den Ausgang der Kämpfe gegen die Osmanen zugunsten der christlichen Armee. Die Herrscher von Innerösterreich und Bayern haben sie zur Schutzpatronin ihres ganzen Landes gemacht, die mit ihrem Mantel alle Christen beschützt. Den engen Zusammenhang zwischen Religion und Machtpolitik zeigt, daß sie auf einigen Darstellungen die Krone der Habsburger auf ihrem Kopf trägt. ${ }^{52}$ Auch heutzutage finden an vielen Orten Dankprozessionen statt, bei denen der Rettung vor den Türken gedacht wird. In St. Benedikten bei Knittelfeld wird zum Beispiel seit über 250 Jahren am zweiten Sonntag nach Fronleichnam eine Dankprozession abgehalten, bei der eine $15 \mathrm{~m}$ hohe Türkenkerze mitgeführt

${ }^{47}$ Vgl. Pauser (1996, pp. 59-97).

${ }^{48}$ Vgl. Özyurt (1972, pp. 31-32).

${ }^{49}$ Ebd. (p. 33).

${ }^{50} \mathrm{Da}$ die Türken ihrer Bezeichnung als »Renner und Brenner« entsprechend viele Häuser anzündeten, bat man besonders diesen Schutzpatron um Hilfe. Vgl. Mezler-Andelberg (1986, p. 180).

${ }^{51}$ Özyurt (1972, p. 31).

${ }^{52}$ Mezler-Andelberg (1986, pp. 179-181). 
wird. Dieser Brauch ist mit einer Legende verbunden, die auf die Ereignisse in den Jahren 1479 und 1480 hinweist. Darin wird von dem Wunder berichtet, wie die Kirche mit Hilfe der Kerze gerettet wurde, bevor die Türken sie anzünden hätten können. ${ }^{53}$

Wenn wir die bisher angeführten angeblichen Greueltaten der Türken mit kritischen Augen betrachten, scheint es offensichtlich zu sein, daß sie entweder der Wahrheit nicht entsprechen oder nicht im geringsten von den Kriegführungstechniken der damaligen Zeit abweichen. Der Vergleich mit Legenden und Sagen aus anderen deutschsprachigen Regionen macht uns darauf aufmerksam, daß zum Beispiel die Franzosen in der Pfalz (1688-1697) auf die gleiche Weise vorgingen wie die Türken während ihrer gewohnten Einfälle. Dieses Phänomen weist eindeutig auf die Typisierung eines Feindbildes hin, dessen Inhalt sich aus mehreren Feinden zusammenstellt. Die Darstellung dieses komplexen Feindbildes erfolgt in einem späteren Kapitel, aber die Kenntnis seiner Komplexität muß bei der Beschreibung der Charakteristika des Türkenbildes unbedingt in Betracht gezogen werden. Es wurde bereits angedeutet, daß diese Feindbilder Produkte der kaiserlichen und der religiösen Propaganda sind. Die in den Sagen und Legenden beschriebenen Geschehnisse erscheinen als Kupferstiche auf der Titelseite der Flugblätter und Zeitungen der damaligen Zeit. Es handelt sich oft um Bilder, auf denen die Türken Säuglinge auf Zäune aufspießen oder Kinder mit einem Schwert in zwei Stücke aufspalten. Karl Vocel$\mathrm{ka}^{54}$ ist der Meinung, daß es hier nicht nur einfach um die bildliche Darstellung des Verhaltens der Soldaten geht, sondern eher um den Einfluß der christlichen Ikonographie, weil diese Bilder dem biblischen Kindermord sehr ähnlich sind. Wir haben wieder mit einem Topos zu tun. Zu diesem Gedankenkreis gehört auch das Phänomen, daß der »böse« Pontius Pilatus im 16-17. Jahrhundert als Türke dargestellt wird. $^{55}$

Das oben geschilderte Türkenbild beschränkt sich jedoch nicht nur auf die Erbländer, weil die Türkenfurcht und die davon hervorgerufenen Vorstellungen durch den Handel und durch die verschiedenen Kanäle der Kommunikation auch die

53 »Heuschrecken hatten die Saatfelder verzehrt, darauf kam der türkische Bluthund ins Land und hauste am Murboden gar schrecklich; er metzelte Menschen und Thiere nieder, plünderte Arme und Reiche, verbrannte Häuser und Dörfer und zerstörte die Kirchen. Da entstand einen schwere Hungersnoth, daß die Leute Baumrinde statt des Brotes essen mußten. Die Türken wollten auch die Kirche St. Benedicten zerstören, konnten sie aber nicht finden, denn so oft sie ihr nahten, wurde das Gotteshaus ihren Augen durch ein hohes undurchdringliches Gebüsch entzogen. Die geängstigten Bewohner gelobten, zur Abwendung der Gefahren eine mehrere Zenter schwere Wachskerze zu opfern. Sie waren nochmals in ihrer Armuth nicht im Stande, eine so schwere Kerze anzuschaffen und ließen es mit der Nachahmung begnügen, indem sie eine lange Stange mit einem Wachsstock spindelförmig überzogen. Als nun später der Feind wieder einmal eingebrochen war und in der Kirche zu St. Benedicten die merckwürdige Kerze sah, nahm er dieselbe weg und vertauschte sie mit einer mit Pulver gefüllten Blechröhre, in der Absicht, daß sie angezündet, explodieren und die Kirche samt den Andächtigen in die Luft sprengen sollte. Zum Glück entdeckte man rechtzeitig diesem reechlosen Anschlag. Die Kerze aber wurde viele Jahre aufbewahrt und erst 1713, dann später 1855 durch eine neue ersetzt.« Zitiert nach: Wiesenberger (1986, p. 184).

${ }^{54}$ Vgl. Vocelka (1988, pp. 29-30).

${ }^{55}$ Nach Grothaus sind solche Bilder zum Beispiel in Wien, Bad Ischl und Lambach zu sehen. Vgl. Grothaus (1983, pp. 67-68). 
anderen Länder des Heiligen Römischen Reiches Deutscher Nation erreichten. Obwohl ihre Bewohner mit dem »Erbfeind der Christenheit« nicht direkt konfrontiert waren, interessierten sie sich trotzdem für diesen unbekannten Gegner. Dieses Interesse ist für das Türkenbild in diesen Ländern verantwortlich, dessen Charakteristika bis zu den achtziger Jahren das 17. Jahrhunderts unverändert bleiben.

\section{Die kaiserliche Propaganda und ihre Medien während der Zeit des Großen Türkenkrieges (1683-1699)}

Die Wandlung des Türkenbildes gehört zu jenen Prozessen, die Ende des 17. Jahrhunderts sowohl auf politischer als auch auf kultureller Ebene stattgefunden haben. Sie sind durch die Erfolge der kaiserlichen Truppen gegen die Türken (1683-1699) hervorgerufen worden. Nach 300 Jahren hat die christliche Welt endlich die Chance bekommen, Europa von den Ungläubigen zu befreien, »den Erbfeind der Christenheit« loszuwerden. Dies brachte die Steigerung des Interesses, einen größeren Anspruch auf neue, »wahrheitsgetreue « Informationen von den Türkenkriegen mit sich, was in verschiedenen Bereichen des menschlichen Lebens Spuren hinterließ. Im Hintergrund verbergen sich jedoch ebenfalls wirtschaftliche und machtpolitische Bestrebungen des Kaiserhofes. Hier verknüpfen sich die wirtschaftlichen und militärischen Faktoren (als Bewegungskräfte der kaiserlichen Politik) mit der politischen Propaganda des Kaiserhofes, deren Aufgabe darin bestand, die Durchsetzung der Zielsetzungen der Machtpolitik zu unterstützen. Dies läßt sich mit dem Begriff des Einflusses in Verbindung setzen. Foucault erklärt den Sinn dieses Begriffes auf folgende Weise: »eine Stütze - eine zu magische, um richtig analysiert zu werden - für die Übertragung- und Kommunikationsfakten liefert. Er bezieht die Ähnlichkeits- oder Wiederholungsphänomene auf einen Prozeß kausalen Anstrichs (aber ohne strenge Begrenzung oder theoretische Definition). Er verbindet auf Entfernung und die Zeit hindurch - wie durch Vermittlung eines Milieus der Verbreitung - als Individuen, Werke, Begriffe oder Theorien definierte Einheiten. ${ }^{56}$ Der Zielsetzung dieser Arbeit entsprechend stellt sich die Frage, ob die Propaganda von Kaiser Leopold I. auch die Charakteristika aufweist, die nach Foucaults Begriffserklärung als Voraussetzung für den Erfolg der Beeinflussung gelten.

\section{III.1. Die Initiativen der kaiserlichen Propaganda}

»Zum Krieg benötigt man drei Dinge: monete, monete e piu monete (Geld, Geld und noch einmal Geld). $\ll^{57}$ Die finanzielle Lage des Kaisers Leopold I. hat sich dafür als gutes Beispiel erwiesen. Nach den Verlusten des »Langen Türkenkrieges« (1593-

\footnotetext{
${ }^{56}$ Vgl. Foucault (1997, S. 33-34).

${ }^{57}$ Zitiert nach Vocelka (1977, p. 20).
} 
1606) und des Dreißigjährigen Krieges (1618-1648) hatten die Habsburger in der zweiten Hälfte des 17. Jahrhunderts große finanzielle Probleme. Da die Steuereinnahmen aus den Erbländern für die Kriegsfinanzierung nicht ausreichten, war der Kaiser auf die Geldzahlungen der Stände seiner anderen Länder angewiesen. ${ }^{58}$ Alle politischen Entscheidungen und Maßnahmen wurden in den letzten zwei Jahrzehnten in Kenntnis dieser Situation getroffen. An dieser Stelle muß darauf hingewiesen werden, daß in Europa gerade zu dieser Zeit bestimmte historische Entwicklungsprozesse, die Ende des 15. Jahrhunderts bzw. Anfang des 16. Jahrhunderts angefangen hatten, ihren Höhepunkt erreichten. Das Resultat dieser Prozesse (nach der Auflösung der »Respublica Christiana«) war die Herausbildung neuer politisch-staatlicher Organisationsformen, nämlich die Entstehung von Territorialstaaten als Vorläufer der späteren Nationalstaaten. Dies hatte zur Folge, daß nicht nur das Papsttum, sondern auch das alte Kaiserreich der Habsburger an Bedeutung verlor. Das Heilige Römische Reich Deutscher Nation wurde als »Flickenteppich in der Mitte Europas « ${ }^{59}$ bezeichnet. Seit dem 15. Jahrhundert ist der Ruf nach einer Reichsreform allgemein geworden. Dies zielte darauf ab, Institutionen zu gründen, die dem Reich zu moderner Staatlichkeit verhelfen konnten. Auch diesbezüglich taucht die Türkenfrage auf. Auf dem sogenannten »Türkenreichstag « zu Regensburg (1454) hatte der Leiter der kaiserlichen Gesandtschaft, der bereits erwähnte Aeneas Silvius Piccolomini, zum Kreuzzug gegen die Türken und zur Wiedereroberung Konstantinopels aufgerufen. In Kenntnis seiner Worte aus dem zitierten Brief, den er am 12. Juli 1453 aus Graz an Papst Nikolaus V. schrieb, können wir uns über diesen Aufruf gar nicht wundern. Von den deutschen Kurfürsten erhielt er jedoch die Antwort, daß sie den Türkenkrieg ohne Reichsreform nicht unterstützen würden, weil sich das Reich »in großer Unordnung « befände. Dieses Beispiel zeigt, daß die deutsche Nation damals politisch verstanden wurde und in der Frühen Neuzeit ein Oppositionsbegriff war, gerichtet gegen die universalen Gewalten von Kaiser und Papst. Als kulturelle Identifikationsidee fungierte dazu der Text der Germania von Tacitus. So entstand um 1500 die Basis für einen deutschen Nationalmythos. Die Geschichtsstudien der humanistischen Gelehrten des 16-17. Jahrhunderts waren nämlich darauf ausgerichtet, die Identität ihrer jeweiligen Nation zu bestätigen und zu stärken. ${ }^{60}$ Dies war im Heiligen Römischen Reich Deutscher Nation umso wichtiger, als es dort sowohl an einem politischstaatlichen Rahmen als auch am sprachlichen Substrat fehlte, ${ }^{61}$ und die territoriale Spaltung des Reichs mit der Reformation durch konfessionelle Spaltung ergänzt und

${ }^{58} \mathrm{Zu}$ den Einkommen und finanziellen Problemen der Habsburger, die wegen dem Zweifrontenkrieg gegen die Türken und die Franzosen (ab 1688) noch größer geworden sind, ausführlicher siehe: Buda Expugnata (1986, pp. 873-875); Zum Beitrag der Erbländer hat Othmar Pick1 mehrere Aufsätze veröffentlicht. Vgl. Pickl (1992, pp. 296-342); Ders. (1990, pp. 81-90); Ders. (1977, pp. 105-136).

${ }^{59}$ Schulze (1999, pp. 127-128).

${ }^{60}$ Schulze (1999, pp. 139-142).

${ }^{61}$ Die deutschen Humanisten (mit einigen Ausnahmen) schrieben nämlich weiterhin in lateinischer Sprache. 
vertieft wurde. Während in Westeuropa die frühmodernen Staaten entstanden sind, brachte der Westfälische Frieden eine Bestätigung der politischen und religiösen Zerrissenheit Deutschlands mit sich. ${ }^{62}$ Die Reichsstände und die Fürsten erhielten jedoch in ihren Territorien die seit langem angestrebte Landeshoheit und das Recht, sich untereinander und mit fremden Mächten zu verbünden. Der Kaiser mußte dagegen, wenn er Krieg führen oder Frieden schließen und Allianzen eingehen wollte, den Reichstag, d.h. die Fürsten und die Stände, um Zustimmung bitten. Aus diesem Grund läßt sich im Vergleich mit den anderen Staaten des frühneuzeitlichen Europas hier eine Gegentendenz beobachten: nach dem Dreißigjährigen Krieg konnte nicht mehr von einem zentralstaatlichen Reich die Rede sein, es zerfiel in etwa 300 Einzelstaaten. Samuel Pufendorf erklärte die Formel »Römisches Reich Deutscher Nation « für widersinnig, weil »das neue deutsche Gemeinwesen mit dem alten römischen Reich nichts zu tun habe ${ }^{63}{ }^{33}$ Damit wurde eigentlich der zentralen Legitimation des Reichs der Boden entzogen. In seiner Schrift über die Reichsverfassung hat Pufendorf das Reich als »einen unregelmäßigen, einem Monstrum gleichenden Staatskörper ${ }^{64}$ bezeichnet. Schulze ${ }^{65}$ ist der Meinung, daß nach 1648 alle Staatlichkeit auf die Territorialstaaten innerhalb Deutschlands übergegangen ist und das Reich nur als rechtliches »Konfliktregulierungs-Institut« weiterexistierte. Auch wenn wir dieser Auffassung recht geben, mußte Leopold I. »als Vorsitzender dieses Konfliktregulierungs-Instituts« zur Kriegführung gegen die gefährlichsten Konfliktauslöser, nämlich die Türken, die Fürsten und die Stände seines Reiches um Hilfe und Unterstützung bitten. Aus diesem Grund ist es gar kein Zufall, daß »offiziell ${ }^{66}$ nicht die Ungarn, sondern die von Ludwig von Baden, Eugen von Savoyen, Maximilian Emmanuel und Karl von Lothringen geführten kaiserlichen Truppen und ihre Alliierten die Türken besiegt haben. Hinter den angeführten Personen sind Länder und Kurfürstentümer verborgen, deren Stände mit ihren Geldzahlungen den letzten Großen Türkenkrieg finanzierten. ${ }^{67}$ Die Protokolle ${ }^{68}$ der verschiedenen Landtage und Reichstage zeugen davon, daß Stände und Bürger in dem von uns untersuchten Zeitraum (1683-1699) - von dem ersten Hilferuf von Leopold I. an -, vor jedem großen Kriegsereignis in bezug auf die Bewilligung der erwünschten Türkensteuer konsultierten.

${ }^{62}$ Die Machtzentren haben sich dadurch aus Mitteleuropa an die Peripherie verlagert: mit Frankreich, England, Schweden und Niederlanden stiegen neue Großmächte auf, die sich wirtschaftlich vorteilhaft entwickelten und ihre staatliche Souveränität uneingeschränkt und zentral ausbauten. Dazu vgl. noch: Holle Universalgeschichte (1988, pp. 463-465).

${ }^{63}$ Zitiert nach: Schulze (1999, p. 144).

${ }^{64}$ Zitiert nach: Ebd. (p. 128).

${ }^{65}$ Vgl. Ebd. (p. 145).

${ }^{66}$ Diese Auffassung wird in den Flugschriften und Zeitungen formuliert, die damals als Medien der kaiserlichen Propaganda fungierten.

${ }^{67} \mathrm{Zu}$ der Anteilnahme der einzelnen Länder siehe: Miksch (1986, pp. 581-600); Kohne (1986, pp. 603-637); Schwertl (1986, pp. 687-723).

${ }^{68}$ Solche Protokolle befinden sich zum Beispiel im Stadtarchiv Köln. Vgl. Buda Expugnata (1986, pp. 747-753). 


\section{III.2. Die Rolle der "Neuen Zeitungen"}

»Die Neuenzeitungen sind der Herren und Potentanten Steuerruder, damit sie nämlich ihren Stato leiten und gubernieren. ${ }^{69}$ Dieses Zitat aus der Zehnjährigen Historischen Relation (1609) von Gregor Wintermonat macht uns darauf aufmerksam, was für eine essentielle Bedeutung die aktuellen, wahrheitsgemäßen und damit zuverlässigen Informationen für die Machtinhaber besaßen. Nach Wintermonats Behauptung handelt es sich hier um einen türkischen Spruch. ${ }^{70}$ Seine Argumentation basiert darauf, daß die Erfolge des Osmanischen Reiches und Venedigs nur damit zu erklären seien, daß ihre Herrscher bereits früh erkannt haben, wie wichtig die »Neuen Zeitungen«, d.h. die aktuellen Nachrichten für die Machtpolitik sind. ${ }^{71}$ Man kann sich natürlich über diese Erklärung wundern, da Wintermonat unter anderem gerade den Staat des »Bluthundes« als Vorbild nennt. Dies unterstützt auch unsere weiter oben angeführte Feststellung, daß es von den Osmanen nie ein einheitliches Bild existierte. Wir haben eher mit ambivalenten Vorstellungen zu tun. Obwohl Wintermonat von der Nachahmung des Feindes spricht, legten auch die Habsburger einen großen Wert darauf, daß die Nachrichten die Stände und den »gemeinen Mann« erreichten, womit sie ihre Bereitschaft zur Zahlung der Türkensteuer zu fördern versuchten. Dazu brauchte man natürlich einen gut organisierten Nachrichtendienst, dessen Ausbau zu den gemeinsamen Charakteristika der frühneuzeitlichen Staaten gehörte. ${ }^{72}$ Interessanterweise hebt Schulze unter den Voraussetzungen der Existenz nationaler Gemeinschaften im frühneuzeitlichen Europa das Vorhandensein des Informationsaustausches, bzw. die »Geschwindigkeit, mit der sich Nachrichten verbreiten konnten « und die »Zahl derer, die Nachrichten entgegennahmen und aussandten «, hervor. ${ }^{73}$ In

${ }^{69}$ Zitiert nach: Schröder (1995, p. 7).

${ }^{70}$ Ebd.

${ }^{71}$ Er hat insofern recht, als die Osmanen der Tradition der moslemischen Staaten im Mittelalter und insbesondere der Seldschuken folgend der Berichterstattung und Nachrichtenübermittlung eine wesentliche Rolle zugeschrieben haben. Auch die osmanischen Fürstenspiegel betonen, wie wichtig es ist, daß ein Herrscher über zuverlässige Informationen und Kenntnisse von seinem Feind, von dessen wirtschaftlicher und militärischer Macht verfügt. Nicht nur Georg Wintermonat am Anfang des 17. Jahrhunderts, sondern auch die Geschichtsschreibung im 20. Jahrhundert hat bisher den Entwicklungsgrad des osmanischen Nachrichtendienstes überschätzt. Gábor Ágoston hebt in seinen Aufsätzen hervor, daß die europäischen Gegner (Spanien, Venedig, die österreichischen Habsburger) zur Zeit der osmanischen Expansion auf den Ausbau eines gut organisierten Nachrichtensystems einen größeren Wert gelegt haben und ihre Organisationen viel systematischer vorgegangen sind, was sich auch in der Wirksamkeit des Nachrichtensystems zeigt. Dies läßt sich auch damit erklären, daß das Osmanische Reich bis zum 18. Jahrhundert nicht nur auf Botschaften in den europäischen Ländern, sondern auch auf die gedruckten Medien verzichten mußte. Vgl. Ágoston (1999, pp. 129-156); Ders. (1993, pp. 126-141); Ders. (1997, pp. 83-99).

${ }^{72}$ Sir William Cecil und sein Mitarbeiter, Sir Francis Walsingham haben z.B. für Königin Elisabeth gegen die Jesuiten und gegen Spanien den besten Nachrichtendienst der damaligen Zeit ins Leben gerufen. Diesbezüglich weist Spanien gewisse Ähnlichkeiten mit seinem englischen Gegner auf. Sein Nachrichtendienst versuchte innerhalb Spaniens von den Morisken und den Juden, im Ausland von England und von seinem großen Gegner im Mittelmeerraum, den Osmanen immer mehr Informationen zu erwerben. Vgl. Ágoston (1999, p. 131).

${ }^{73}$ Vgl. Schulze (1999, p. 127). 
diesem Sinne ist das Heilige Römische Reich Deutscher Nation mit dem Ausbau des Nachrichtendienstes den europäischen Entwicklungstendenzen gefolgt. Géza Pálffy teilt die Geschichte des Nachrichtendienstes der österreichischen Habsburger gegen die Osmanen im 15-17. Jahrhundert in drei Epochen. Die erste Periode (vom Ende des 14. Jahrhunderts bis 1526) fällt mit der ersten Epoche der Geschichte des Grenzverteidigungssystems ${ }^{74}$ und dem Beginn der Auseinandersetzung mit dem Osmanischen Reich überein. $\mathrm{Zu}$ dieser Zeit bildeten sich die anfänglichen Methoden und Mechanismen des Nachrichtensystems und der Ostspionage heraus. In der zweiten Periode (1526-1606) sind in der Erwerbung und Auswertung der Nachrichten und in der Finanzierung des Nachrichtendienstes neue Erscheinungen zu beobachten. Neben der Aufstellung einer ständigen habsburgischen Botschaft in Konstantinopel im Jahre $1547^{75}$ ist an dieser Stelle die Errichtung des Wiener Hofkriegsrates (1556) zu erwähnen. Parallel mit der Lenkung des neuen Verteidigungssystems erhielt der letztere die Aufsicht über die gesamte Ostpolitik und begann mit dem Ausbau eines neuen Nachrichtensystems. Unter den Beauftragten der Habsburgerdiplomatie finden wir bereits zu jener Zeit Personen, die aus den Erbländern stammten. ${ }^{76}$ Auch an der Finanzierung dieses Nachrichtendienstes waren die Erbländer beteiligt: die Hofkammer Wien, die Niederösterreichische Kammer in Wien und die Innerösterreichische Kammer in Graz spielten dabei eine wesentliche Rolle. ${ }^{77}$ Wir dürfen jedoch auch die Kaufleute nicht vergessen, die sich auf den türkischen Gebieten frei bewegten. In der dritten Periode (nach 1606) baute der Hofkriegsrat seit Beginn der zwanziger Jahre des 17. Jahrhunderts in den wichtigsten Verwaltungszentren im Osmanischen Reich (Konstantinopel, Sofia, Belgrad, Ofen usw.) ein System der Geheimkorrespondenten aus. Sie waren bereits wirkliche Informatoren und Agenten mit guter Ausbildung und regelmäßiger Entlohnung und wurden von dem Hofkriegsrat mit einem schriftlichen Vertrag angestellt. ${ }^{78}$ Diese Schilderung der Geschichte des Nachrichtenwesens zeigt, daß der kaiserliche Hof seit Beginn der Konfrontation mit dem Osmanischen Reich mit Informationen über den gefährlichen Gegner versorgt war. Dasselbe läßt sich auch von den anderen Ländern des Heiligen Römischen Reichs Deutscher Nation sagen, wozu die Stellung Augsburgs und Nürnbergs im frühneuzeitlichen Kommunikationssystem wesentlich beigetragen hat. Unter den wichtigsten Kommunikationszentren des frühneuzeitlichen Europas sind nämlich seit dem 15. Jahrhundert neben Venedig die genannten Städte zu erwähnen. ${ }^{79}$ Sie sind als Erwerber und Vermittler neuer Informationen bekannt. Wenn wir den Weg der Nachrichten von den Ereignissen der Türkenkriege auf dem deutschsprachigen Gebiet verfolgen möchten, kommen wir nach Wien zuerst in Nürnberg an, von wo sie für die anderen Städte weitergegeben

${ }^{74}$ Pálffy (1999, p. 36).

${ }^{75}$ Vgl. Ágoston (1999, p. 139).

${ }^{76}$ Pálffy (1999, pp. 41-42).

${ }^{77}$ Ebd. (p. 51).

${ }^{78}$ Ebd. (p. 54).

${ }^{79}$ Zur Herausbildung und zum Funktionieren des europäischen Kommunikationssystems in der Frühen Neuzeit siehe ausführlicher: Pieper (1995, pp. 45-50). 
wurden. ${ }^{80}$ Weiter oben wurde schon angedeutet, daß im ausgehenden 17. Jahrhundert mehrere Umwandlungsprozesse stattfanden. Eines von diesen betrifft gerade das Kommunikationssystem im Reich. 1672 wurde nämlich der Feldpostdienst ins Leben gerufen und der Kaiser ernannte Carl Graf von Paar zum Feldpostmeister des Reiches. Die Finanzierung des Postwesens in Ungarn war im 16-17. Jahrhundert die Aufgabe einerseits der Hofkammer in Wien, andererseits der Ungarischen Kammer in Preßburg. Auf dem kroatisch-slawonischen Grenzgebiet finanzierten die innerösterreichischen Länder (die Steiermark, Kärnten und Krain), im westlichen Teil Transdanubiens die niederösterreichischen Stände den Postdienst. ${ }^{81}$ Nach der zweiten Belagerung Wiens durch die Türken erstreckten sich die Feldzüge auf das ganze Gebiet Ungarns und später bis nach Belgrad und Siebenbürgen. Die Vermittlung von Nachrichten von einem so riesigen Kriegsschauplatz bedeutete für den zuständigen Feldpostmeister gleichzeitig einen großen Gewinn. Aus diesem Grund kristallisierte sich eine Rivalität zwischen der Familie Taxis (Reichspostmeister) und Paar (Postmeister in den Erbländern) um das kaiserliche Privileg für seinen Ausbau. In diesem Kampf ging ebenfalls Paar als Sieger hervor, der das Privileg 1689 für das ganze Reich bekam. ${ }^{82}$

Aus dieser Schilderung geht hervor, daß die Informationen von den Ereignissen des Großen Türkenkrieges (1683-1699) die Bewohner des ganzen deutschsprachigen Gebietes erreichten. Erst jetzt, Ende des 17. Jahrhunderts, konnte man mit Hilfe von Informationen erfolgreich gegen die Osmanen vorgehen. Solange die Entwicklung des Militärs, der Logistik, des Finanzwesens und die Veränderung der machtpolitischen Verhältnisse die Voraussetzungen für die große Offensive gegen die Türken nicht geschaffen haben, konnte man aus der Fülle von Informationen über das Osmanische Reich für das ersehnte Ziel kaum profitieren. ${ }^{83}$

\section{III.3. Die Charakteristika der Propaganda}

Wenn wir die Lage von Leopold I. in diesen Jahren betrachten, müssen wir der Feststellung recht geben, daß »wir (...) gerade dort mit einer großen Anzahl von Flugschriften rechnen können, wo die Zentralmacht zeitweise oder für längere Zeit schwach war und Pressefreiheit herrschte. ${ }^{84}$ Das gilt für England und die Niederlanden nicht so antreffend, weil zu dieser Zeit auch in diesen Ländern Propaganda getrieben wurde, obwohl die Situation der Zentralmacht gar nicht als krisenhaft zu

\footnotetext{
${ }^{80}$ Die anderen wichtigen Städte waren: Frankfurt am Main, Köln, Leipzig und Breslau. Interessanterweise sind in ihnen viel mehr »Türkenzeitungen« veröffentlicht worden als in Nürnberg. Ursache für dieses Phänomen kann genau die Aufgabe Nürnbergs als Vermittler von Informationen sein. Weiteres zum Kommunikationssystem im Heiligen Römischen Reich Deutscher Nation vgl. Sporhan-Krempel (1968).

${ }^{81}$ Pálffy (1999, pp. 55-58).

${ }^{82}$ Zur Geschichte des Postwesens im Heiligen Römischen Reich Deutscher Nation siehe: Wurth (1985); Clement (1964, pp. 17-29).

${ }^{83}$ Vgl. Ágoston (1999, p. 142).

${ }^{84}$ Mörke (1995, p. 18).
} 
bezeichnen ist. Daraus folgt, daß die antitürkische Propaganda des Kaiserhofes nicht nur als ein Zeichen der schwachen Zentralmacht anzusehen ist, sie war nämlich Bestandteil des damaligen politischen Systems. Diese Tatsache liefert einen weiteren Beweis dafür, daß auch das Heilige Römische Reich Deutscher Nation an dem bereits erwähnten Entwicklungsprozeß beteiligt war, der die Auflösung der Respublica Christiana und die Entstehung der späteren Nationalstaaten zur Folge hatte. Es ist interessant, daß gerade die antitürkische Propaganda eine Komponente der Parallelen bei dieser Entwicklung bildet. Für diese antitürkische Propaganda war allgemein charakteristisch, daß die Nachrichten von den Kämpfen gegen die Türken bewußt selektiert wurden, was gleichzeitig die Manipulation mit den zur Verfügung stehenden Informationen bedeutete. Die Türkenfurcht wurde eigentlich zwecks erfolgreicher Beeinflussung der Untertanen »eingesetzt«, womit man die Bewilligung der Türkensteuer zu erreichen versuchte. Es war jedoch nur mit bestimmten Mitteln möglich, die gewünschte Wirkung zu erzielen. In diesem Zusammenhang bekommen wir eine Antwort auf die Frage, warum die Gestaltung und dann die ständige Wiederholung und Betonung eines Feindbildes - wobei die Greueltaten der Türken hervorgehoben wurden - für die kaiserliche Propaganda so wichtig war. Ein Spruch aus dem 17. Jahrhundert erhellt das Wesen der von uns untersuchten Problematik: »Man ти $\beta$ аи $\beta$ einem heimlichen Feind einen öffentlichen machen « ${ }^{85}$ Danach war die Propaganda auf die Anwendung von Klischees, Stereotypen angewiesen, um die gesellschaftlichen Zielgruppen für sich gewinnen zu können. Der andere Grund für die kontinuierliche Wiederholung des Feindbildes waren jene positiven Vorstellungen, die von den Osmanen unter der Bevölkerung (besonders unter den Bauern) verbreitet wurden. Dabei müssen wir an die Einrichtung des Osmanischen Reiches und an die darin herrschende religiöse Toleranz denken, die bei den unteren Gesellschaftsschichten des Habsburgerreiches eine gewisse Sympathie hervorgerufen hatte. ${ }^{86}$ Mit der Betonung der negativen Eigenschaften der Türken versuchte man diese positiven Vorstellungen zu unterdrücken.

Das war auch zur Zeit des Großen Türkenkrieges (1683-1699) nicht anders, womit sich ebenfalls die Intensität der Propagandatätigkeit erklären läßt. Die ausführliche Darstellung des Nachrichtendienstes im Heiligen Römischen Reich Deutscher Nation diente mehreren Zwecken. Wir haben gesehen, daß die Informationen von den Türkenkriegen die Machtinhaber und die Bevölkerung des Reiches durch verschiedene Kanäle der frühneuzeitlichen Kommunikation erreichen konnten. Daß die Ereignisse in dem von uns untersuchten Zeitraum (1683-1699) sehr schnell aufeinanderfolgten, erklärt, daß die Türkenfrage sowohl auf den Reichs- und Landtagen als auch im alltäglichen Leben der Menschen des deutschsprachigen Gebietes ständig anwesend war. Neben der Türkenfurcht, d.h. neben der Angst vor dem Vordringen der Osmanen, spielten dabei ebenfalls andere Faktoren eine wesentliche Rolle. Die Stände wollten natürlich wissen, was für Erfolge die aus ihrem Geld aufgestellten

\footnotetext{
${ }^{85}$ Dieser Spruch ist in einem 1639 veröffentlichten Werk von Christoph Lehmann zu lesen, das den Titel »Florlegium politicum. Politischer Blumen Garten« trägt. Es wird von Wolfgang Harms zitiert. Vgl. Harms (1992, p. 164).

${ }^{86}$ Vgl. Vocelka (1988, pp. 21-23), und Szakály (1972, pp. 251-266). 
kaiserlichen Truppen gegen den »Feind der Christenheit« erreichten. Wir dürfen nicht außer acht lassen, daß in diesem Krieg auch Soldaten aus dem Heiligen Römischen Reich Deutscher Nation kämpften, was auch das Interesse der Heimatstädte und -Dörfer mit sich brachte. Infolgedessen wurde das ganze Reich direkt vom Türkenkrieg betroffen.

\section{III.4. Die Reichweite der Propaganda}

Das größte Interesse zeigten immer diejenigen Gebiete, die von den Türkeneinfällen am stärksten gefährdet waren. In den ersten Phasen der Auseinandersetzung mit dem Osmanischen Reich (1408-1426, 1469-1493) war das Erlebnis der direkten Konfrontation mit dem Feind bestimmend. Bei der Behandlung der Türkensagen haben wir gesehen, was für tiefe Spuren diese Erlebnisse, die Türkenfurcht im Bewußtsein der Menschen hinterließen. Die Bilder der weiter oben zitierten Chronik aus dem 17. Jahrhundert zeugen davon, daß die Charakteristika des Türkenbildes in den Erbländern bis zu den achtziger Jahren des 17. Jahrhunderts konstant geblieben sind. Obwohl die Kämpfe des Großen Türkenkrieges (1683-1699) nicht auf »heimischem« Boden stattgefunden haben, warteten die Einwohner des Heiligen Römischen Reiches Deutscher Nation spannend auf die Nachrichten aus den Kriegsschauplätzen in Ungarn, die außer den »offiziellen« Kanälen des Kommunikationssystems auch aus den Erzählungen der Kaufleute, der am Krieg beteiligten Söldner und der ungarischen Studenten stammten. ${ }^{87}$

Die Intensität des Interesses für die Türkenkriege war von mehreren Faktoren abhängig, wie z.B. von der geographischen Lage des jeweiligen Gebietes oder seinen politischen und kulturellen Beziehungen. Diesbezüglich steht die Entfernung in einem umgekehrten Verhältnis zu Art und Intensität des Interesses. Flugblätter und »Neue Zeitungen« zeugen davon, daß die Details für die Bewohner der Gebiete von größerer Entfernung (Straßburg, Magdeburg, Frankfurt und Norddeutschland) nicht so wichtig waren. Das beweisen auch die sogenannten Meßrelationen, ${ }^{88}$ die zu den Handelsmessen in Frankfurt am Main, Leipzig, Magdeburg und Köln veröffentlicht wurden. Diese »zusammenfassenden Medien« informierten die Leser in deutscher Sprache über die zeitgeschichtlichen Ereignisse der seit der vorangegangenen Messe verstrichenen Monate, wobei der Schwerpunkt auf den wichtigen politischen und militärischen Geschehnissen lag. Eine ausführliche Schilderung der Ereignisse bieten die in Wien, Nürnberg und Augsburg erschienenen Zeitungen. ${ }^{89}$ Je nördlicher wir uns befinden, desto geringer ist die Anzahl jener Zeitungen, die über die Geschehnisse der Türkenkriege berichten. Als ein weiteres Kennzeichen ist noch zu erwähnen, daß diese Zeitungen die in Osteuropa existierenden Probleme von einem ent-

\footnotetext{
${ }^{87}$ Vgl. Hubay (1948, pp. 1-14).

${ }^{88}$ Sie sind halbjährlich zu den Frühjahrs- und Herbstmessen und noch zum Leipziger Neujahrsmarkt erschienen, die ebenfalls Absatzmärkte gewesen sind. Vgl. Schröder (1995, pp. 19-22).

${ }^{89}$ Ebd. (pp. 1-17), und Németh (1994, p. 15).
} 
fernteren Standpunkt aus betrachten. Nicht selten heben sie eher die lokalen Nachrichten hervor. ${ }^{90}$

\section{III.5. Die Rezipienten}

In den vorangehenden Kapiteln wurde ausführlich erläutert, warum die Einwohner des Heiligen Römischen Reiches Deutscher Nation die Berichte über den Großen Türkenkrieg (1683-1699) mit großem Interesse verfolgten und weshalb die mit Klischees und Stereotypen operierende kaiserliche Propaganda erhebliche Erfolge verzeichnen konnte. In diesem Zusammenhang stellen sich jedoch gleich mehrere Fragen, die in der letzten Zeit in mehreren Disziplinen der Kommunikationswissenschaft formuliert wurden. An wen wendet sich die politische Propaganda der frühen Neuzeit? Was ist für den Rezipientenkreis der Propaganda charakteristisch? Darf der Begriff »Öffentlichkeit« am Ende des 17. Jahrhunderts überhaupt verwendet werden? Diesbezüglich gibt es verschiedene Auffassungen. Manche betonen, daß »die Öffentlichkeit« für das 17. Jahrhundert kein relevanter Begriff ist, weil er erst im 18. Jahrhundert entstanden ist. Nach Habermas kann von einer »bürgerlichen Öffentlichkeit« vor dem 18. Jahrhundert gar nicht die Rede sein. Davor war die Öffentlichkeit mit der Person des Herrschers gleichzusetzen. Aus diesem Grund gebraucht er den Begriff der »repräsentativen Öffentlichkeit «. ${ }^{91}$ Peer Schmidt weist jedoch darauf hin, daß gerade das Beispiel der Türkengefahr zeigt, warum diese Kategorie der damaligen historischen Wahrheit nicht entspricht. Die Reichweite der Flugblätter und Neuen Zeitungen, die infolge der Türkengefahr entstanden waren, war viel größer, als man es früher angenommen hatte. Wir könnten nämlich die politische Propaganda der frühen Neuzeit und die damit zusammenhängende große Anzahl von Flugschriften kaum verstehen, wenn wir die von Habermas genannte Kategorie der »repräsentativen Öffentlichkeit« akzeptieren würden. ${ }^{92}$ Vocelka wendet sich mit scharfer Kritik gegen Habermas' Auffassung und spricht von einer »repräsentativen-qualitativen Öffentlichkeit«. Als Begründung dafür nennt er das Argument, wonach sich die politische Propaganda von Herrschenden grundsätzlich an Herrschaftsstützende wendet. Darunter versteht er die Stände und die Beamten der noch in Entwicklung begriffenen Bürokratie. Die letztgenannte Gruppe spielte eigentlich eine doppelte Rolle. Einerseits wurden die Angehörigen dieser Gruppe als Untertanen mit den Propagandaschriften angesprochen, wodurch man ihre Bereitschaft zur Zahlung der Türkensteuer zu steigern versuchte. Andererseits kommt ihnen in der damaligen Gesellschaft eine Verteiler- und Vermittlerfunktion von Informationen zu, weil sie gleichzeitig auch Grundherren waren.

Der Aufstieg der genannten Gesellschaftsschicht hängt mit der Wandlung der militärischen Funktion des Adels zusammen. Zwischen Beginn des 16. und Mitte des 17. Jahrhunderts vollzog sich nämlich die Umgestaltung des Heerwesens in Europa.

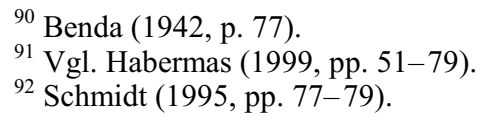


Die Schaffung der regulären Infanterie und der Ersatz des Aufgebotes der Landschaft durch die Aufstellung von Söldnertruppen im 15-16. Jahrhundert führten zum Verlust der Monopolstellung des Adels auf dem Gebiet des Kriegswesens. Dies ist ebenfalls eine Komponente der bereits erwähnten historischen Entwicklungsprozesse, die Ende des 15. Jahrhunderts mit der Auflösung der Respublica Christiana ihren Anfang nahmen. Unter den neuen Verhältnissen konnte der Adel in seiner alten Funktion als »miles christianus«, Verteidiger der Christenheit, des jeweiligen Staates und der Untertanen nicht weiter fortbestehen. Die Vertreter dieser Gesellschaftsschicht waren gezwungen, ihre Existenz und Aufgabe in der Gesellschaft neu zu definieren. Mit der militärischen Revolution ${ }^{93}$ wurde dieser Zwang noch mehr verstärkt. Sie wollten jedoch ihre Funktion in der Bewältigung der Türkengefahr, im Kampf gegen den »Erbfeind der Christenheit« nicht völlig aufgeben. So erfolgte die Ablösung der persönlichen Leistungen durch finanzielle Zahlungen. Daneben besaßen sie die Übermittler- und Organisationsfunktion des allgemeinen Steueraufkommens für die Finanzierung des Heerwesens des Kaisers. In der Bürokratie und in diplomatischen Diensten führten sie den Krieg gegen die Osmanen auf »theoretischer Ebene« weiter. $^{94}$

Weiter oben wurde schon darauf hingewiesen, daß eine der zwei Hauptcharakteristika des Türkenbildes die Europäisierung ist, wonach die unbekannte, fremde Welt der Osmanen mit eigenen, europäischen Kategorien beschrieben wird. Ein Beispiel dafür liefert uns eine spezielle Gattung von Flugschriften, die die sogenannten »Absagebriefe« und »Kriegserklärungen« der Sultanen beinhalten. Es handelt sich eindeutig um Propagandaschriften, weil sie in bezug auf ihre Terminologie in einer auf diese Schichten ausgerichteten Sprache formuliert wurden. Der Sultan fordert in ihnen seine »Kurfürsten« auf, ihm Gefolgschaft gegen den Kaiser zu leisten. Dadurch wird eine Vorstellung projiziert, die aus dem eigenen, mitteleuropäischen Bereich übernommen wurde. Dabei wird eigentlich der größte Wunsch der Kaiser artikuliert. Karl Vocelka hat diese »Absagebriefe« bzw. »Kriegserklärungen« mit osmanischen Staatsurkunden und mit deren Übersetzungen in der kaiserlichen Kanzlei verglichen. Während dieser Untersuchung stellte sich heraus, daß sie über die Vermittlung der kaiserlichen Kanzlei gelaufen waren und so veröffentlicht wurden. Das eindeutige Ziel des Kaiserhofes war, die Angst vor den Osmanen zu verstärken und die Stände zur Zahlung der Türkensteuer zu motivieren. ${ }^{95}$

Vocelka sieht die zweite Funktion der genannten Gesellschaftsschicht in der Vermittlung von Informationen und Propaganda. Danach hätte die kaiserliche Propaganda ihre Wirkung auf die unteren Gesellschaftsschichten nur durch sie, d.h. indirekt ausgeübt. Diesbezüglich bezweifle ich, daß die Nachrichten jene Gesellschaftsschichten, die sich außerhalb der Kategorie der »repräsentativen-qualitativen Öffentlichkeit« befinden, nur durch ihre Vermittlung erreicht haben. Nicht einmal die Kenntnis der Buchstaben war eine Voraussetzung für den Erfolg der kaiserlichen

\footnotetext{
${ }^{93} \mathrm{Zu}$ der militärischen Revolution und Umwandlung des Kriegswesens ausführlicher siehe: Parker (1992); Black(1991); und Ágoston (1995, pp. 465-485).

${ }_{94}$ Mandlmayer - Vocelka (1981, pp. 112-125).

${ }^{95}$ Vgl. Vocelka (1988, pp. 23-25).
} 
Propaganda. Kupferstiche aus dem 16-17. Jahrhundert zeugen davon, daß der Zugang zu Informationen sowohl auf visuellem als auch auditivem Weg möglich war. Dabei spielten die sogenannten Fahrenden eine wichtige Rolle, die die Flugschriften und die Neuen Zeitungen inner- und außerhalb von Städten und Dörfern verkauften. Manchmal lasen sie die Texte vor oder erzählten einfach ihren Inhalt. ${ }^{96}$

\section{III.6. Medien im Dienste der politischen Propaganda}

Der Kaiserhof bediente sich verschiedener Mittel, um die Untertanen zur Durchsetzung seiner politischen Ansprüche erfolgreich beeinflussen zu können. Es stellt sich natürlich die Frage, welche Medien ${ }^{97}$ dazu geeignet waren. Grundsätzlich können wir die Medien in zwei große Gruppen teilen: die erste Gruppe bilden die schriftlichen Quellen, die andere diejenigen, die ihre Wirkung mit visueller Kraft ausüben. Als eine weitere, besondere Gruppe sind die verschiedenen religiösen und weltlichen Feste und die Triumphzüge zu nennen. ${ }^{98}$ Sie lassen sich zwar den traditionellen Medien nicht zuordnen, üben jedoch auf der theoretischen Ebene die gleiche Funktion aus wie die zwei bereits erwähnten Gruppen.

Den schriftlichen Quellen gehören Produkte der frühen Presse, verschiedene Flugblätter, Flugschriften, Einzeldrucke, Meßrelationen, Neue Zeitungen und Werke der Barockliteratur an. In bezug auf die von uns untersuchten Problematik ist an dieser Stelle eines der wichtigsten Kennzeichen der Barockliteratur zu erwähnen. Die Autoren griffen meistens aus einem bestimmten Anlaß zur Feder und reagierten auf jedes historische Ereignis. Das gilt auch für die Türkenkriege, die eines der wichtigsten Probleme darstellten, was natürlich auch in der Literatur seine Spuren hinterließ. Die meisten Dichter schufen Gelegenheitsgedichte (»Causalcarmina«), die in Momentaufnahmen ihrer Entstehungszeit »Erfahrungsmodelle« bieten. ${ }^{99} \mathrm{Zu}$ dieser Zeit ist es hinsichtlich der Literatursprache Deutschlands mit dem Buch von der Deutschen Poeterey von Martin Opitz zu einem Durchbruch gekommen. Opitz wollte mit

${ }_{96}^{96}$ G. Etényi (1995, pp. 101-103).

${ }^{97}$ Es handelt sich um eine große Anzahl von Medien, die alle im Rahmen dieser Arbeit ausführlich nicht dargestellt werden können. Ich werde mich auf die detailliertere Analyse der schriftlichen Quellen, besonders der Flugschriften und Flugblätter beschränken. Bei den anderen Medien wird nur auf ihre Hauptcharakteristika hingewiesen.

${ }_{98}$ Vgl. Vocelka (1981, pp. 1-2).

${ }^{99}$ Vgl. Meid (1986, pp. 9-10). Die andere charakteristische Gattung der Barockliteratur war der Roman. Der bedeutendste Autor war Grimmelshausen, dessen Simplizissimus in der zweiten Hälfte des 17. Jahrhunderts für viele Nachahmer als Vorbild galt. Diese Nachahmungen werden als Simpliziaden genannt. Daniel Speers »Ungarischer oder Dacianischer Simplizissimus« (1683) und E. W. Happels $»$ Der Ungarische Kriegs-Roman oder ausführliche Beschreibung des Jüngsten Türcken-Kriegs« sind Beispiele für diese Simpliziaden. Der erste Band des letztgenannten Werkes beschäftigt sich mit der zweiten Türkenbelagerung Wiens im Jahre 1683. Dieser Kriegsroman ist zwischen 1685 und 1697 jährlich erschienen. Im letzten Band erwähnt Happel Miklós Zrínyi und behauptet, er sei von seinem Bruder Péter Zrínyi getötet worden, wodurch er seine Treue zu dem Österreichischen Haus ausdrücken wollte. Aber auch der Autor selbst zweifelt an der Richtigkeit dieser Behauptung. Vgl. Köpeczi (1976, pp. 308-321) und Newald (1951, pp. 354-370). 
seiner normativen Poetik an die allgemeine Entwicklung in Europa anknüpfen. ${ }^{100}$ Sein Ziel war, eine dem Lateinischen ebenbürtige deutsche Dichtersprache zu schaffen. Dies brachte natürlich bestimmte Veränderungen mit sich. Bisher waren nämlich die Produzenten und Rezipienten der Literatur weitgehend identisch. Durch die Reform von Opitz hat sich dieser Rezipientenkreis erweitert, weil die Kenntnis der lateinischen Sprache zur Rezeption literarischer Werke keine Voraussetzung mehr darstellte. ${ }^{101}$

Während der Zeit des Großen Türkenkrieges (1683-1699) wurden weiterhin viele Chroniken und Kriegsromane veröffentlicht, in denen neben der Schilderung der geschichtlichen Ereignisse ebenfalls auf die Darstellung der Charakteristika des Osmanischen Reiches und der darin herrschenden Verhältnisse großer Wert gelegt wurde. Davon zeugen die bereits zitierten Werke von Johann Christoph Wagner. ${ }^{102}$ Der Einfluß der kaiserlichen Propaganda ist besonders in dem Werk aus 1685 nachzuweisen, das sein Autor dem Kaiser selbst widmet. Er lobt seine Verdienste und berichtet von seinen Taten, wobei die Erfolge »des Siegesadlers« im Kampf gegen die »barbarischen Tataren und Türken« hervorgehoben werden. Wagner schenkt den Geschehnissen der zweiten Türkenbelagerung Wiens viel Aufmerksamkeit. Es sei nämlich seine Pflicht, diese Ereignisse zu verewigen. In diesem Sinne weist diese Widmung gewisse Ähnlichkeiten mit den für die Zeit typischen Lobgedichten auf.

Der Sieg der kaiserlichen Truppen über den »Erbfeind der Christenheit« hat viele Künstler, Maler und Bildhauer der Barockzeit zur Schaffung von Kunstwerken veranlaßt bzw. inspiriert. $\mathrm{Zu}$ dieser anderen Art von Medien, die ihre Wirkung visuell, mit Hilfe von Bildern ausüben, gehören Kupferstiche, Gemälde, Altar- und Votivbilder. Unter ihnen spielten Kupferstiche die wichtigste Rolle, weil sie auf dem Titelblatt von Flugschriften und Neuen Zeitungen viele Menschen mit Informationen versehen konnten. Es stellt sich jedoch die Frage, ob es Unterschiede in bezug auf die Wirksamkeit zwischen den in schriftlicher Form und den mit Hilfe von Bildern vermittelten Informationen gibt. Ob die visuellen Informationen wohl ausreichen oder ist auch die Schrift erforderlich? ${ }^{103}$ Wenn wir diese Fragestellungen von der Sicht der Zielsetzung der politischen Propaganda aus betrachten, dann können wir feststellen, daß die besprochenen Medien ihre Aufgabe auch einzeln erfüllen können. Die Beeinflussung ist jedoch mit der Verbindung der zwei Arten von Medien viel wirksamer. Diese Tatsache muß auch der Kaiserhof erkannt haben, wovon die auf dem Titelblatt der Flugschriften und Neuen Zeitungen veröffentlichten Kupferstiche zeugen. Auch in dem von uns untersuchten Zeitraum (1683-1699) wurden zahlreiche Schlacht-

\footnotetext{
${ }^{100}$ Die Literaturen Spaniens, Frankreichs und Englands folgten zu dieser Zeit dem Beispiel Italiens, wo die Dichtung in der Volkssprache seit dem 14. Jahrhundert charakteristisch war. In den erstgenannten Ländern führte dies zur Entstehung der Nationalliteraturen. In diesem Sinne ist in der Literatur die gleiche Entwicklung zu beobachten, die wir bereits auf anderen Ebenen geschildert haben. Auch dieser Entwicklungsprozeß hat seinen Höhepunkt in der zweiten Hälfte des 17. Jahrhunderts erreicht. Vgl. Meid (1986, p. 2).

${ }^{101}$ Deutsche Literaturgeschichte. (1989, pp. 85-96.)

${ }_{102}$ Vgl. Wagner Norimberg (1685) und Ders. (1687).

${ }^{103} \mathrm{Zu}$ dieser Problematik ausführlicher siehe: Prümm (1996, pp. 52-69). Prümm nimmt in seinem Aufsatz die Bilder in Schutz. Weiterhin: Kapp (1990), und Talkenberger (1994, pp. 289-313).
} 
bilder, allegorische Kompositionen, Gemälde über die Feldherren und auch Karikaturen geschaffen.

Ihre Aufgabe wäre gewesen, ein wahrheitsgetreues Bild über die historischen Ereignisse zu vermitteln. Die Frage der Authentizität ist aber in diesem Fall sehr problematisch. Die Mehrheit der Darsteller von Festungsbelagerungen, Schlachten, türkischen oder ungarischen Soldaten hat nie mit eigenen Augen einen Türken gesehen. (Das gleiche gilt ebenfalls für die Kupferstecher und besonders für die Erzähler von Sagen und Legenden.) Aus diesem Grund können wir oft auf Darstellungen stoßen, auf denen sowohl die Türken, als auch die Ungarn in westlichen Panzer gekleidet, mit langem, geradlinigem Schwert, eine deutsche Hose tragend auf ihren robusten Pferden sitzen. Höchstens haben die Türken einen langen Bart, was den Unterschied zu den ungarischen und deutschen Soldaten anzeigen sollte. Dieses Phänomen läßt sich nur dadurch erklären, daß wegen den fehlenden oder mangelnden Erfahrungen die Bilder der eigenen Wirklichkeit auf die Gestalten des Feindes übertragen wurden. Eine Analogie bieten die bereits untersuchten Sagen und Chroniken über die Türkenkriege. Allgemein fehlen auf diesen Bildern die persönlichen Züge: sowohl die Kleidung als auch die Gesichtszüge der dargestellten Personen sind schablonenhaft. Manchmal wurden sogar einfach die Unterschriften gewechselt oder einer bekannten Person ein anderer Name gegeben. Auf einer Flugschrift aus dem Jahre 1686 sind Portraits von mehreren ungarischen Personen zu sehen. Sie stammen eigentlich aus einer Chronik von 1578. Der Verfasser hat konsequent die Unterschriften gewechselt. So hat sich z.B. Skanderbeg zu Tamás Nádasdy »verwandelt«. ${ }^{104}$

Parallel mit den Kupferstichen existierte im 17. Jahrhundert noch ein weiteres Medium, das über den größten kommunikativen Wert verfügt. Die Münzen gehörten zu den wirksamsten Medien der kaiserlichen Propaganda. Das Geld war nämlich auch Ende des 17. Jahrhunderts jenes Kommunikationsmittel, das wenigstens zeitweilig sowohl der reiche Adelige, als auch der arme Bauer in der Hand gehabt hat. Es war schwer, auf ihnen komplizierte Bewußtseinsinhalte darzustellen, was sich für die Propaganda gar nicht als Hindernis erwies. Ihr Inhalt war so für jeden leicht zu verstehen. Gerade in der zweiten Hälfte des 17. Jahrhunderts erschien die historische Medaille (histoire metallique), bei derer Anfertigung künstlerische und ästhetische Aspekte eine wesentlichere Rolle spielten. Das war ihr Nachteil im Vergleich zu den einfachen Münzen, weil ihren hohen Preis nur bestimmte Gesellschaftsschichten bezahlen konnten. ${ }^{105}$ Sie erreichten jedoch diejenigen, die mit ihrem Geld die Türkenkriege finanzierten und die politischen Entscheidungen trafen. Auf diese Weise erhielten sie eine Bestätigung dafür, daß ihr Geld zu einem guten Zweck verwendet wurde. Diese Tatsache zeigt, daß die Leiter der kaiserlichen Propaganda ihre Aufmerksamkeit nicht nur in eine Richtung lenkten, sondern auch darauf achteten, die Kommunikation mit den Rezipienten aufrechtzuerhalten.

Neben den Münzen waren noch die dreidimensionalen Werke der Architektur und des Kunstgewerbes von großer Bedeutung. Schlösser, Statuen, Plastiken, kunst-

\footnotetext{
104 »Wahrhaffte und ausführliche Beschreibung der Hungarischen königlichen Haupt- und Residenz-Stadt Ofen... Frankfurt am Main, 1686, zitiert nach: Benda (1942, p. 45).

${ }^{105} \mathrm{Zu}$ den Münzen siehe: Vocelka (1981, pp. 36-55), und Galavics (1986, pp. 104-108).
} 
voll angefertigte Waffen waren Teil der Repräsentation der Macht des Kaisers und der Feldherren, was ebenfalls für die bereits erwähnten Feste und Triumphzüge gilt. Im Hintergrund der am Kaiserhof veranstalteten Feste verbargen sich auch propagandistische Ansätze. ${ }^{106}$ Der Sieg über den »Erbfeind der Christenheit« wurde in den letzten zwei Jahrzehnten des 17. Jahrhunderts nach den einzelnen bedeutenden Schlachten nicht nur mit weltlichen, sondern auch mit religiösen, von der katholischen Kirche organisierten Festen gefeiert. ${ }^{107}$ An den letztgenannten hat oft der Kaiser selbst teilgenommen, was die enge Verbundenheit des Katholizismus mit der kaiserlichen Ideologie beweist. ${ }^{108}$ Dies findet in der Tätigkeit von Abraham a Sancta Clara $^{109}$ einen deutlichen Ausdruck. Er spielte bei der Vorbereitung des Großen Türkenkrieges durch seine Predigten eine wichtige Rolle. 1683 wurde er nach Graz bestellt, wo er sein berühmtes Werk »Auff, auff ihr Christen!« verfaßte, das auch in Ulm und Salzburg veröffentlicht wurde. Darin fordert er die Menschen auf, den Ungarn im Krieg gegen die Türken Hilfe zu leisten: »Auff, auff Ihr Christen und vorderist ihr tapfere Ungarn, verharret gehorsamist den Österreichischen Scepter..., lasset die Türkischen Tyrannen nicht ferners einschleichen! « Im Laufe des Großen Türkenkrieges hat er mit seinen Predigten zur Beeinflussung der Meinung der Öffentlichkeit wesentlich beigetragen. In seinem zitierten Werk hebt er auf »traditionelle Weise« die negativen Eigenschaften der Osmanen hervor. In den meisten seiner Schriften wendet er eine besondere, ungewöhnliche Methode der Beeinflussung an. Überraschenderweise ist er der Meinung, daß die Christen hinsichtlich der Barmherzigkeit den Armen und des Mitgefühls den Leidenden gegenüber einiges von den Türken lernen könnten. Er weist auf die in der türkischen Armee herrschenden Disziplin hin. Danach wurden die Soldaten schon wegen dem kleinsten Verbrechen hingerichtet (z.B. wenn sie mit ihren Pferden die Felder der Bauern zerstört oder als uneingeladene Gäste auf einem Bauernhof Milch getrunken hatten). Angesichts dieser Zeilen stellt sich die Frage, ob es sich hier wirklich um die Äußerungen eines mit dem Kaiser in enger Verbindung stehenden, ihn oft beratenden Predigers handelt. Allem Anschein nach haben wir es mit einer bestimmten Methode der politischen Propaganda zu tun, was wiederum andeutet, daß sich die Leiter und Organisatoren der Propagandatätigkeit dessen völlig bewußt waren, wie die erwünschte Wirkung bei den Menschen zu erzielen war. Wir können mit der Auffassung einverstanden sein, daß Abraham a Sancta Clara den Christen auf diese Weise den richtigen Weg zeigen wollte. Einen empfindlichen Bereich ansprechend scheint er ihnen folgendes

${ }^{106}$ Vgl. Vocelka (1981, pp. 56-62).

${ }^{107}$ Nach der Befreiung von Ofen (2. September 1686) wurden z.B. in Ulm, Prag, Steinau, Coblenz Dankgottesdienste gehalten. III. Buda és Pest (1935, Nr. 1038., 904., 99., 1007).

${ }^{108}$ Eine Flugschrift aus Nürnberg berichtet, daß nach der Befreiung Ofens (1686) in Wien eine Dankprozession stattfand, die von der Hofkirche bis zum Stephansdom zog. Daran nahmen auch der Kaiser und die Frau des bayrischen Kurfürsten teil. Auch die unteren Gesellschaftsschichten ließen sich vertreten, was die Anwesenheit der Handwerkerzünfte zeigt. In der Flugschrift wird angegeben, daß während der Prozession »Te Deum Laudamus« gesungen wurde. Vgl. Ebd. (Nr. 792).

${ }^{109}$ Sein ursprünglicher Name ist Ulrich Megerle. Als Augustinermönch wurde er unter dem Namen Abraham a Sancta Clara Prediger in Wien. Vgl. Ebd. (p. 25). 
gesagt zu haben: »Ein Türke, der gar keine richtige Religion hat, ist aufrichtiger und barmherziger als ihr. Ihr könnt mehr als die Türken sein, weil ihr eine richtige Religion habt ... ${ }^{110}$ Abraham a Sancta Clara war weiterhin das Vorbild für die anderen Prediger. ${ }^{111}$

\section{III.6.1. Flugschriften und Neue Zeitungen}

Unter den angeführten Medien sind für unsere Untersuchung die Flugblätter, Flugschriften und Neuen Zeitungen die relevantesten Quellen. Die Gründe dafür sind folgende:

1. Als Mittel der kaiserlichen Propaganda erfolgt die Gestaltung und Verbreitung des Türkenbildes mit ihrer Hilfe.

2. Durch die von ihnen vermittelten Informationen gelangt das Türkenbild in die andere Medien.

3. Sie berichten über die Kriegsereignisse im Zeitraum von 1683-1699. Infolgedessen widerspiegelt sich in ihnen das Echo des Großen Türkenkrieges. Aus diesem Grund sind sie Indikatoren der Wandlung des Türkenbildes, die durch die von ihnen vermittelten Nachrichten beginnt.

4. Diese Wandlung des Türkenbildes - ähnlich wie seine Entstehung - läßt sich zuerst in ihnen rekonstruieren.

5. Mit ihrer Hilfe bzw. durch ihre Inhalte erscheint dieses veränderte Türkenbild in den anderen Medien.

Bevor wir uns der ausführlichen Darstellung des wichtigsten Mediums der antitürkischen Propaganda zuwenden, muß von einem Werk eines Zeitgenossen, namens Johann Georg Schielen, die Rede sein, das die Richtigkeit des oben geschilderten Gedankengangs unterstützt. Die Themen der Discursen, die 1683 monatlich veröffentlicht wurden, stammen aus den gerade laufenden Türkenkriegen. Der Gattung nach handelt es sich hier um ein Gesprächsspiel, das für die Barockliteratur besonders charakteristisch war. Die Namen der drei Hauptprotagonisten Christusio (Historicus), Toplicus (Politicus) und Philosophus deuten bereits darauf hin, daß es um historische, politische und philosophische Gespräche geht. Sie erklären den anderen Mitgliedern der Gesellschaft die aktuellen politischen Ereignisse. Schielen ist als Sekretär anwesend, der die Gespräche aufzeichnet. Obwohl er sich besonders für die großen historischen Geschehnisse interessiert, weiß er als Autor ganz genau, womit das Interesse seiner Leser geweckt werden kann, worüber sie lesen wollen. Mit seinen Discursen trägt Schielen dazu bei, daß in den Gesprächen der bürgerlichen Gesellschaft seiner Zeit auch die Politik und die verschiedenen Kriegsereignisse ihren Platz fanden. Sein Werk liefert uns dadurch den Beweis dafür, daß die Menschen auf dem deutschsprachigen Gebiet über Kenntnisse von den laufenden Türkenkriegen verfügten. Die Mitglieder der Gesellschaft beschäftigen sich nämlich in erster Linie

\footnotetext{
${ }^{110}$ Zitiert nach: Kocadoru (1990, pp. 154-156).

${ }^{111} \mathrm{Zu}$ der Tätigkeit und Rolle von Abraham a Sancta Clara ausführlicher siehe: Eybl (1992, pp. 43-170). 
mit den Ereignissen des Großen Türkenkrieges, von denen »der an den Schlachten persönlich anwesende Mercurius« berichtet. Ähnlich wie die anderen Protagonisten ist auch er eine fiktive Person und seine Informationen stammen aus verschiedenen Flugschriften und Neuen Zeitungen. In bezug auf einige Kriegsereignisse nennt der Verfasser sogar seine Quellen: »Neue Zeitungen« aus Wien, »Wienerische Novellen«, Meßrelationen, ein »Exact-Schreiben«, das am 28. April aus Buda eingetroffen ist. Der Verfasser des letzteren, angeblich eine vornehme Persönlichkeit, deutet den Abzug der Türken an. Es ist interessant, daß sich die Herrscher von Europa als Protagonisten des Gesprächsspiels sehr oft mit der Frage beschäftigen, ob man diesen »Zeitungen« glauben schenken kann. In den meisten Fällen kritisieren jedoch Christusio, Toplicus und Philosophus am stärksten die erwähnten Medien und dadurch auch Mercurius, der die Informationen vermittelt. Er gibt es selbst zu, daß ihre Inhalte der historischen Wahrheit nicht immer entsprechen, fügt jedoch hinzu: »Ich wisse der Zeit nichts sonderliches, ausser, was die wochentliche Advisen mitbrächten. « ${ }^{112}$ Diese Aussage verrät sehr viel von den damals herrschenden Verhältnissen. Obwohl die Zeitgenossen die Authentizität der »Neuen Zeitungen« in Frage gestellt haben, mußten sie mangels Quellen anderer Art die nötigen Informationen ihnen entnehmen. Dies war nicht nur für Johann Georg Schielen aus Ulm charakteristisch, weil die meisten Autoren nicht aufgrund eigener Erfahrungen von den Ereignissen der Türkenkriege berichteten.

Der andere Grund dafür, warum die Behandlung des besprochenen Werkes notwendig war, ist, daß es auf die Rolle der verschiedenen Medien Ende des 17. Jahrhunderts hinweist und sie auch beweist. Sie erscheinen nämlich alle im Laufe der verschiedenen Gespräche. Auf jedem Titelblatt finden wir z.B. Kupferstiche, was von der Verbindung von schriftlichen mit visuellen Informationen zeugt.

Schielen weist oft darauf hin, daß die Türken nicht nur Ungarn gefährden und deswegen auch die Deutschen gegen sie kämpfen müssen. Er formuliert eine klare Aufforderung, wonach sie Ungarn nicht alleine lassen dürfen. ${ }^{113}$

\section{III.6.1.1. Die Verbindung von Druck und Politik}

1453 ist aus mehreren Gründen ein wichtiges Datum in der Geschichte Europas. In diesem Jahr eroberten die Osmanen Konstantinopel, womit eigentlich die Bedrohung des Abendlandes begann. Die Bedeutung der Gefahr wurde den europäischen Herr-

${ }^{112}$ Zitiert nach: Németh S. (1994, p. 15).

113 »Wende ich bey diesen erschröcklichen Kriegs-Troublen mein Gesicht nun auf Ungarn (...) so zittern und beben alle Gliedmassen an meinem Leibe, wann ich die alten Historien durchblättere, wie vor diesem die Ungarische Könige, mit ihrer Nation allein, dem Türcken so dapffer unter Augen getreten seyn, und ihme den Weg wieder nach Constantinoppel zurück gewiesen haben, uns Theutschen aber, solle vor diesem Wütterliche den Mut einfallen? O nein! Das wäre je unserer renomierten Theutschen Treu schimplich und verkleinerlich, wann wir das edle Königreich Ungarn, welches vorzeiten eine starcke Vormaur, Schutzwehr, fleissiger Wächter und Vorfechter des Römischen Reichs geschächtzt worden, der Zeit so Hülffloß und allein in seinem Blut herum wältzen, nur anschauen wollten und solches dem Machometischen Tyrannen unter sein grimmisches Joch, wie er vormahlen der Bulgarey und dem gantzen Bosnia gethan, zu werffen gestatten.«, zitiert nach: Ebd. (pp. 1-18). 
schern erst mit der Veröffentlichung der Bulle von Papst Callixtus III. am 29. Juni 1455 bewußt. Da die Aufrufe seines Vorgängers Nikolaus V. zum Kreuzzug gegen die Türken nur wenig Gehör bei den Fürsten und Reichsständen gefunden hatten, verkündigte Papst Callixtus III. in feierlicher Weise die erwähnte Bulle mit der gleichen Aufforderung. Um ihren Inhalt für alle Menschen des deutschsprachigen Gebiets verständlich zu machen, wurde sie ins Deutsche übersetzt. Diese Tatsache weist eindeutig darauf hin, was für eine wichtige Rolle die Sprache als Mittel der Propaganda spielte. Verschiedene Bewußtseinsinhalte lassen sich nämlich mit ihrer Hilfe formulieren. Dazu benötigt man einen gemeinsamen Kode zwischen den Beteiligten des Kommunikationsprozesses, den in diesem Fall die deutsche Sprache repräsentiert. In einem folgenden Kapitel wird noch ausführlich erläutert, warum auf die Verfassung von Propagandaschriften in deutscher Sprache Ende des 17. Jahrhunderts ein so großer Wert gelegt wurde. Die ins Deutsche übersetzte Bulle wurde Ende 1455 oder Anfang 1456 in Gutenbergs Urtype gedruckt. Das ist das erste Beispiel für die Verknüpfung von Druckkunst und Politik. Damals hat die Druckkunst zum ersten Mal in das weltpolitische Geschehen eingegriffen. Obwohl der Auftraggeber offiziell nicht bekannt ist, geschah der Druck gar nicht ohne oder gegen den Willen von Kirche und Reich. Dieses Phänomen ist im Zusammenhang mit der von uns untersuchten Problematik besonders interessant, weil es infolge des Türkenschrecks entstanden ist. ${ }^{114}$

Seit diesem Zeitpunkt ist es allgemein zu beobachten, daß das Volumen der Veröffentlichungen der Druckkunst immer von der jeweiligen politischen Situation abhängt. Houston hebt hervor, daß zur Zeit von Veränderungen politischer, ökonomischer, und religiöser Art immer mehr Menschen mit Produkten der Druckkunst konfrontiert werden. ${ }^{115}$ Wenn wir die zweite Hälfte des 17. Jahrhunderts unter diesem Aspekt untersuchen, sind darin folgende Perioden zu unterscheiden:

1. Nach dem Westfälischen Frieden (1648) ist die Anzahl der Drucke erheblich gesunken.

2. Die zweite Periode beginnt mit der zweiten Türkenbelagerung Wiens (1683), als aus den weiter oben angeführten Gründen, infolge des großen Interesses für die Ereignisse des Türkenkrieges wieder viele Flugschriften und Neue Zeitungen gedruckt wurden.

3. Ab 1697 wurden wieder weniger »Türkenzeitungen« veröffentlicht.

Parallel zu der letztgenannten Tendenz beginnt die inhaltliche Umdeutung des Türkenbildes, wodurch an der Stelle der Türkenfurcht die Türkenmode erscheint. Die detaillierte Darstellung dieses komplexen Phänomens erfolgt in einem späteren Kapitel. Es muß jedoch bereits hier angedeutet werden, daß die große Anzahl der Flugschriften ab 1683 das erste Anzeichen für den erwähnten Wandlungsprozeß bedeutete. Anfangs waren viele im Heiligen Römischen Reich Deutscher Nation mit dem Krieg gegen die Türken nicht einverstanden. Einige haben sogar die Frage gestellt, ob es nicht sinnvoller wäre, mit den Osmanen ein Bündnis einzugehen. Auch 1683

${ }^{114}$ Halbey (1994, pp. 19-28).

${ }^{115}$ Vgl. Houston (1995, p. 155).

Acta Orient. Hung. 54, 2001 
sind Flugschriften erschienen, die vielmehr von der großen Angst als von der Bereitschaft zum Kampf zeugen. Neben der Angst vor den Türken war noch die Furcht vor den Franzosen vorhanden, die mit ihrer Expansionspolitik den westlichen Teil des Reichs gefährdeten. ${ }^{116}$ In diesem Zusammenhang ist der Vergleich der drei Komponenten des Feindbildes im Heiligen Römischen Reich Deutscher Nation, der in dem nächsten großen Kapitel erfolgt, unbedingt notwendig.

Die oben angesprochene Angst wurde durch die Inhalte der Produkte der damaligen Druckerpresse hervorgerufen und später gesteigert. Flugschriften von 16821683 berichten sensationlüsternd über das Erscheinen des Halley-Kometen, der von August bis September des Jahres 1682 über jede Residenzstadt zu sehen war. ${ }^{117}$ Der Verfasser der von uns untersuchten Flugschrift hat noch hinzugefügt, daß er etwa dort erschienen sei, wo damals der Komet von 1618. ${ }^{118}$ Ob eine Analogie zwischen den beiden Fällen besteht? Vermutlich wollte der Autor diesen Eindruck erwecken und die Rezipienten zum Nachdenken bewegen, was ihm wahrscheinlich auch gelungen ist. Zum Schluß überlegt er die Möglichkeiten der Deutung der besprochenen Naturerscheinung. ${ }^{19}$ Diese Flugschrift liefert uns ein Beispiel für die Manipulation mit Informationen. Die Menschen des 17. Jahrhunderts haben solche Naturerscheinungen immer mit nahenden Kriegen in Verbindung gebracht. Der Hinweis auf das Jahr 1618 mußte wesentlich dazu beigetragen haben, daß diese Vorstellung noch stärker wurde. Die Erinnerungen an die Leiden des Dreißigjährigen Krieges waren nämlich noch sehr lebendig. Es ist nicht zu übersehen, daß viele Ausdrücke dem Wortschatz der antitürkischen Propaganda entnommen sind, wie z.B.: »Seuchen«, $»$ Pestilenz«, »Hungernoten«, »Straffen«. Außer den Kometen wird in den Flugschriften noch von Luft- und Feuerzeichen erzählt, die »fast auff einen Tag und Stund in deß 4 Reich - Statt Regensburg/Frankfurt am Mayn/Speyer/Cölln und anderen Orten mehr sich sehen lassen. « ${ }^{120}$ »ein hell weit - leuchtenden Corpus, $(\ldots) /$ mit einem rothen Schweiff auß Süden gegen Nord - wert in der Luft erschienen (...). $\ll^{121}$ Was könnte wohl dieses sich vom Süden nach Norden bewegende Feuerzeichen symbo-

${ }^{116}$ Köpeczi (1976, p. 199).

117 »Jetzt - bemeldeten August - Monats/ liesse sich in denen Nordischen Quartiren/ Nachts gegen 11 Uhren/wiederumb ein neuer Comet - Stern/ und zwar unter den auff dem lincken Hinterfuß $\beta$ deß grossen bären sitzenden zweyen Sternen drey und funffzig und ein halb Grad - weit von der Capello (...) sehen. (...) Eben diß und auch vorigen Tages ward er zu Leipzig Morgens gegen 2. und 3. Uhren/ etwa dritthalb Grad deß Löwen 24 halbe Grad vpn der Eclyptica unter den fordern Füssen deß Bären (...). Jeder Churfürst. Residenz -Satt bemerkte man ihn gleichfalls auff erst-gedachte Zeit Abends gegen 9. Uhren (...). Wolfenbüttel MAB. Gv. 74 (2). 88. 1. Ebd.

$118 \gg(. .$.$) in welcher gegend auch der in Anno 1618$ erschienene Comet gestanden/ (...)«.

119 »Was nun aber eygentlich die Bedeutung mehrangeregten Cometen seyn möge/ davon seynd die Astrologi nicht einig/ inmassen viele auß dessen bleicher Farbe Seuchen und Pestilenz/ andere hingegen Krieg/ und Hungerboten vermuthen wollen/so aber doch Gott dem Allmächtigen allein bekannt ist/ der dann nach seinem Vätterlichen Willen solche Übel und Straffen von uns und dem lieben Vaterland abkehren/ und bey dem so bleuer erworbenen Frieden in Gnaden erhalten wolle.«, Ebd.

${ }^{120}$ Wolfenbüttel MAB, Gv 74 (2) 89. 1. 
lisieren? Vielleicht das gefährliche Heer des Osmanischen Reiches, das sich in der Zukunft auch die nördlicher liegenden Gebiete angreifen würde? Wird hier der Beginn des Großen Türkenkrieges angedeutet? Als mögliche Erklärungen sind beide - die Geschehnisse von dem heutigen Standpunkt aus betrachtet - gar nicht auszuschließen. Die Absicht der Propaganda war eben, den Menschen solche Fragen zu suggerieren. Es gab jedoch auch damals Personen, die solchen Deutungen keinen Glauben schenkten. Eine von ihnen war Johann Georg Schielen, der Verfasser der bereits zitierten Discursen. ${ }^{122}$

\section{III.6.1.2. Techniken der Propaganda}

Berichte über ungewöhnliche Naturerscheinungen, Luft- und Feuerzeichen bildeten nur eine der von der antitürkischen Propaganda in den Flugschriften angewandten Techniken. Oft war auf dem Titelblatt folgende Überschrift zu lesen: »Kauff und ließ mich, ich will dir sagn, wie du solt recht den Türcken schlagn! « ${ }^{123}$ Die Rezipienten waren der Manipulation mehrfach ausgesetzt: sie wurden eigentlich »gezwungen«, die Flugschriften, Neue Zeitungen zu kaufen, weil sie aus ihnen erfahren konnten, wie »der Erbfeind der Christenheit« zu besiegen sei. Andererseits fand ebenfalls eine Art »Gehirnwäsche« statt, weil den Lesern folgendes geraten wurde: sie sollen »sich ordentlich verhalten«, fleißig arbeiten, um die Türkensteuer bezahlen zu können. Es stellt sich doch die Frage nach den anderen Techniken der antitürkischen Propaganda.

Johann Georg Schielens Werk zeigt, daß bereits die Zeitgenossen die Authentizität der Informationen der Flugschriften in Frage stellten. Demzufolge kann es überhaupt nicht überraschend vorkommen, daß eine der wichtigsten Techniken der antitürkischen Propaganda die Veröffentlichung von Fälschungen, d.h. der historischen Wahrheit nicht entsprechenden Nachrichten war. Diese Tatsache möchten die Verfasser verheimlichen, wenn sie ihre Neutralität betonen. Sie heben hervor, sie würden nichts verschweigen, oder nie etwas niederschreiben, was der Wahrheit nicht entsprechen würde. Die meisten widersprachen der vorigen Äußerung bereits im Titel ihrer Schriften. Verständlicherweise beriefen sie sich selten auf Personen, die gegen den Mißbrauch ihres Namens noch hätten protestieren können. Höchstens machten sie nur Anspielungen auf Zeugen, die nicht oder nur schwer zu identifizieren waren. »Das habe ich mit großem Fleiß aus den Erzählungen der an den Geschehnissen persönlich teilnehmenden Personen erfahren « - steht in einem »Relatio «, in dem über die Befreiung von Ofen berichtet wird. ${ }^{124}$ Ein jeder kann einen Zeugen anführen, auch wenn es manchmal um den Autor selbst geht: »(...) ich bin auch lan-

\footnotetext{
${ }^{122}$ Er ist der Meinung, daß uns die Geschichten über Saturnus, Jupiter, verschiedene Kometen und Planeten von den zukünftigen politischen Ereignissen überhaupt nichts verraten. Sie sind mit ihnen gar nicht in Verbindung zu bringen. Höchstens auf den Verlauf der Jahreszeiten und auf das Wetter kann man mit ihrer Hilfe Schlußfolgerungen ziehen. Vgl. Németh (1994, p. 15).

${ }^{123}$ Zitiert nach: Kocadoru (1990, p. 160).

124 »Journal, oder wahrhafftig- und ausführliche Erzehlung dessen, was zu Anfang und Ende ..., 1686, In: Benda (1942, p. 36). 
ge Zeit dort gewesen und habe gesehen. ${ }^{125} \mathrm{Er}$ weiß, daß diesem Hinweis niemand nachgehen kann. Da der Erfolg besonders im Fall von Sensationsnachrichten gesichert war, kommt es oft vor, daß die Flugschriften von unmöglichen, fiktiven Ereignissen berichten. Manchmal ist schon die Erwerbung der Nachricht zur Sensation geworden, wie es bei einem Bericht über die Zurückeroberung Ofens der Fall war, der durch einen Eilboten, 18 Stunden in einem Stücke geritten, von Ofen nach Wien überbracht wurde. Bei dieser Karriere habe er sogar seinen Hut, seine Pistole und seinen Schwert verloren. ${ }^{126}$ Auch die Flugschriften über die konkreten Auseinandersetzungen der kaiserlichen Truppen mit den Türken starren von überraschenden und verblüffenden Behauptungen. Daß der Zeitpunkt von Festungsbelagerungen unrichtig und manchmal irreführend angegeben wird, scheint noch die harmloseste Fälschung zu sein. Die bemerkenswertesten Fälschungen bietet uns die große Menge von Flugschriften über die Kriegsereignisse des Jahres 1686. Überraschenderweise stoßen wir in einigen historischen Rückblicken vor der konkreten Schilderung der Belagerungen auf den Namen von Attila, ${ }^{127}$ der an der jeweiligen Schlacht unmöglich teilgenommen haben konnte. Um den Ruhm und Heldenmut der kaiserlichen Truppen zu vergrößern, erfanden manche Autoren ganze Kriegsaktionen: einige Flugschriften berichten z.B. über Kriegsoperationen, die der Geschichtsforschung gar nicht bekannt sind. ${ }^{128}$ Der Verfasser einer Flugschrift zählt gründlich die an der Bestürmung Ofens beteiligten Feldherren, unter denen auch der Name des 1664 verstorbenen Miklós Zrínyi auftaucht. ${ }^{129}$ Seine Erwähnung muß ebenfalls Propagandazwecken gedient haben. ${ }^{130}$

${ }^{125} »$ Diarium der andermahligen Belagerung Ofen, Riga, 1686«, In: Ebd. (p. 37).

${ }^{126} \gg$ Kurtze Relation wegen dapffer und glücklicher Eroberung der Königl. Hauptstadt und Vestung Ofen ..., 1686«. In: Benda (1942, p. 37).

${ }^{127}$ Zur Erwähnung des Namens von Attila in Berichten am Ende des 17. Jahrhunderts konnte es dadurch kommen, daß König Matthias (1458-1490) die Überzeugung von der ungarisch-hunnischen Verwandtschaft wieder in den Vordergrund gestellt hatte. Er ließ mit seinen Propagandisten sich als »zweiter Attila« apostrophieren und die Rolle seines Landes als »Bollwerk der Christenheit« betonen. Durch den Briefwechsel der ungarischen Humanisten mit den deutschen wurden diese Vorstellungen auch im Heiligen Römischen Reich Deutscher Nation bekannt. Dazu vgl. V. Kovács (1971) und Fodor (1997, pp. 33-34). Viele haben sogar mit großen Hoffnungen darauf gewartet, daß er die Türken aus Europa vertreibt. Es ist nicht auszuschließen, daß die erwähnten Ideen im 17. Jahrhundert noch nicht in Vergessenheit geraten sind und als Legende weiterlebten. Es kann gar nicht überraschend vorkommen, daß der Name von Attila besonders im Zusammenhang mit der Befreiung von Ofen (1686) erscheint. Wenn wir daran denken, wie schwach die kaiserliche Macht unter Leopold I. war, dann ist es anzunehmen, daß die Person von Kaiser Leopold I. vielleicht bewußt mit den zwei bedeutenden Herrschergestalten in Parallele gestellt wurde.

${ }^{128}$ Dazu Beispiele: »Ausführliche Vorstellung und Beschreibung der Belägerten Ungarischen Stadt Ofen, Frankfurt am Main, 1684«, »Diarium Der Andermaligen Belagerung Ofen, Riga, 1696«, »Wahrhaffte Relation der königlichen Hauptstadt und Vestung Ofen.... Augsburg, 1686«, »Ausführliche Relation Desz jüngsten .... beschehenen Sturms..., 1686«, In: Benda (1942, pp. 44-55).

129 »Diarium der Andermaligen Belagerung Ofen, Riga, 1686«. In: Ebd.

${ }^{130} \mathrm{G}$. Etényi Nóra beschäftigt sich in einem ihrer Aufsätze mit der bewußten Hinweisung auf Zrínyis Person in den Schriften der kaiserlichen Propaganda. Vgl. G. Etényi (1999, pp. $83-105)$. 
Auch die Magie der Zahlen gehörte zu den wichtigsten Mitteln der kaiserlichen Propaganda. Diese Feststellung wird besonders offensichtlich, wenn wir bei der Beschreibung der verschiedenen Schlachten und Festungsbelagerungen die Zahl der Kämpfenden mit jener der Verstorbenen vergleichen. Die meisten Autoren geben zuerst nach komplizierten Rechnungen die Kriegsstärke des kaiserlichen Heers an, die oft einfach fiktive Zahlen sind. Danach zählen sie für jeden Tag die Anzahl der Toten auf. Wenn wir die Resultate der zwei Kalkulationen miteinander vergleichen, stellt sich heraus, daß danach mehr Menschen gestorben sind, als überhaupt anwesend waren. 131

Weiter oben wurde schon über eine besondere Technik, nämlich über die Übertragungen auf biblische Elemente gesprochen. Die negativen Gestalten der Bibel, wie z.B. Pontius Pilatus, werden dabei »türkisch gekleidet«, d.h. als Türke dargestellt. ${ }^{132}$ Diese Technik wird nicht nur in den Flugschriften angewandt, sondern auch in der bildenden Kunst. In den Kirchen wird auf den Altären die christliche Vergangenheit mit ihren Märtyrer auf die Gegenwart übertragen, wo die Feinde ebenfalls als Türken dargestellt werden. ${ }^{133}$ In den Flugschriften finden wir die gleichen Bilder wieder, die bereits bei der Behandlung der Türkensagen angeführt wurden: der Türke erscheint als Kindertöter und Frauenschänder. ${ }^{134}$

Von der engen Verbindung der religiösen und weltlichen Macht zeugt das Phänomen, daß der Türke mit dem Teufel identifiziert oder als sein Verbündeter dargestellt wird. ${ }^{135}$ Auch die katholische Kirche war sich dessen bewußt, wie man den größten Einfluß auf die Gläubigen ausüben konnte. Es wurde dabei wie folgt argumentiert: Die Christen müßten zueinanderhalten, um den »Erbfeind der Christenheit« besiegen zu können, weil die Niederlage der Türken gleichzeitig die Niederlage des Teufels beinhalte. Diesbezüglich erscheint hier wieder das Prinzip der Dualität, weil in den Flugschriften mit der Gegenüberstellung des Guten (Gott) und des Bösen (Teufel) operiert wird. Das hatte zur Folge, daß der Türke nicht nur als Feind im politischen und militärischen Sinne gefürchtet wurde, sondern auch wegen seiner nicht-christlichen Religion eine Gefahr für die Christenheit bedeutete. Die kaiserliche Propaganda und die katholische Kirche legten einen großen Wert darauf, diese doppelte Gefahr immer und überall zu betonen. Wenn wir jedoch in Betracht ziehen, daß der weiter oben zitierte Johann Christoph Wagner sowie viele andere Autoren (z.B. Abraham a Sancta Clara) die tiefe Religiosität der Muslime hervorheben, stellt sich

\footnotetext{
131 „Journal oder wahrhafftig- und ausführliche Erzehlung alles dessen, was zu Anfang und Ende..., 1686. In: Benda (1942, p. 44).

${ }^{132}$ Vocelka (1988, p. 25).

${ }^{133}$ Ein Beispiel dafür liefert der Rangersdorfer Altar in Kärnten, auf dem bei der Kreuzigung von Petrus ein Mann mit Turban und orientalischen Kleidern zu sehen ist. Vgl. Kocadoru (1990, pp. 170-171).

${ }_{134}$ Auch in dem Kapitel über die Stereotype wurde dieses Phänomen ausführlich erläutert. Aus diesem Grund wird an dieser Stelle darauf nur hingewiesen. Wenn wir die zwei Medien unter dem erwähnten Aspekt untersuchen, weisen sie keine Unterschiede auf. Das läßt sich damit erklären, daß das Türkenbild zuerst in den Flugschriften erschienen war und durch die von ihnen vermittelten Informationen in die anderen Medien gelangte.

${ }^{135}$ Vgl. Kocadoru (1990, p. 177). 
die Frage, ob die Propaganda einen vollständigen Erfolg verzeichnen konnte. Hinsichtlich der Bereitschaft zur Zahlung der »Türkensteuer« zwecks Finanzierung des Großen Türkenkrieges können wir die Frage bejahen. Aber wenn wir die verschiedenen Vorstellungen über die Osmanen im Bewußtsein der einzelnen Menschen betrachten, stoßen wir wieder auf die bereits angeführte These, wonach »der Fremde« sowohl positiv (Gast) als auch negativ (Feind) empfunden werden kann.

Die Verwendung von Tiermetaphern gehört zu den allgemeinen Charakteristika der Zeit. Jede Komponente des im Reich existierenden »Feindbildes« wurde durch ein bestimmtes Tier repräsentiert. ${ }^{136}$ Obwohl der Vergleich dieser Feindbilder erst im folgenden Kapitel erfolgt, muß an dieser Stelle betont werden, daß wir in jedem Fall mit einem bestimmten Tier zu tun haben, das immer denselben Feind darstellte. Die Analyse der Türkenlieder hat gezeigt, daß zu jeder Zeit die gleichen Bilder wiederholt wurden. In bezug auf die Türken enthält ihr Wortschatz folgende Ausdrücke: »Bluthund«, »Türckischer Hund«, »Mordhund«, usw. Der Krieg gegen die Türken wurde als Kampf des Adlers gegen den Bluthund dargestellt. ${ }^{137}$

Die angeführten Mittel bzw. Techniken stellen jedoch nur die Patronen einer Kanone dar, die ihre Aufgabe an sich allein, ohne Magazin nicht ausüben können. In unserem Fall repräsentieren die Flugschriften und Neue Zeitungen die Patronen und die deutsche Sprache die Kanone, aus der sie »geschossen« werden können. Bestimmte Bewußtseinsinhalte können nämlich nur mit ihrer Hilfe formuliert und ausgedrückt werden.

\section{III.6.1.3. Die Sprache}

In den letzten zwei Jahrzehnten des 17. Jahrhunderts begann eine neue Phase in der Entwicklung der deutschen Sprache. Weiter oben wurde bereits erwähnt, daß das Heilige Römische Reich Deutscher Nation nach dem Westfälischen Frieden (1648) nicht nur politisch und konfessionell, sondern auch sprachlich geteilt war. Der im katholischen Österreich vorherrschenden bayrisch geprägten Form der Schriftsprache als oberdeutsche Varietät stand die ostmitteldeutsche schriftsprachliche Variätet des protestantischen Nordens gegenüber, die auf Martin Luthers Einfluß zurückgeht. Solange im katholischen Süden auch im 17. Jahrhundert neben dem Lateinischen die bayrisch geprägte Form der Schriftsprache - die sich aus der kanzleisprachlichen Tradition am Hofe Kaiser Maximilians I. entwickelt hatte - vorherrschend war, schlug die Sprachentwicklung des protestantischen Nordens infolge der Bibelübersetzung von Luther einen neuen, eigenen Weg ein. Die Forschungsergebnisse der letzten Jahre zeigen jedoch, daß diese Spaltung bereits in den letzten zwei Jahrzehnten des 17. Jahrhunderts geringer wurde. Die meisten Germanisten waren bisher der Meinung, daß die Entstehung der deutschen Standardsprache erst in der Mitte des 18. Jahrhunderts, zur Regierungszeit Maria Theresias begann. Das ist eigentlich ein Verdrängungsprozeß, der die Durchsetzung der Präferenz einer ostmitteldeutsch domi-

\footnotetext{
${ }^{136}$ Schmidt (1995, pp. 234-239).

${ }^{137}$ Die analysierten Türkenlieder sind bei Buchmann und Özyurt zu finden. Vgl. Buchmann (1983) und Özyurt (1972).
} 
nierten Varietät als Schriftsprache für den gesamten deutschen Sprachraum impliziert. Peter Wiesinger und Paul Rössler heben jedoch hervor, daß schon während des 17. Jahrhunderts ostmitteldeutsche Spracheinflüsse auf Österreich einwirkten. ${ }^{138}$

Das Beispiel der bereits zitierten Bulle von Papst Callixtus III. zeigt, was für eine essentielle Rolle die Sprache in der Verwirklichung der politischen Beeinflussung spielte. Pukánszky weist darauf hin, daß die meisten Drucker in Augsburg, Nürnberg und Wien die in lateinischer Sprache verfaßten Berichte ins Deutsche übersetzen ließen und diese deutschsprachige Version veröffentlichten. ${ }^{139}$ In bezug auf den Rezipientenkreis der kaiserlichen Propaganda wurde weiter oben bereits angedeutet, aus welchen Gründen eine Übersetzung notwendig war. Elisabeth Eisenstein vertritt die Auffassung, daß die Trennlinie zwischen einem auf Latein lesenden und einem in der Landessprache lesenden Publikum mit der Trennlinie zwischen den einzelnen sozialen bzw. gesellschaftlichen Schichten nicht gleichzusetzen sei. Unter den Rezipienten der erwähnten deutschsprachigen Übersetzungen finden wir nämlich nicht nur einfache Bürger, sondern auch Edelknaben, Höflinge, Lehrburschen, Landinhaber, Kaufleute und Sekretäre. ${ }^{140}$ Diese Tatsache war sowohl den Leitern der kaiserlichen Propaganda, als auch den Druckern bewußt. Die letzteren versuchten ein freundschaftliches Verhältnis mit dem Kaiserhof und seinen Beamten zu pflegen, was auf mehrere Gründe zurückzuführen ist. Sie hatten vom Kaiser das Privileg für Gründung und Betrieb von Druckereien erhalten. In den meisten Fällen war der Kaiser ebenfalls der Auftraggeber für das Drucken von Verordnungen, Erlässen, Bullen, Ablässen, Flugschriften und Traktaten. Als ein weiterer Faktor erwies sich noch, daß man in den kaiserlichen Beamten einerseits potentielle Zensoren, andererseits potentielle Kunden sah. ${ }^{141}$ Dies erklärt die große Bedeutung der Druckereien für die antitürkische Propaganda. In diesem Zusammenhang muß an dieser Stelle angeführt werden, daß zwischen 1618 und 1705 ein Drittel der Besitzer der 40 Offizinen in Wien aus dem protestantischen Gebiet stammte, ${ }^{142}$ und diese brachten allem Anschein nach »ihre Sprache« mit.

Wenn wir konkret die Periode des Großen Türkenkrieges betrachten, wird es noch deutlicher, warum Leopold I. den Zusammenhalt der politisch, konfessionell und sprachlich geteilten Teile seines Reichs zur Bewältigung der Türkengefahr anstrebte. Es wurde oft darauf hingewiesen, daß der Kaiser für die Finanzierung des Türkenkrieges auf die Steuerbewilligung der Stände angewiesen war. Um das erwünschte Ziel erreichen zu können, war er sogar bereit, auch die konfessionellen Unterschiede beiseite zu schieben. Man war daran interessiert, daß die antitürkischen Propagandaschriften möglichst von vielen Einwohnern des Reiches, auch im protestantischen Norden rezipiert wurden. Aus diesem Grund durften die Flugschriften

\footnotetext{
${ }^{138}$ Verwiesen sei diesbezüglich auf: Wiesinger (1987, pp. 83-109); Ders. (1985a, pp. $1633-$ 1651), Ders. (1985b, pp. 1939-1949); Roessler (1998, pp. 623-642).

${ }^{139}$ Vgl. Pukánszky (1931, p. 213).

${ }^{140}$ Vgl. Eisenstein (1997, pp. 28-30).

${ }^{141}$ Ebd. (p. 26).

${ }^{142}$ Vgl. Roessler (1998, pp. 626-629). 
und Neue Zeitungen keinesfalls in lateinischer Sprache veröffentlicht werden. Daß in Österreichs Druckorten die mitteldeutschen Gegebenheiten eindringen konnten und in den Drucken der Einfluß der mittel- und norddeutschen Traditionen auf die österreichische Schriftsprache nachzuweisen ist, zeigt die Vorrangstellung der politischen Zielsetzungen. Als Zusammenfassung läßt sich feststellen, daß in den letzten zwei Jahrzehnten des 17. Jahrhunderts mit Hilfe der Sprache die Annäherung der zwei oppositionellen Teile Deutschlands, des katholischen Südens und des protestantischen Nordens, beginnt. Dieser Prozeß vollzog sich im Interesse des erfolgreichen Krieges gegen die Türken zwischen 1683 und $1699,{ }^{143}$ was mit den Initiativen der kaiserlichen Propaganda zu erklären ist.

\section{Feindbilder}

Kulturkontakte, politische Beziehungen zwischen Völkern und Staaten führen zwangsläufig zur Entstehung von Images und Feindbildern. ${ }^{144}$ Das gilt besonders für die Frühe Neuzeit, als sich infolge des weiter oben erläuterten Entwicklungsprozesses, nach der Auflösung der Respublica Christiana, die frühmodernen Staaten herausbildeten. In der politischen Welt Europas galt der Universalismus einer einheitlichen Christenheit nicht mehr, und die neuen Staaten versuchten, eine eigene Identität aufzubauen, um sich dadurch legitimieren zu können. Das brachte die qualitative Umdeutung der seit dem Mittelalter existierenden Beziehungen mit sich. Es kam auch zu quantitativen Veränderungen, wovon die verstärkten Kontakte der Völker zueinander (durch den Fernhandel, Ausbau des Nachrichtendienstes, usw.) zeugen. Das hatte die Zunahme der potentiellen Konflikte bzw. Konfliktsituationen zur Folge. Weiter oben haben wir gesehen, daß an den europäischen Entwicklungsprozessen in der Frühen Neuzeit auch das Heilige Römische Reich Deutscher Nation beteiligt war. Im 17. Jahrhundert sah sich das Reich mit drei Mächten nachhaltig konfrontiert. Diese waren: das Osmanische Reich, Spanien und Frankreich. In diesem Zusammenhang scheint die Fragestellung gerechtfertigt zu sein, ob wir uns bei der Behandlung

${ }^{143}$ Vgl. Bodi (1995, pp. 19-22).

${ }^{144}$ Allgemein kommt es in den verschiedenen Kommunikationsprozessen zuerst immer zur Entstehung von Images. Es stellt sich jedoch die Frage, aus welchem Grund und auf welche Weise sie sich zum Feindbild verwandeln können. Diese »Mutation« vollzieht sich, wenn während einer politischen und militärischen Konfrontation das eine Volk dem anderen mit der Zerstörung seiner politischen, sozialen und religiösen Ordnung droht oder seine ökonomische Grundlage gefährdet. Die Wandlung wird von der Angst hervorgerufen. Diese Entwicklung ist für das spanische Feindbild im Reich charakteristisch. Vgl. Schmidt (1995, p. 209). In bezug auf die Osmanen läßt sich eine Gegentendenz beobachten. Am Anfang der vorliegenden Arbeit haben wir gesehen, daß die erste Begegnung der christlichen Welt mit den Osmanen sofort die Entstehung eines Feindbildes mit sich brachte. Im Kapitel II.2.1. über »das als >türkisch` gekleidete Osmanische Reich« wurde angedeutet daß gleichzeitig ebenfalls die Kennzeichen des positiven Images anwesend waren. Trotz allem dominierten bis zu den achtziger Jahren des 17. Jahrhunderts die negativen Vorstellungen. Erst mit den Erfolgen der kaiserlichen Truppen nahm ein Wandlungsprozeß seinen Anfang, dessen Resultat die Entstehung der Türkenmode am Ende des 17. bzw. zu Beginn des 18. Jahrhunderts war. 
der kaiserlichen Propaganda mit einem Feindbild oder mit mehreren Feindbildern beschäftigen müssen. Das als Oberbegriff zu verwendende »Feindbild« stellte sich aus den Vorstellungen von den erwähnten drei gefährlichen Mächten zusammen. In den Flugschriften wurde oft einfach mit dem Ausdruck »Feind « operiert, ohne daß dabei der bestimmte Gegner, d.h. das genus proximum genannt worden wäre. ${ }^{145}$ Weiter oben wurden die Techniken der antitürkischen Propaganda ausführlich dargestellt. Diesbezüglich stellt sich die Frage, ob sie nur in den gegen die Türken gerichteten Flugschriften angewandt wurden, oder bestimmte Parallelen zu Techniken der antispanischen und antifranzösischen Propaganda aufweisen. Das würde gleichzeitig bedeuten, daß in den verschiedenen Feindbildern ebenfalls Ähnlichkeiten zu entdecken sind.

Es gilt als gemeinsames Charakteristikum, daß die Verfasser der Flugschriften über die konfessionellen Unterschiede erhabend, in der Hoffnung der Minderung der politischen und konfessionellen Spaltung des Reiches, mit der Aufforderung zum Kampf gegen »das fremde Kriegsvolk« das Zusammengehörigkeitsgefühl der Untertanen zu wecken und zu verstärken suchten. Neben dieser integrativen Wirkung besteht die wesentliche Funktion der Darstellung des Fremden in der Reflexion der eigenen Identität, weil seine Präsenz Anlaß zur Selbstbetrachtung gab. Feindbilder fungieren in den meisten Fällen als Leitfaden der Außenpolitik und wirken möglicherweise konfliktverschärfend. Ihre Verwendung innerhalb der sich bedroht fühlenden Gruppe ist typischerweise von den wahrheitsgemäßen Handlungen und Eigenschaften des Feindes unabhängig und wird vielmehr von den innenpolitischen Vorgängen und politischen Ansätzen der Machtinhaber gesteuert. ${ }^{146}$

\section{IV.1. Die »Erbfeinde der Christenheit»}

Um dieses komplexe Phänomen besser verstehen zu können, muß an dieser Stelle der Bedeutungswandel des bei der Darstellung der Türken häufig angeführten Begriffs »Erbfeind« erläutert werden. Die Erbfeindthematik lieferte einerseits die Legitimation für politische Abwehrmaßnahmen, andererseits zielte sie auf emotionale Wirkung ab. Diesbezüglich handelt es sich im 17. Jahrhundert keinesfalls von einem neuen Verfahrensprinzip. Unter den veränderten politischen Rahmenbedingungen wird auf traditionelle politische Erklärungsschemata zurückgegriffen. Dieses Phänomen spricht eindeutig für die zitierte Begriffserklärung von Foucault hinsichtlich der Tradition, die darauf abzielt, »eine Menge gleichzeitig sukzessiver und identischer (zumindest analoger) Phänomene ein besonderes zeitliches Statut zu geben; er ge-

\footnotetext{
${ }^{145}$ Aus dem Kontext stellte es sich natürlich immer heraus, von welchem »Feind« in der jeweiligen Flugschrift die Rede war. Dieses Phänomen könnte auch darauf hindeuten, daß die gegen drei Gegner gerichtete Propaganda in jedem Fall mit den gleichen Methoden und Techniken vorgegangen ist. Den drei verschiedenen Feindbildern entsprechend wurde natürlich auch auf die differentia specifica, d.h auf die spezifischen Eigenschaften der einzelnen »Feinde« Rücksicht genommen. Zur allgemeinen Verwendung des Wortes »Feind« siehe: Harms (1992, p. 144).

${ }^{146}$ Vgl. Schmidt (1995, pp. 211-240). 
stattet, die Streuung der Geschichte in der Form des Gleichen erneut zu denken«. ${ }^{147}$ Der »Bedeutungswandel« des Begriffs »Erbfeind« stellt diese Erklärung unter Beweis. Nach den einzelnen Bedeutungen lassen sich folgende Perioden unterscheiden: ${ }^{i 48}$

1. Im Mittelalter, zur Zeit der Respublica Christiana wurde der christlich-religiösen Gedankenwelt und dem Weltbild entsprechend der Teufel als Erbfeind bezeichnet. Interessanterweise wird in den Wörterbüchern auch heute noch unter dem Lemma »Erbfeind « diese Bedeutung ebenfalls angeführt. ${ }^{149}$

2. Im ausgehenden Mittelalter und zu Beginn der Frühen Neuzeit gelangte dieser Begriff aus der religiösen Sphäre in die weltliche und gewann eine ins Politische reichende Bedeutung. Mit dem Vordringen der Osmanen in Europa erfolgte die Übertragung auf den Türken, der als Sohn bzw. Verbündeter des Teufels angesehen wurde. Dieses Phänomen zeugt von der engen Verbindung der politischen und religiösen Macht. Das Wort »Erbfeind« wurde der wichtigste Bestandteil des antitürkischen Propagandavokabulars.

3. Vom 15. Jahrhundert an hing es von den machtpolitischen Verhältnissen ab, in welchem Zusammenhang der erwähnte Ausdruck verwendet wurde. Kaiser Maximilian I. bezeichnete 1513 die Franzosen als »erbfeinde wider das heilig reiche und Tewtsche Nation«. In dem 1544 erlassenen Speyerer Reichsabschied steht folgender Vergleich: »gedachten König von Frankreich nicht weniger dann den Türcken für einen gemeinen Feind der Christenheit zu halten $\ll{ }^{150}$ Durch diese analoge Verwendung wurde die Bezeichnung auf die Franzosen übertragen. ${ }^{151}$ Diese Übertragung war jedoch nicht so manifest und nachhaltig, wie es im Fall der Osmanen zu beobachten war. Die Identifizierung Frankreichs mit dem Erbfeind bildete keinesfalls den festen Bestandteil der Techniken der antifranzösischen Propaganda.

4. An die Stelle der Franzosen traten in dieser Hinsicht bis in die Zeit des Dreißigjährigen Krieges die spanischen Habsburger, die die Verwirklichung einer Universalmonarchie strebten. Diese gegenreformatorische Hegemonialmacht bedeutete für das Reich, besonders die deutschen Protestanten auf politischer, konfessioneller und militärischer Ebene eine Bedrohung, was die Herausbildung des Feindbildes zur Folge hatte. Um die erwünschte Wirkung bei den Rezipienten erreichen zu können, operierte auch die antispanische Propaganda mit der Gleichsetzung der Spanier mit den Türken. ${ }^{152}$ Dazu gaben die Parallelen zwischen den zwei bedeutendsten

${ }^{147}$ Vgl. Foucault (1997, p. 33).

${ }^{148}$ Diese Periodisierung stammt von Franz Bosbach. Vgl. Bosbach (1992, pp. 121-125).

${ }^{149}$ Vgl. Drosdowski (1989, p. 445). In dem etymologischen Wörterbuch von Kluge steht folgende Erklärung: »(<13. Jh.) Mhd. erbevînt ist eigentlich der Teufel, dessen Feindschaft die Menschheit mit der Erbsünde geerbt hat. Dann übertragen auf die Türken, und schließlich auch auf die Franzosen.« Vgl. Kluge (1995, p. 228).

${ }^{150}$ Zitiert nach: Bosbach (1992, pp. 124-125).

${ }^{151}$ Diese analoge Verwendung der Erbfeindbezeichnung läßt sich mit den außenpolitischen Bestrebungen Frankreichs erklären. 1544 hat sich nämlich Franz I. auf ein Bündnis mit dem Osmanischen Reich eingelassen. Daneben spielte noch die osmanische militärische Unterstützung für die Franzosen eine wichtige Rolle. Vgl. Ebd.

${ }^{152}$ Ebd. (p. 126). 
Mächten der Frühen Neuzeit einen Anlaß. In beiden Fällen handelte es sich um Reiche mit großer geographischer Ausdehnung, die mit ihrer Expansionspolitik die Deutschen gefährdeten. Zur Zeit des Dreißigjährigen Krieges marschierten z.B. die Spanier nach Böhmen und nahmen an der Schlacht am Weißen Berg teil, besetzten die Rheinpfalz und operierten in Nordwestdeutschland. Durch diese direkte Konfrontation erlebten sie die Deutschen, ähnlich wie die Osmanen, in erster Linie als Soldaten, und die spanische Herrschaft verbanden sie mit Krieg. Weiterhin galten auch die Spanier als von Natur aus kriegerisch. Die antispanischen Flugschriften berichten über die gleichen Greueltaten, die in bezug auf die Türken weiter oben bei der Behandlung der Stereotype aufgezählt wurden. Auch die spanischen Soldaten schonten weder alt noch jung, weder Mann noch Frau. Das Bild des wilden, plündernden Spaniers hat sich jedoch viel früher, während des Aufstiegs von Spanien zur Weltmacht, zur Zeit von Karl V. herausgebildet. Bei der Verfassung von antispanischen Flugschriften wurde einfach auf Berichte zurückgegriffen, die seit der Zeit Karls V. entstanden waren. Aus diesem Grund entwickelte sich während des DreiBigjährigen Krieges kein neues Spanienbild, vielmehr rief man die Vorstellungen der wütenden spanischen Soldaten in Erinnerung. Der Eroberung Konstantinopels durch die Osmanen (1453) entspricht hinsichtlich der Spanier das Sacco di Roma (1527). Beide Ereignisse bedeuteten für die Menschen im Reich keine direkte Konfrontation mit dem jeweiligen Feind, trugen jedoch zur Entstehung des lange Zeit konstanten Feindbildes wesentlich bei. ${ }^{153}$

5. Bis zu den achtziger Jahren des 17. Jahrhunderts gibt es nur eine geringe Zahl von Flugschriften, in denen die Gleichsetzung des Gegners mit dem Türken zu finden ist. Weiter oben wurde darauf hingewiesen, daß nach dem Westfälischen Frieden auch die Anzahl der veröffentlichten Flugschriften gesunken ist, was natürlich mit den politischen Verhältnissen in Europa zusammenhängt.

6. Von der zweiten Türkenbelagerung Wiens (1683) an liegt wieder eine große Menge von antitürkischen Flugschriften vor. Wegen der Angriffe Frankreichs auf den westlichen Teil des Reiches war Kaiser Leopold I. zur Führung eines Zweifrontenkrieges gezwungen. Auch in der antifranzösischen Publizistik wurde auf die traditionellen antitürkischen Traditionen zurückgegriffen. Es geschah wieder die Identifikation der Franzosen mit dem »Erbfeind der Christenheit«, nämlich dem Türken, was gleichzeitig die Gleichsetzung der französischen und der türkischen Politik bedeutete. Ludwig XIV. wurde vorgeworfen, daß er in seiner Außenpolitik türkischen Verhaltens- und Verfahrensweisen folgt, weil er ohne Kriegserklärung Konflikte beginnt, und die anderen Staaten in Europa, besonders seine Nachbarn »durch geheuchelte Freundlichkeit« täuscht ${ }^{154}$ und sie später trotzdem überfällt. In einigen

${ }^{153} \mathrm{Zu}$ der antispanischen Propaganda siehe: Schmidt (1995, pp. 210-222).

${ }^{154}$ In diesem Zusammenhang ist es interessant, daß der Ausdruck »Türke« nicht nur für die Bezeichnung eines Volkes benutzt wird, sondern über eine zusätzliche Bedeutung verfügt. Dabei handelt es sich gerade um die Ludwig XIV. vorgeworfenen Verhaltensweise. Diese zweite Bedeutung heißt wie folgt: »Vorspiegelung falscher Tatsachen«. Da es hier um eine Handlung geht, wurde später dementsprechend - vermutlich aus dem Substantiv - ein Verb »türken« gebildet. Vgl. Kluge (1995, p. 841). 
Flugschriften steht sogar, daß Ludwig XIV. zu einem zweiten Suleiman geworden sei. Eine analoge Erscheinung läßt sich in England beobachten, wo in einem Flugblatt der französische König als »the most Christian Turk « bezeichnet wurde. ${ }^{155}$ Später wurde Frankreich nicht nur mit dem Türken, dem ursprünglichen »Erbfeind der Christenheit « verglichen, sondern selbst zum neuen Erbfeind erklärt, sogar direkt als »Erbfeind « apostrophiert. Davon zeugt z.B. der Titel einer antifranzösischen Flugschrift von 1690, in dem Ludwig XIV. »occidentalischen Erb-Feindt« genannt wird. ${ }^{156}$ In den neunziger Jahren des 17. Jahrhunderts sah man infolge der Siege der kaiserlichen Truppen gegen die Türken auf dem ungarischen Kriegsschauplatz bereits die größere Gefahr für das Reich in der Expansionspolitik des französischen Königs. Das ist die Erklärung dafür, warum keine einfache Übertragung mehr geschieht.

\section{IV.2. Die "Fremden"}

Alle drei »Feinde« bzw. Völker wurden von den Einwohnern des Heiligen Römischen Reiches Deutscher Nation als fremd empfunden. Man verfügte über die wenigsten Kenntnisse immerhin bezüglich der Osmanen. Der Eindruck ihrer Fremdartigkeit wurde auch dadurch gesteigert, daß sie im Vergleich zu den Franzosen und Spaniern keine Christen waren, nicht aus Europa stammten und ein großer Teil ihres Reiches sich nicht auf dem europäischen Kontinent befand. Das Osmanische Reich gehörte einem anderen Kulturkreis an. Die aus den kulturellen Unterschieden stammenden Verständigungsschwierigkeiten bei unbekannten Erscheinungen versuchte man mit der Verwendung von europäischen Begriffen und Kategorien zu überwinden, was sich nicht immer als eine erfolgreiche Methode erwies. Bei der Berührung der zwei Kulturen stoßen die Deutschen auf unbekannte Phänomene nicht nur im politischen und religiösen Bereich, sondern auch in bezug auf das alltägliche Leben. Auch das Äußere der Menschen und ihre Kleidungsgewohnheiten erwiesen sich, verglichen mit der eigenen Wirklichkeit, als unterschiedlich, unbekannt, aber gleichzeitig auch als faszinierend. All diese Faktoren trugen dazu bei, daß das Interesse der Einwohner des Habsburgerreiches für diese unbekannte, andersartige Welt bereits früh geweckt wurde. Das Gefühl der Fremdartigkeit blieb trotz des Interesses und der Faszination weiterhin erhalten. Das wird auch dadurch deutlich, daß man sich in der Frühen Neuzeit für die Bezeichnung von fremden, unbekannten Erscheinungen oft des Terminus »türkisch « bediente. Der aus Amerika stammende Mais wurde z.B. türkischer Weizen genannt. Nach den Äußerungen mancher Reisenden auf der Iberischen Halbinsel sollen die spanischen Frauen »türkisch« gekleidet ausgesehen haben. Auf die ethnisch-völkischen Unterschiede zwischen Nord- und Südeuropäern wurde ebenfalls mit diesem Ausdruck hingewiesen. ${ }^{157}$ Bei den Franzosen war dieser Unterschied nicht vorhanden.

\footnotetext{
${ }^{155}$ Von Ludwig XIV. wird sogar behauptet, daß er seine eigenen Untertanen umbringt und sich in einer unmittelbaren Nachbarschaft mit dem Teufel befindet. Die Analogie zum türkischen Sultan und zu den Osmanen liegt hier auf der Hand. Vgl. Mörke (1992, p. 27).

${ }^{156}$ Vgl. Bosbach (1992, p. 133).

${ }^{157}$ Vgl. Schmidt (1995, pp. 231-232).
} 
Weiter oben wurde die Hypothese aufgestellt, daß sich im Bewußtsein der sich mit dem Fremden konfrontierenden Menschen von einem fremden Volk - nach dem Prinzip der Dualität - sowohl ein positives als auch ein negatives Bild herausbilden kann. Manchmal sind beide Meinungen gleichzeitig vorhanden, die eine ist dabei jedoch immer dominierend, wie wir es im Fall des Türkenbildes gesehen haben, wo eindeutig die negativen Eigenschaften von größerer Bedeutung waren. Das Werk eines Zeitgenossen namens Joseph Langius scheint diese Hypothese zu belegen. Die Anthologia sive florilegium wurde zwischen 1598 und 1662 mehrfach aufgelegt und erlebte während des 17. Jahrhunderts eine weite Verbreitung. Der Verfasser spricht von zwei Möglichkeiten hinsichtlich des potentiellen Verhaltens gegenüber Fremden bzw. Feinden. Neben dem negativen Ansatz könnte man nämlich die Feinde ertragen und vor Gott sollte man sie lieben. ${ }^{158}$ Die letzteren entsprechen eigentlich der Bedeutung des Gastes des indogermanischen Wortes »ghostis« (Fremde). Diese Dualität war jedoch nicht nur dem Türkenbild eigen, auch in der antifranzösischen Publizistik sind neben den negativen Tönen positive Einschätzungen zu finden, was mit der verschiedenen politischen Einstellung der Reichsstände zu erklären ist. ${ }^{159}$

\section{IV.3. Die Apokalypse: Luther, der Teufel und der Antichrist}

»Wider die Türcken streiten / ist nicht anders / denn wider Gott streiten / der durch den Türcken unser Sünd strafft. ${ }^{160}$ Martin Luther wurde wegen dieser Äußerung stark kritisiert. Selbst die Lutheraner warfen ihm das vor. ${ }^{161}$ Man war nämlich nur damit einverstanden, daß Gott die Türken als Strafe geschickt hatte, um die Menschen dadurch zu verbessern und für ihre Sünden büßen zu lassen. Diese Aussage Luthers läßt sich dadurch erklären, daß er am Anfang gegen die Türkenkriege war, ${ }^{162}$ da er die größere Gefahr für die Christenheit in der katholischen Kirche, in dem Papst selbst sah: „so müste ich sagen / beydes bey den Türcken (...) were es sicherer (der Geistlicher Gefahr halber) als eben bey den Papisten. « In der besprochenen Flugschrift steht sogar, daß er im Fall einer Auseinandersetzung zwischen den »Machometischen Türcken« und den »Christlichen Türcken« »unserm Herren« raten würde, den »Machometischen Türcken« zu helfen. Einerseits geschieht bei ihm in einigen seiner Schriften die Gleichsetzung von Papst und Türke, ${ }^{163}$ andererseits steht in

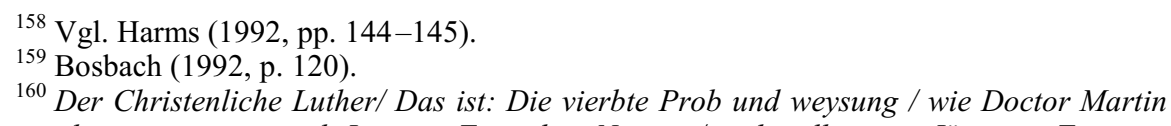
Luther an der verwustung und Jammer Teutscher Nation / sich selber am Jüngsten Tag entschuldigen werde. Allen Liebhabern Göttlicher Warheit und Seligkeit zum Besten gestellet: Durch. M. Conradum Andrea.Getrucktim Jar / M. D. XCVIII., Steiermärkische Landesbibliothek, C 129854 (im weiteren: »Der Christenliche Luther ... «(1598).

${ }^{161}$ In dem Dialog zwischen Luther und den Lutheranern in der zitierten Flugschrift äußerten sich die letzteren diesbezüglich auf die folgende Weise: »Ab dem sich nit Papisten / sonder auch wir Lutheraner selber entsetzen / und schemen müssen«. Ebd.

${ }^{162}$ Dazu ausführlicher siehe: Hoyer (1983, pp. 30-35).

${ }^{163}$ Vgl. »Der Christenliche Luther...«(1598), und Bosbach (1992, p. 124). 
der Flugschrift von 1598 folgender Satz: »Ich halte den Mahomet nicht für den Endechrist/ ec. Aber der Papst bey uns ist der rechte Endechrist. ${ }^{164}$ Bevor wir uns der Problematik der Apokalypse zuwenden, muß an dieser Stelle darauf hingewiesen werden, daß die katholische Kirche mit der gleichen Waffe zurückgeschlagen hat, als sie Luther mit dem Türken identifiziert hat. ${ }^{165}$ Danach wurde in der konfessionellen Polemik, im Kampf zwischen Protestantismus und Katholizismus ebenfalls auf antitürkische Traditionen zurückgegriffen. Ein Beispiel dafür liefert uns ein Hinweis, der auf der ersten Seite der zitierten Flugschrift von 1598 zu lesen ist: »Wann du vvilt sein ein rechter Christ: So sey ein Türck vvie Luther ist. Merck diß mein lieber Papist. ${ }^{166}$

Dieses Werk ist für uns auch deswegen von großer Bedeutung, weil darin die Wandlung von Luthers Türkenbild zu rekonstruieren ist. Nach der ersten Türkenbelagerung Wiens (1529) begann er, sich plötzlich ganz intensiv mit der Türkenfrage zu beschäftigen. Bereits die Titel seiner Werke wie »Vom Krieg wider die Türken« und »Heerpredigt wider den Türken $«{ }^{167}$ verweisen auf den Sinneswandel. ${ }^{168}$ In diesem Zusammenhang dürfen wir es nicht außer acht lassen, daß die deutsche Übersetzung des weiter oben zitierten Werkes von Johannes Lichtenberger in 1527 mit Luthers Einleitung veröffentlicht wurde. Darin wird darüber geschrieben, daß die Osmanen fast alle Länder in Europa erobern und bis Köln vorstoßen werden, wo es zu einer eschatologischen Endschlacht kommen wird. ${ }^{169}$ Auch die Vision Daniels in der Bibel über den endzeitlichen Widersacher ${ }^{170}$ muß auf Luther eine große Wirkung ausgeübt ha-

${ }^{164}$ Vgl. »Der Christenliche Luther... « (1598).

${ }^{165}$ Vgl. Bosbach (1992, p. 124).

166 »Der Christenliche Luther...« (1598).

${ }^{167}$ Zitiert nach: Hoyer (1983, p. 35).

${ }^{168} \mathrm{Zu}$ dieser Wandlung konnte unter anderem auch das Werk von Georgius de Hungaria, das Luther zu dieser Zeit wieder veröffentlichte, beigetragen haben. Der Mühlbacher Anonymus (Georgius de Hungaria) war 20 Jahre in türkischer Gefangenschaft. In seinem »Incipit prophemium in tractatum de moribus, conditionibus et nequica Turcorum « erzählt er seine Erfahrungen, die er in der Gefangenschaft gesammelt hatte. In bezug auf dieses Werk sei auf Tardy (1977, pp. 49-153); Streitfeld (1973); Capesius - Göllner (1944) verwiesen.

${ }_{169}$ In der antitürkischen Propaganda Roms und der Humanisten sind die eschatologischen Elemente erst in der zweiten Hälfte des 15. Jahrhunderts (nach der Eroberung Konstantinopels, 1453) erschienen. Gerade zu dieser Zeit sind die Staaten auf dem Balkan dem Vordringen der Osmanen zu Opfer gefallen (Serbien 1459, Bosnien 1463, Albanien 1468). Die Muslime (die Sarazene) wurden jedoch bereits im Mittelalter den apokalyptischen Völkern zugeordnet, die Gott als Strafe wegen den Sünden der Christen auf die Erde geschickt hatte. Zur Verbreitung dieser Auffassung hat das Werk von Pseudo-Methodios, das im 8. Jahrhundert ins Lateinische übersetzt wurde, wesentlich beigetragen. Seine Gedanken über die Expansion des Islams wurden in Westeuropa überall bekannt. Dazu vgl. Fodor (1997, pp. 26-27). In der zweiten Hälfte des 15. Jahrhunderts beschäftigen sich auf dem deutschsprachigen Gebiet viele Verfasser mit der Apokalypse bzw. mit dem Antichristen. Der wichtigste von ihnen war der Dominikaner Wolfgang Aytinger, der 1496 Pseudo-Methodios' Werk ins Deutsche übersetzte und veröffentlichte. Vgl. McGinn (1995, p. 201). Diese Übersetzung schien den früheren Prophezeiungen (z.B. Lichtenbergers »Pronosticatio«) eine Bestätigung zu geben, die die Apokalypse mit den Osmanen in Verbindung gebracht haben.

${ }^{170} \mathrm{Zu}$ dieser Vision ausführlicher siehe: Szent Biblia (1995, pp. 839-840), und Wolter (1992, pp. 26-28). 
ben. ${ }^{171}$ Bis 1529 war für ihn ausschließlich der Papst der Antichrist. Erst von dem genannten Zeitpunkt an erscheint in seinen Schriften die Gleichsetzung von Türken, Teufel und Antichrist. Dementsprechend steht in der weiter oben zitierten Flugschrift von 1598 auch folgende Aussage: »Darumb ist kein zweiffel / das wer wider den Türcken streit / daß er wider den Teuffel selbst streit. Also das / wann er ein Türcken erwürgt / erwürget er gewißlich einen Feind Gottes unnd Lästerer Christi. ${ }^{172}$ Luther sah keinen großen Unterschied zwischen den Begriffen Antichrist und Teufel. Nach seiner Auffassung haben wir es eigentlich mit einem dualen Antichristen zu tun, der die Christenheit von zwei Seiten aus bedrohte: von innen die katholische Kirche, von außen die Osmanen. Es läßt sich dadurch feststellen, daß sich bei Luther die gleiche Entwicklung vollzogen hat, die wir bei Bedeutungswandel bzw. -erweiterung des Begriffs »Erbfeind « beobachtet haben, der aus der ursprünglichen religiösen Sphäre in die weltliche gelangte. Andererseits weist die Veränderung seiner Auffassung im Vergleich mit der von den meisten anderen Bewohnern des Reiches gerade eine Gegentendenz auf, weil die negativen Charakteristika erst nach der Wandlung betonter geworden sind.

$\mathrm{Da}$ es in diesem großen Kapitel nicht nur um die Türken, sondern um die Feindbilder im Heiligen Römischen Reich Deutscher Nation geht, muß an dieser Stelle auch von den anderen zwei Feinden die Rede sein. Die gegenreformatorische Ausrichtung der Politik von Karl V. gibt Erklärung für die antispanische Haltung Luthers. Er war der Meinung, daß die Deutschen wegen ihrer katholischen Religion vielmehr vor den Spaniern zu fürchten haben als vor den Osmanen. Aus diesem Grund antwortete er (laut einer ihm zugeschriebenen Sentenz) auf die Frage, ob Gott die Spanier oder die Türken unterstützen solle, auf folgende Weise: »Er sollte dem Machmetischen Türcken glück geben (...). Ursach ist diese /daß die Mahmetischen Türcken grobe unflätige Sew seynd / nicht wissen was sie leben oder glauben/ haben Gottes Wort nicht / noch Prediger desselben / hette sie ihr aber / so möchten sie vielleicht / ja doch etliche aus Sewen Menschen werden. Aber unsere Christliche Türcken haben Gottes Wort und Prediger / wollens gleichwol nicht hören / und werden aus Menschen eitel Sewe / schänden darzu den Nahmen Christi. ${ }^{173}$ Hier wurde bei der Argumentation das gleiche Motiv zur Hilfe gerufen, die wir im Fall der Flugschrift von 1598 gesehen haben. Viele Verfasser der antispanischen Flugschriften bedienten sich auch den Tiermetaphern. In diesem Sinne galt nicht nur der türkische Bluthund, sondern auch die spanische Mücke als Tier des Teufels oder stellte sogar den Satan selbst dar. ${ }^{174}$ Eine Analogie läßt sich in den antifranzösischen Flugschriften vom Ende des 17. Jahrhunderts beobachten, in denen den Franzosen teuflischer Charakter zugeschrieben wird. Im Mittelpunkt steht natürlich die Person von Ludwig XIV.: »eine schöne tripel-alliance, Mahomet, der allerchristliche Ludwig der grosse und der Teuffel. ${ }^{175}$ Der französische König habe nämlich seinen

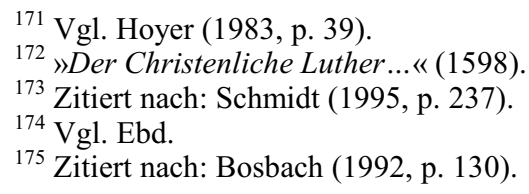


Taufbund mit Christus gekündigt und sich dem Teufel und seinem Sohn, dem türkischen Sultan angeschlossen.

Franz Bosbach ist der Meinung, daß die angeführten Übertragungen der Vorstellungen von den Türken auf andere Feinde, nämlich auf die Spanier und Franzosen, mit jenen tiefgreifenden Veränderungen in Verbindung zu bringen sind, die im ausgehenden Mittelalter und am Anfang der Frühen Neuzeit zur Auflösung der traditionellen und zur Entstehung neuer politischer Formen führten. ${ }^{176}$ In diesem Sinne bilden sie eine Komponente des weiter oben ausführlich geschilderten Entwicklungsprozesses.

\section{Die Verwandlung}

\section{V.1. Vom unbesiegbaren zum besiegten Feind}

Images und Feindbilder widerspiegeln das Gedankengut der sich mit dem Fremden konfrontierenden Gemeinschaft. Sie geben Anlaß zur Selbstbetrachtung, deswegen sind sie als Reflexionen der eigenen Identität zu bewerten. ${ }^{177}$ Zur Bestätigung des positiven Selbstbildes wurde im ganzen Türkenkriegzeitalter (auch zur Regierungszeit von Leopold I.) betont, daß nicht die Habsburger und ihre Untertanen für den Ausbruch der Türkenkriege verantwortlich sind. Diese Überzeugung fand bis 1683 in der Darstellung des habsburgischen Herrschers als "Germania ${ }^{178}$ einen besonderen Ausdruck. Ihre Gestalt wurde dem türkischen Sultan und dem spanischen und französischen König gegenübergestellt. Neben der Anspielung auf das Werk von Tacitus ${ }^{179}$ und der Bestätigung der eigenen Unschuld könnte dieses Phänomen eine weitere Bedeutung haben. Als ganz konkrete Selbtsreflexion könnte die Darstellung der »Germania« darauf hindeuten, daß den Habsburgern die Position und Machtstellung ihres Reiches unter den Staaten des frühneuzeitlichen Europas und die geringe Macht des Kaisers den Reichsständen und den Fürsten gegenüber bewußt war.

Das Jahr 1683 bedeutet auch in bezug auf die Selbstbetrachtung einen Wendepunkt, obwohl es zum eigentlichen Wandel erst nach der Befreiung Ofens (1686)

${ }^{176}$ Vgl. Ebd. (p. 139).

${ }^{177}$ Vgl. Schmidt (1995, p. 243).

${ }^{178}$ Man denke nur an die Discursen von Johann Georg Schielen, in denen unter den europäischen Herrschergestalten auch die Figur von Germania erscheint. Sie ist immer diejenige Person, die als »schwache Frau« während der Diskussionen der »Männer« (der anderen Herrscher) die Rolle der Schiedsrichterin spielt und sie zur Türkenabwehr auffordert. Vgl. Németh S. (1994, pp. 1-18).

${ }^{179}$ Es wurde bereits darauf hingewiesen, daß die »Germania« von Tacitus als kulturelle Identifikationsidee fungierte und die Geschichtsstudien der humanistischen Gelehrten des 16-17. Jahrhunderts durch den Hinweis auf dieses Werk darauf ausgerichtet waren, diese Identität zu bestätigen und zu stärken. 
kommen wird. ${ }^{180}$ Ein Gemälde mit dem Titel »Der Empfang der Osmanen« bringt das Wesen dieses Wandels zum Ausdruck. Es wurde nach der Befreiung von Belgrad (6. September 1688) geschaffen. Auch das Datum ist von großer Bedeutung, weil es den Habsburgern zu dieser Zeit, zwei Jahre nach der Befreiung Ofens (1686), mit Sicherheit bewußt geworden ist, daß das Osmanische Reich nicht mehr der unbesiegbare, höchtsgefährlichste Feind ist. Auf dem Bild zeigt sich diese Erkenntnis in der Gegenüberstellung der Figur des jungen Kurfürsten mit den Mitgliedern der türkischen Gefangenschaft, die alle sehr alt sind. Die Attribute »alt« und »jung« beweisen, daß das Resultat des besprochenen Wandlungsprozesses für die Habsburger einen Anfang und für die Osmanen ein Ende bedeutet. Ende des 17. Jahrhunderts beginnt nämlich die Großmachtstellung Österreichs und das Osmanische Reich verwandelt sich »zum Kranken am Bosporus«. Diesbezüglich läßt sich die Zeit des Großen Türkenkrieges (1683-1699) in folgende Perioden aufteilen:

1. Bis 1683 wurde der Türke für den unbesiegbaren Erbfeind gehalten. Es brauchte Zeit, bis die Habsburger ihre »Minderwertigkeitsgefühle«, die sich infolge der großen Erfolge der Osmanen im 16. Jahrhundert herausgebildet hatten, überwinden konnten, obwohl ihnen die im Osmanischen Reich herrschenden Verhältnisse $^{181}$ aus den Berichten ihrer Gesandten bekannt sein mußten. Es hat nämlich viel an Glanz verloren und die innenpolitischen Probleme hinterließen ihre Spuren auch in der Außenpolitik. Es ist jedoch fragwürdig, inwieweit der Kaiserhof über diese Probleme informiert war. Miklós Pálffy, der bedeutendste ungarische Feldherr des »langen Türkenkrieges«, formulierte seine Eindrücke 1594 auf folgende Weise: ${ }^{182}$

»Wir haben das muslimische Volk bisher für ein Kästchen gehalten, das unsere Vorfahren nicht zu öffnen wagten, weil gesagt wurde, es sei voll von Schlangen, Tausendfüßlern und Skorpionen, und wenn wir dieses Kästchen öffnen würden, würden diese unser Land überströmen und

${ }^{180}$ Bevor wir uns der Darstellung dieses Wandlungsprozesses zuwenden, muß darauf hingewiesen werden, daß wir es mit einem ganz komplexen Phänomen zu tun haben, das im Rahmen dieser Arbeit vollständig nicht dargestellt werden kann. Ich werde mich auf die Beschreibung der Haupttendenzen konzentrieren.

${ }^{181}$ Die Periode von der Niederlage der Osmanen bei Lepanto 1571 bis zum Frieden von Zsitvatorok bedeutet einen Wendepunkt in der Entwicklung der osmanischen Wirtschaft und Gesellschaft, der den Beginn einer neuen Epoche in der Geschichte des Osmanischen Reiches ankündigt. Obwohl das Reich in der ersten Hälfte des 17. Jahrhunderts noch keine großen Gebiete verlor, führten die erheblichen Kriegskosten zu einem Defizit des Budgets und zur Entwertung des akçe, was die innere Ordnung des Reiches erschütterte. Seine Wirtschaft konnte mit der Wirtschaftsentwicklung im Europa der Frühen Neuzeit nicht Schritt halten. Demzufolge kam es in der Sphäre der Regierung zu Machtkämpfen, woran auch die nach politischer Macht strebenden Janitscharen beteiligt waren. $\mathrm{Zu}$ weiteren Informationen siehe: Inalcik (1973, pp. 41-52) und Itzkowitz (1980, pp. $63-85)$.

${ }^{182}$ Im Winterzug von 1593/1594 haben sich die christlichen Heere zum ersten Mal in der Geschichte der habsburgisch-türkischen Auseinandersetzungen beachtenswerte Erfolge verzeichnen und dabei ein zusammenhängendes Gebiet zurückerobern können. Dazu ausführlicher siehe: Ágoston (1992, pp. 61-69). 
das Volk vernichten und töten. Aber jetzt, da es nötig war, machten wir es auf, und das Kästchen ist ganz leer, es gibt geradezu überhaupt nichts drin. Schade, daß wir bisher in diesem Wahn gelebt haben. ${ }^{183}$

Karl Nehring vertritt die Auffassung, daß sich die Vorstellungen der christlichen Welt von den Osmanen bereits nach dem Frieden von Zsitvatorok (11. November 1606) verändert hätten und das Osmanische Reich von diesem Zeitpunkt an als »Kranke von Bosporus« betrachtet worden wäre. Seine Argumentation basiert auf der Tatsache, daß der Sultan in diesem Frieden den Kaiser zum ersten Mal als gleichrangigen Herrscher anerkannte. ${ }^{184}$ Ich bin der Meinung, daß der Frieden von Zsitvatorok nur eine, natürlich wichtige, Komponente des erwähnten Wandlungsprozesses bildet. Zur Zeit der Köprülü-Großwesire (ab 1656) ist es noch einmal zu einer »scheinbaren Blüte« in der Geschichte des Osmanischen Reiches gekommen. Durch ihre Tätigkeit (besonders unter Köprülü Mehmed) konnte man die innere Krise zeitweise überwinden. Die positive Lage der Finanzen, des Heeres und der Flotte machten sogar weitere Expansionen möglich. Nach einer Friedensperiode von 57 Jahren führte Köprülü Ahmed seine Kriegsleute in 1663 wieder gegen Ungarn. Deswegen schien das Osmanische Reich von außen betrachtet viel stärker und gefährlicher zu sein als die eigentliche Wirklichkeit, die sich hinter der Fassade verbarg. ${ }^{185}$ Aus diesem Grund ist es verständlich, daß die Habsburger auch Anfang der achtziger Jahre des 17. Jahrhunderts die Türken für einen unbesiegbaren Feind hielten.

2. Erst die Kriegsereignisse zwischen 1683 und 1686, die Erfolge der kaiserlichen Truppen konnten die Habsburger davon überzeugen, daß die »Erbfeinde der Christenheit« besiegbar sind. In diesen Siegen kommt die Überlegenheit der europäischen Gesellschaftsordnung zum Ausdruck, die als Resultat der weiter oben geschilderten Entwicklungsprozesse, der Herausbildung der frühmodernen Staaten, zu bewerten ist. Parallel damit vollzog sich ebenfalls ein anderer Prozeß im Militärwesen Europas, der zu den Siegen der Kaiserlichen wesentlich beitrug. Das war die militärische Revolution, die die Aufstellung des stehenden Heeres und verschie-

${ }^{183}$ Übersetzt von Zsuzsa Barbarics. »Mi a muzulmán népet mostanáig olyan doboznak tartottuk, amelyet elödeink nem mertek felnyitni, mert azt mondták, hogy telis-tele van kígyókkal, százlábú férgekkel, skorpiókkal, s ha ezt a dobozt felnyitnánk, ezek országunkra kiáradnak, s a népet elpusztitják, megölik. Most azonban, szükséges lévén, mi felnyitottuk, és a doboz teljesen üres, éppen semmi sincs benne. Kár, hogy ilyen hiedelemben töltöttük mostanáig életünket. « Zitiert nach: Ebd. (p. 64).

${ }^{184}$ Nehring (1986, pp. 3-49). Seit diesem Zeitpunkt nennt der Sultan den habsburgischen Herrscher einen Kaiser statt der alten Bezeichnung, die »Wiener König« hieß. Außerdem machte die Pforte eine bedeutende Geste: sie verzichtete auf die Steuerzahlung der Habsburger, die jährlich 30000 Forint betrug. Der Kaiser mußte nur einmal ein Geschenk in Höhe von 200000 Forint nach Konstantinopel schicken. Wir dürfen es nicht außer acht lassen, daß die Osmanen zu dieser Zeit im Osten schwierige Probleme zu bekämpfen hatten, wie z.B. die Dschelali-Aufstände in Anatolien oder den Krieg gegen Persien, die ihre Bereitschaft zu den Friedensverhandlungen erhöhten. Vgl. Pannon Enciklopédia (1997, p. 139). $52-56)$.

${ }^{185}$ Über die Köprülü-Großwesire ausführlicher siehe: Fodor-Hegyi-Ivanics (1993, pp. 
dene technische Innovationen mit sich brachte. ${ }^{186}$ Auch mit dieser Entwicklung konnten die Osmanen nicht Schritt halten. ${ }^{187}$

3. Die Überzeugung von der Besiegbarkeit der Türken ist in der dritten Periode, zwischen 1686 und 1697/1699 fest geworden. Ein Beweis für diese Feststellung liefert uns das erwähnte Bild mit dem Titel »Der Empfang der Osmanen«, das nach der Befreiung von Belgrad geschaffen wurde. Viele vertreten die Meinung, daß der Sieg des christlichen Heeres bei Zenta (11. September 1697) gleichzeitig als Geburtsstunde der Österreichisch-Ungarischen Monarchie zu interpretieren ist. ${ }^{188}$ Bis 1699 war diese Schlacht die letzte, deren Echo in den Flugschriften des deutschsprachigen Raums noch zu rekonstruieren ist. ${ }^{189}$ Das scheint die Hypothese von Houston zu belegen, wonach die Anzahl der Produkte der Druckkunst immer von der jeweiligen politischen Situation bzw. von den politischen Veränderungen abhängt. ${ }^{190}$ Nach 1697 finden wir immer weniger antitürkische Propagandaschriften, was auch mit dem Beginn des Krieges gegen Frankreich zu erklären ist. Es wurde bereits darauf hingewiesen, daß man die größere Gefahr zu dieser Zeit schon in der Expansionspolitik Ludwigs XIV. sah.

4. Mit dem Friedensschluß von Karlowitz (26. Januar 1699) wurde der »Erbfeind der Christenheit« endlich zu einem besiegten Feind. In diesem Frieden mußte die Pforte eigentlich nur auf Gebiete verzichten, die sie im Laufe des Großen Türkenkrieges bereits verloren hatte. Siebenbürgen und fast das ganze Gebiet Ungarns (außer Temesköz) wurde von den Türken befreit. ${ }^{191}$ Von diesem Zeitpunkt an wird das Osmanische Reich nicht mehr als »Erbfeind der Christenheit« betrachtet. Es wird

${ }^{186}$ Zu der militärischen Revolution in Europa siehe: Parker (1992), und Black (1991).

${ }^{187}$ Gábor Ágoston hebt in seinen Aufsätzen hervor, daß die Gründe dafür - im Gegensatz zu früheren Meinungen -, nicht in der Abneigung der Osmanen gegen alles, was aus Europa stammte, zu suchen ist. Ansonsten könnte man die Anwesenheit deutscher, italienischer, französischer, ungarischer und niederländischer Artilleristen, Kanonengießer und Ingenieuroffiziere im osmanischen Heer, durch die die europäischen Innovationen auch im Osmanischen Reich bekannt und angewandt waren, nicht erklären. Die Entwicklung der osmanischen Artillerie hat ihren Höhepunkt im 15. Jahrhundert erreicht. Die meisten Forscher sind der Meinung, daß die militärische Revolution in Europa bereits in der zweiten Hälfte des 15. Jahrhunderts beginnt. Von diesem Zeitpunkt an bildet sich eine Kluft zwischen dem Entwicklungsgrad des osmanischen Militärwesens und der typologischen Vielfalt der europäischen Artillerie und anderer qualitativer Entwicklungen des Militärs in Europa heraus. Obwohl die Osmanen die Innovationen übernommen haben, haben sie jedoch den Fehler begangen, da $\beta$ sie auf die europäische Herausforderung nicht mit qualitativen, sondern mit quantitativen Veränderungen reagierten. Es wurde bereits in dieser $\mathrm{Ar}-$ beit darauf hingewiesen, daß den Osmanen bis zum Ende des 18. Jahrhunderts keine gedruckten Bücher zur Verfügung standen. Aus diesem Grund waren ihnen auch die Werke der europäischen Ballistikliteratur nicht bekannt. Auch dieses Phänomen beweist, was für eine wichtige Rolle die Druckkunst im Laufe der Geschichte gespielt hat, wie ihr Fehlen das Schicksal eines Reiches beeinflussen konnte. Vgl. Ágoston (1998, pp. 176-185), Ders. (1995, pp. 465-485), Ders. (1992, pp. 173-198).

${ }^{188}$ Vgl. Reifenscheid (1990, pp. 188-189).

${ }^{189}$ Buzási (1979, p. 128), und Galavics (1986, p. 109).

${ }^{190} \mathrm{Vgl}$. Houston (1995, p. 155).

${ }^{191}$ Szakály (1986, pp. 92-122). 
zum Teil des europäischen Staatensystems, mit dem man bei der Schaffung und Aufrechterhaltung des politischen Gleichgewichts in Europa immer rechnen muß. ${ }^{192}$

\section{V.2. Aus hostis naturalis zum Partner europäischer Staaten}

Der Frieden von Karlowitz (1699) bedeutete das Ende der Bedrohung des Abendlandes. Europa konnte endlich aufatmen. Diese »Erleichterung « hinterließ natürlich nicht nur auf der politischen, sondern auch auf der geistigen Ebene ihre Spuren. $\mathrm{Zu}$ diesen Spuren gehört die Wandlung des bisher konstanten Türkenbildes, die Umdeutung der verschiedenen Vorstellungen, die jahrhundertelang von den Türken ebenfalls existierten. Interessanterweise nahm dieser Prozeß nicht auf den der Gefahr konkret ausgesetzten Gebieten - in unserem Fall in den Erbländern -, sondern im weiter entfernt liegenden England und Frankreich seinen Anfang. ${ }^{193}$ Die erwähnte inhaltliche Umdeutung brauchte auch in diesen Ländern Zeit. Sie beginnt in der zweiten Hälfte des 15. Jahrhunderts und erreicht ihren Höhepunkt zur Zeit des Großen Türkenkrieges bzw. mit dem Friedensschluß von Karlowitz. Es wurde oft darauf hingewiesen, daß die Wandlung des Türkenbildes eine Komponente jenes komplexen Entwicklungsprozesses bildet, der die Auflösung der Respublica Christiana und die Entstehung der frühmodernen Staaten in Europa zur Folge hatte. Parallel zum Anfang dieses Entwicklungsprozesses lassen sich die Konturen eines neuen Türkenbildes beobachten, weil mit der Auflösung der Respublica Christiana auch ihr einheitliches Bild von den Sarazenen verschwindet bzw. eine Veränderung erfährt. Es wurde auch angedeutet, daß die an ihrer Stelle entstehenden Territorialstaaten (die Vorgänger der späteren Nationalstaaten) eine eigene Identität aufzubauen und zu behaupten versuchten. Dazu gehörte die Formulierung eigener politischer Ansätze bzw. Zielsetzungen, die auch die Richtlinien der Außenpolitik bestimmten. In erster Linie wollte man den Frieden für das ungestörte Leben der Untertanen und die Bedingungen für wirtschaftliche Entwicklung ungefährdet wissen. Das war jedoch vom Gleichgewicht der Kräfte unter den europäischen Staaten abhängig. Vom 16. Jahrhundert an waren immer mehr Machtinhaber von verschiedenen Staaten der Meinung, daß man in diesem Zusammenhang für die Aufrechterhaltung des Gleichgewichts der Kräfte in der Politik Europas auch den »Erbfeinden der Christenheit«, den Osmanen, eine bestimmte Rolle zuschreiben sollte. Mit der Aufstellung der ständigen Botschaften in Konstantinopel, ${ }^{194}$ d.h. durch den Beginn der diplomatischen Beziehungen, wurde offiziell anerkannt, daß das Osmanische Reich zum Teil des europäischen Staatensystems geworden ist, mit dem nicht nur Frieden, sondern auch Allianzen geschlossen werden konnten. ${ }^{195}$ Dem Beispiel Venedigs folgend versuchte Frankreich von

192 Ágoston (1997, pp. 83-99).

${ }^{193}$ Vgl. Grothaus (1983, pp. 82-88).

${ }^{194}$ Als erste europäische Macht hatte Venedig bereits ab 1454 einen ständigen diplomatischen Vertreter in Konstantinopel. Die Habsburger folgten seinem Beispiel erst 1547. Vgl. Ágoston (1997, pp. 89-90).

${ }_{195}$ Ebd. (pp. 86-98). 
den zwanziger Jahren des 16. Jahrhunderts an als Verbündeter des türkischen Sultans seine außenpolitischen Ziele zu verwirklichen. England und Frankreich pflegten sogar Beziehungen anderer Art mit den Osmanen. Davon zeugen die Handelsverträge, die die Basis für die türkisch-englischen bzw. französischen Handelsbeziehungen bildeten. ${ }^{196}$ England importierte daneben noch Kriegsmaterialen für die Osmanen, wie Schießpulver, Zinn, Blei usw. Diese Kriegsmateriallieferungen erregten natürlich allgemeines Mißfallen in den anderen europäischen Staaten. Der englische Botschafter gelangte deswegen in eine schwierige Lage. Nach Ottavio Bon (Botschafter der Republik Venedig) soll er sich diesbezüglich 1606 in seiner Verwirrung wie folgt geäußert haben: es gäbe in England genügend Schießpulver, aus diesem Grund schadet es niemandem, wenn »sie es für solche gute Freunde, wie die Türken exportieren $\ll{ }^{197}$ Diese Beispiele beweisen, wie sich das ursprüngliche Türkenbild polarisierte, da die einzelnen Staaten in Europa ihren außenpolitischen Zielsetzungen entsprechend ihr eigenes Türkenbild herausbildeten. Dadurch wurde der Türke aus hostis naturalis zum Partner europäischer Staaten. Diese Entwicklung erreicht in ganz Europa zur Zeit des Großen Türkenkrieges ihren Höhepunkt.

Die oben geschilderten Veränderungen sind im Heiligen Römischen Reich Deutscher Nation erst mit einer zeitlichen Verspätung zu beobachten. Charakteristischerweise sind die ersten Anzeichen der inhaltlichen Umdeutung des Türkenbildes im Norden des Reiches erschienen, wo die Menschen im Türkenkriegzeitalter der direkten Gefahr nie ausgesetzt waren. Diese veränderten Vorstellungen von den Türken können in den Erbländern erst später an Boden gewinnen. Davon zeugt z.B. die Zeit der Errichtung der Kaffeehäuser: das erste Kaffeehaus wurde in Hamburg bereits 1677 eröffnet, in Wien wurde das Privileg für den »Verkauf des östlichen Getränkes« erst nach der zweiten Türkenbelagerung Wiens (1683), im Jahre 1685 vergeben. ${ }^{198}$ In diesem Sinne vollzieht sich dieser Wandlungsprozeß im Vergleich mit der Entstehung des Türkenbildes, geographisch gesehen, in eine entgegengesetzte Richtung, nämlich von Norden nach Süden.

Die oben dargestellten Entwicklungssphasen, wie der Türke vom unbesiegbaren, zunächst zum besiegbaren und letztendlich zum besiegten Feind wird, lassen sich mit Hilfe der als Flugschriften veröffentlichten Türkenlieder rekonstruieren. ${ }^{199}$

${ }^{196}$ In der früheren Fachliteratur wurde angenommen, daß der erste offizielle türkisch-französische Vertrag 1536 unterschrieben wurde und als Wendepunkt in den türkisch-französischen Beziehungen betrachtet werden müßte. Dieser Vertrag wurde jedoch nie ratifiziert; aus diesem Grund bedeutet die Kapitulation von 1569 den Ausgangspunkt für die Handelsbeziehungen zwischen den beiden Staaten. Vgl. Ebd. (p. 90). Die englischen Kaufleute erhielten 1580 ein Handelsprivileg von dem Sultan. Danach sind die türkisch-englischen Handelsbeziehungen noch intensiver geworden. Vgl. Ágoston (1996, pp. 188-189).

${ }^{197}$ Zitiert nach Ebd. (p. 191).

${ }^{198}$ Vgl. Fodor (1993, pp. 35-39).

${ }^{199}$ Die besprochenen Entwicklungsphasen wurden aufgrund der Analyse von den Türkenliedern aufgestellt, die von Buchman und Özyurt herausgegeben wurden. Vgl. Buchmann (1983) und Özyurt (1972). An dieser Stelle kann diese Analyse vollständig nicht ausgeführt werden. Ich möchte die aufgestellte Hypothese mit einigen exemplarischen Beispielen belegen. 
Im Titel einer Flugschrift aus dem Jahre 1683 erscheint noch das ursprüngliche, von stereotypen Vorstellungen bestimmte Türkenbild: »(...) als im Jahr 1683 die Türcken und Tatern mit grosser Macht / unversehens / in Oesterreich eingefallen / und unerhörten Schaden / mit Morden, Rauben und Brennen hin und wider angerichtet. ${ }^{200}$ Ein ebenfalls 1683 veröffentlichtes Soldatenlied zeigt uns den Türken schon als besiegbaren Feind: »Türck, jetzt ist es dahin gekommen, Daß du werdest ganz labeth, Dann wir haben's vorgenommen, Daß dein Reich zu geht! « ${ }^{201}$ Von diesem Zeitpunkt an werden auch solche Bilder geschaffen, auf denen schon der besiegte Türke dargestellt wird. Diese Tatsache zeugt davon, daß das veränderte Türkenbild von den anderen Medien übernommen wurde. Infolge der Siege über die Türken zur Zeit des Großen Türkenkrieges erscheint eine neue Art von Türkenliedern, in der der Türke ausschließlich als besiegter Feind vorkommt: »(...) die Ottomaner Porten Wancket und zu Boden fallt.«, »(...) die Türkenhund (...), Voll und Toll zur Erd gesunken. « ${ }^{202}$ Dieses Lied ist eigentlich als Reflexion der eigenen Identität zu interpretieren, weil darin nicht mehr die Gestalt der »Germania« erscheint, sondern: »dem Röm. Adler die gebundene Flügel gelöst worden. ${ }^{203}$ Das beste Beispiel für die inhaltliche Umdeutung des ursprünglichen Feindbildes liefern uns die sogenannten Spottlieder. Wie ist es möglich, daß der »Erbfeind der Christenheit« in Spottliedern dargestellt und so gleichzeitig verspottet wird? Dieses Phänomen läßt sich nur mit dem Verschwinden der Türkenfurcht bzw. der Minderung der Gefahr erklären. Man fühlte sich nicht mehr bedroht, aus diesem Grund können in einem solchen Spottlied folgende Worte stehen: »Packe dich Bluthund, du PRIMO-VEZIER Nichts verfanget dein hundisches Pochen! Laufe nach Hause, du Mahomets Thier. «204 Das am häufigsten verwendete Motiv ist die Darstellung der Krankheit des Sultans, was eigentlich als eine Anspielung auf die laufenden historischen Ereignisse $\mathrm{zu}$ bewerten ist.: »Der nunmehr in letzten Zügen liegende Türkische Groß-Suldan und der ausländischen Medicorum über dessen Kranckheit gehaltenes Consilium. ${ }^{205}$ Es ist sehr interessant, daß die Teilnehmer dieses Consiliums die europäischen Herrscher, darunter auch die Reichsfürsten sind, die den türkischen Sultan »heilen« sollten.

${ }^{200}$ Zitiert nach: Buchmann (1983, p. 35).

${ }^{201}$ Zitiert nach: Ebd. (p. 43).

${ }^{202}$ Die Zitate stammen aus einem Türkenlied, das folgenden Titel trägt: »Poetisches TE DEUM LAUDAMUS, oder Glückwünschender Freuden-Ruff, als die Kays. Residentz und Haupt Statt WIEN der langwierigen Belägerung glücklich entsetzt, und dem Röm. Adler die gebundene Flügel gelöst worden.«In: Ebd. (p. 79).

${ }^{203}$ Ebd.

${ }^{204} \gg$ Hertz- und Magen-VOMITIV zur Kühlung Des Heiß-hungrigen und Blut-Durstigen Wolff-Magend, des PRIMO VEZIERS, Von den Hohn- und Spott-Ingredienten der Christlichen Potentanten, und von der Wienerischen Geschütz und Stück-Massa, Auff eine Dosis zugerichtet, und an statt eines kühlenden Syrups außzutrinken, fürgesetzet Von Gott Hilfft Wunderlich! Im Jahr Als Starnbergs Kvnst VerstanD Vnd Witz, BesCHVtzethat Des KäISers Sitz.«In: Ebd. (p. 87).

${ }^{205}$ Zitiert nach: Özyurt (1972, pp. 287-288). 


\section{Von der Türkenfurcht zur Türkenmode}

Die in den Flugschriften rekonstruierte Wandlung des Türkenbildes wurde langsam auch von den anderen Medien adaptiert. Es wurde bereits darauf hingewiesen, daß die veränderten Vorstellungen von dem »Erbfeind der Christenheit« im Heiligen Römischen Reich Deutscher Nation am spätesten in den Erbländern an Boden gewinnen konnten, wo sie sich ursprünglich herausgebildet haben. Grothaus hebt bereits in bezug auf diese Anfangsperiode hervor, daß das Türkenbild der Adelskultur und des einfachen Volkes bestimmte Unterschiede aufwies. Wegen der Dominanz der Stereotype waren jedoch diese Unterschiede ziemlich gering. Erst Ende des 17. Jahrhunderts ist diese Kluft größer geworden, sie entfernten sich Schritt für Schritt voneinander. ${ }^{206}$ Das für das Türkenbild charakteristische Dualitätsprinzip findet im Türkenbild dieser verschiedenen Gesellschaftsschichten einen neuen Ausdruck. Mit der Verminderung der Gefahr und der Angst kommen die von den negativen Stereotypen in den Hintergrund gestellten Vorstellungen an die Oberfläche. Dadurch wurde eigentlich die am Anfang aufgestellte Hypothese belegt, wonach die sich mit dem »Fremden« konfrontierende Gemeinschaft von ihm sowohl ein positives, als auch ein negatives Bild herausbilden kann. Die positive Annäherung wird der Adelskultur eigen, für das Türkenbild des einfachen Volkes bleiben für lange Zeit die negativen Stereotype bestimmend. Der Adel zeigte auch früher großes Interesse für die von den Türken repräsentierte Kultur des Orients, wovon die »Europäisierung«, eines der zwei Hauptcharakteristika des Türkenbildes, zeugt. Nach dem Großen Türkenkrieg fand dieses Interesse in der Türkenmode einen besonderen Ausdruck. Sie zeigte sich in verschiedenen Bereichen der menschlichen Kultur. Auch die Vertreter bzw. Forscher einzelner wissenschaftlicher Disziplinen richteten ihre Aufmerksamkeit auf die Kultur des ehemaligen »Erbfeindes der Christenheit«, wovon z.B. die Tätigkeit zweier Wiener Drucker zeugt. ${ }^{207}$ Johann B. Podesta studierte Orientalistik an der Universität von Rom, später trat er als Dolmetscher der orientalischen Sprachen in kaiserliche Dienste und verbrachte eine kurze Zeit als Gesandter in Konstantinopel. Nachdem er nach Wien zurückgekehrt ist, gründete er, als Professor der Universität Wien (ab 1674), mit einem Drucker namens Meninski das erste Institut für Orientalistik in Wien. ${ }^{208}$ Auch Die Märchen aus Tausendundeiner Nacht wurden erst Anfang des 18. Jahrhunderts ins Deutsche übersetzt. ${ }^{209}$ An dieser Stelle muß auf eine interessante Analogie hingewiesen werden. Hundert Jahre früher, Ende des 16. Jahrhunderts, hat sich der gleiche Prozeß in Spanien vollzogen. Die Wandlung des Türkenbildes in Spanien war eben-

${ }^{206}$ Vgl. Grothaus (1983, pp. 63-64).

${ }^{207}$ Im Rahmen dieser Arbeit kann ihre Tätigkeit ausführlich nicht dargestellt werden. Hier wird nur auf die relevantesten Elemente hingewiesen. $\mathrm{Zu}$ weiteren Informationen siehe: Mayer (1883).

${ }^{208}$ Das wissen wir aus seinen Hofeingaben und Zuschriften an den Hofkriegsrat und an die niederösterreichischen Stände. In einer seiner Zuschriften von 1677 betont er, wie wichtig die Kenntnis der orientalischen Sprachen für das Vaterland sei. Aus diesem Grund bittet er um Erlaubnis für die Gründung »des projektierten Collegiums« und der »von ihm mit eigenen Unkosten errichteten Arabisch-Türckische Truckerey«. Vgl. Ebd. (pp. 319-320).

${ }^{209}$ Vgl. Smitek (1992, pp. 53-58). 
falls Folge bestimmter Kriegsereignisse. Das wichtigste unter ihnen war die Niederlage der Osmanen bei Lepanto (1571), die die Spanier von der Besiegbarkeit der Osmanen überzeugte. Das türkisch-spanische Waffenstillstandsabkommen von 1578 und die Gründung der Kompanie von Levante deuten schon auf eine andere Art von Beziehungen hin. Auch die Spanier zeigten nach der Verminderung der Bedrohung ein großes Interesse für die Kultur des Osmanischen Reiches. ${ }^{210}$ Auf dem deutschsprachigen Gebiet mußte man auf diese Wandlung noch ein Jahrhundert warten.

Der Türke ist zum Symbol des orientalischen Lebensstils geworden, was natürlich auch in den bildenden Künsten ihre Spuren hinterließ. In der Adelskultur stößt man auf Portraits, auf denen die Adeligen türkische Kleidung tragen. Auch auf den Hoffesten kleidet man sich oft »türkisch«. Zu dieser Zeit erscheinen türkische Motive in der Barockarchitektur Österreichs. ${ }^{211}$ Die im Laufe des Großen Türkenkrieges erbeuteten türkische Waffen, Fahnen, und andere Gegenstände, die mit einem Oberbegriff »Türkenbeute« bezeichnet werden, galten als Statussymbol (besonders für den Adel in den Erbländern) und waren ein bedeutendes Mittel der Repräsentation und Propaganda. ${ }^{212}$ Besonders Ende des 17. Jahrhunderts war ein höfisches Vergnügen, das sogenannte »Türkenkopfstechen « ${ }^{213}$ bei dem österreichischen Adel beliebt. Auch auf dem Gebiet der Militärmusik in Österreich lassen sich türkische Einflüsse beobachten. Anfang des 18. Jahrhunderts bestand nämlich das Feldspiel der Infanterie immer noch aus Trommeln und Pfeifen. Den erwähnten Einfluß übte die türkische Janitscharbande mit seinen vielen Instrumenten aus. ${ }^{214}$ Auch große Komponisten wie Haydn, Mozart, Beethoven schrieben Werke »alla turca ${ }^{215}$

Im Gegensatz zu den oben geschilderten Erscheinungen in bezug auf die Adelskultur blieben die von negativen Stereotypen bestimmten Vorstellungen von den Türken in der Volkskultur noch lange erhalten. Das Erlebnis der direkten Konfrontation hinterließ in der Erinnerung der Menschen tiefe Spuren, was sich als ein Hindernis für die inhaltliche Umdeutung des Türkenbildes erwies. Auch hier spielten später die Türkenköpfe als Keilsteine in den Torbögen von Häusern eine wichtige Rolle, denen apotropäische Funktionen zugewiesen wurden. ${ }^{216}$ Danach kam es - zwar mit einer zeitlichen Verspätung - auch in der Volkskultur zu einer inhaltlichen Umdeutung des Türkenbildes.

Der im Rahmen dieser Arbeit dargestellte Prozeß beweist, daß sich ein lange Zeit konstantes Feindbild infolge einer kriegerischen Auseinandersetzung in Die Märchen aus Tausendundeiner Nacht verwandeln kann.

${ }^{210}$ Korpás (1999, pp. 31-32).

${ }^{211}$ Vgl. Vocelka (1977, pp. 32-34).

${ }^{212}$ Vgl. Selinsek (1996, pp. 38-40).

${ }^{213}$ Das eroberte Haupt des Gegners spielte in den Auseinandersetzungen mit den Osmanen immer eine wichtige Rolle. Durch dieses Fechtspiel, wobei auf einen entweder aus Holz oder aus Stein angefertigten Türkenkopf gezielt wurde, gingen die Wunschvorstellungen der Bewohnern des Habsburgerreiches - diesmal »theatralisch inszeniert - in Erfüllung. Vgl. Witzmann (1983a, p. 283).

${ }^{214}$ Vgl. Gall (1972, pp. 134-135); Sudár-Csörsz Rumen (1996).

${ }^{215}$ Vgl. Brunner (1996, pp. 22-23).

${ }^{216}$ Ebd. (p. 25). 


\section{Literatur}

Ágoston, G. (1992a): A hódolt Magyarország. Budapest.

Ágoston, G. (1992b) Párhuzamok és eltérések az oszmán és az európai tüzérség fejlődésében a 1517. században. Történelmi Szemle, 1992/3-4, pp. 173-198.

Ágoston, G. (1993): Habsburgs and Ottomans: Defense, Military Change and Shifts Power. Turkish Studies Association Bulletin, Vol. 22, No. 1, pp. 126-141.

Ágoston, G. (1995): Az európai hadügyi forradalom és az oszmánok. Történelmi Szemle, 1995/4, pp. $465-485$.

Ágoston, G. (1996): Koraújkori kiviteli tilalmak és fegyverkereskedelem: az oszmánok és Anglia. In: Lengvári, I. (szerk.): In Memoriam Barta Gábor. Tanulmányok Barta Gábor emlékére. Pécs, pp. 188-189.

Ágoston, G. (1997): Az oszmán és az európai diplomácia a kölcsönösség felé vezető úton. In: Híd a századok felett. Tanulmányok Katus László 70. születésnapjára. Pécs, University Press, pp. 83-99.

Ágoston, G. (1998): A tüzfegyverek elterjedése a muszlim világban. In: Tusor, P. (szerk.): $R$. Várkonyi Ágnes emlékkönyv. Budapest, pp. 176-185.

Ágoston, G. (1999): Információszerzés és kémkedés az Oszmán Birodalomban a 15-17. században. In: Információáramlás a magyar és a török végvári rendszerben. (Studia Agriensa 20). Eger, pp. 129-156.

Aulinger, R. (1980): Das Bild des Reichstages im 16. Jahrhundert. Beiträge zur typologischen Analyse schriftlicher und bildlicher Quellen. Göttingen, Vandenhoeck \& Ruprecht.

Bauer, J. (1982): Die Türken in Österreich. Geschichte, Sagen, Legenden. St. Pölten, Verlag Niederösterreichisches Pressehaus.

Benda, K. (1942): A törökkor német újságirodalma. A XV-XVII. századi német hírlapok magyar vonatkozásainak forráskritikájához. Budapest, Athenaeum Irodalmi és Nyomdai Rt.

Black, J. (1991): A Military Revolution? Military Change and European Society, 1500-1800. London.

Bodi, L. (1995): Traditionen des österreichischen Deutsch im Schnittpunkt von Staatsräson und Sprachnation. In: Österreichisches Deutsch. Linguistische, sozialpsychologische und sprachpolitische Aspekte einer nationalen Variante des Deutschen. Hrsg. von R. Muhr, P. Schrodt, P. Wiesinger. Wien, pp. 720-758.

Boronkai, I. (1980): Pápa vagy zsinat? Válogatott levelek. Aeneas Silvius Piccolomini. Budapest, Bibliotheca Historica.

Bosbach, F. (1992): Der französische Erbfeind. Zu einem deutschen Feindbild im Zeitalter Ludwig XIV. In: Feindbilder. Die Darstellung des Gegners in der Politischen Publizistik des Mittelalters und der Neuzeit. Hrsg. von Franz Bosbach. (= Bayreuther Historische Kolloquien Band 6). Köln-Weimar-Wien, Böhlau, pp. 117-139.

Brunner, M. (1996): Die Türkensagen in Oststeiermark. Graz.

Brunner, W. (1986): Türken, Pest und Habergeiss. Volkssagen aus dem Aichfeld und seinen Nebentälern. Graz.

Buchmann, B. M. (1983): Türkenlieder zu den Türkenkriegen und besonders zur zweiten Wiener Türkenbelagerung. Wien-Köln-Graz, Böhlau.

Buda Expugnata (1986): Buda Expugnata 1686. Europa et Hungaria 1683-1718. A török kiüzésének levéltári forrásai II. Budapest, Budapest Fővárosi Levéltárának kiadványa.

III. Buda és Pest (1935): III. Buda és Pest 1686 évi visszafoglalásának egykorú irodalma 16831718. A Fövárosi Nyilvános Könyvtár Budapesti gyüjteményének bibliográfiai munkálatai. Különnyomat a Fővárosi Könyvtár Évkönyve V. kötetéből. Budapest. 
Buzási, L. (1979): Haus-, Hof- und Staatsarchiv Wien. A birodalmi levéltárak magyar vonatkozású iratai. Bd. 1, Budapest.

Capesius, B.-Göllner, C. (1944): Der unbekannte Mühlbacher. Sibiu.

Clement, A. (1964): Handbuch der Feld- und Militärpost in Österreich. Graz.

Deutsche Literaturgeschichte (1989): Deutsche Literaturgeschichte. Von den Anfängen bis zur Gegenwart. 3. Auflage. Stuttgart, Metzler.

Drosdowski, G. (1989): Duden. Deutsches Universalwörterbuch. Mannheim-Wien-Zürich, Dudenverlag.

Eisenstein, E. (1997): Die Druckerpresse. Kulturrevolutionen im frühen modernen Europa. WienNew York, Springer.

Eybl M., F. (1992): Abraham a Sancta Clara. Vom Prediger zum Schriftsteller. Tübingen, Niemeyer.

Fodor, P. (1993): A kávészemek karrierje. Rubicon, 1993/1-2, pp. 35-39.

Fodor, P. (1997): Az apokaliptikus hagyomány és az ,aranyalma” legendája. A török a 15-16. századi magyar közvéleményben. Történelmi Szemle, 1997/1, pp. 21-49.

Fodor, P. - Hegyi, K. - Ivanics, M. (1993): Török és tatár hóditók. Budapest, Kossuth Könyvkiadó.

Foucault, M. (1997): Archäologie des Wissens. Frankfurt am Main, Suhrkamp.

Fügedi, R. (1976): Kimondhatatlan nyomorúság. Két emlékirat a 15-16. századi oszmán fogságról. Budapest, Európa Könyvkiadó.

Galavics, G. (1986): Kössünk kardot az pogány ellen. Török háborúk és képzőmüvészet. Budapest, Képzőmüvészeti Kiadó.

Gall, F. (1972): Türkische Einflüsse auf das äußere Bild der kaiserlichen Armee. In: Österreich und die Türken. Internationales Kulturhistorisches Symposion Mogersdorf 1969. Band 1. Eisenstadt, pp. 85-93.

G. Etényi, N. (1995): A 17. századi közvéleményformálás és propaganda Érsekújvár 1663-as ostromának tükrében. Aethas, pp. 95-139.

G. Etényi, N. (1999): Magyarországi ostromhírek az európai sajtóban (1663-1664). In: Információáramlás a magyar és a török végvári rendszerben. Studia Agriensa 20. Eger, pp. 83-105.

Göllner, C. (1978): Turcica III. Die Türkenfrage in der öffentlichen Meinung Europas im 16. Jahrhundert. Bukarest-Baden-Baden, Koerner.

Grothaus, M. (1983): Zum Türkenbild in der Adels- und Volkskultur der Habsburgermonarchie von 1650 bis 1800. In: Das Osmanische Reich und Europa von 1683 bis 1789. Konflikt, Spannung und Austausch. (= Wiener Beiträge zur Geschichte der Neuzeit. Band 10.) Hrsg. von Heiss, G. und Kligenstein, G. Wien, Verlag für Geschichte und Politik, pp. 63-87.

Grothaus, M. (1985): Zum Türkenbild in der Kultur der Habsburgermonarchie zwischen dem 16. und 18. Jahrhundert. Beihefte zur Wiener Zeitschrift für Kunde des Morgenlandes, pp. 67-89.

Habermas, J. (1999): A társadalmi nyilvánosság szerkezetváltozása. Budapest, Osiris.

Habey, H. A. (1994): Druckkunde für Germanisten, Literatur- und Geschichtswissenschaftler. Bern-Berlin-Frankfurt a. M.-New York-Paris-Wien, Peter Lang. (= Langs Germanistische Lehrbuchsammlung. Hrsg. von Roloff, H.-G. Band 50).

Harms, W. (1992): Feindbilder im illustrierten Flugblatt der frühen Neuzeit. In: Feindbilder. Die Darstellung des Gegners in der politischen Publizistik des Mittelalters und der Neuzeit. Hrsg. von F. Bosbach. (=Bayreuther Historische Kolloquien, Band 6).Wien-Köln-Weimar, Böhlau, pp. 141-177.

Heppner, H. (1986): Das Vordringen der Osmanen in Europa. In: Die Steiermark. Brücke und Bollwerk. Graz, pp. 143-145. 
Houston, R. A. (1995): Literacy in Early Modern Europe. Culture and Education 1500-1800. London-New York, Longman.

Hoyer, S. (1983): A török mint Antikrisztus. Adalék Luther Márton törökképéhez. Világtörténet, 1983/3, pp. $30-35$.

Hubay, I. (1948): Röplapok, újságlapok, röpiratok az Országos Széchényi Könyvtárban 14801718. Budapest.

Inalcik, H. (1973): The Ottoman Empire. The Classical Age 1300-1600. London.

Itzkowitz, N. (1980): Ottoman Empire and Islamic Tradition. Chicago, The University of Chicago Press.

Jontes, G. (1983): Leoben im Türkenjahr 1983. Die Auswirkungen der zweiten Wiener Türkenbelagerung auf das Land um den Steirischen Erzberg. 1. Teil. Alt = Leoben. Geschichtsblätter zur Vergangenheit von Stadt und Bezirk. Folge 15, März.

Káldy-Nagy, Gy. (1974): Szulejmán. Budapest, Gondolat Könyvkiadó.

Kapp, V. (1990): Die Sprache der Zeichen und Bilder. Rhetorik und nonverbale Kommunikation in der frühen Neuzeit. Marburg, Hitzeroth.

Kluge, F. (1989): Etymologisches Wörterbuch der Deutschen Sprache. 22. Aufl. Berlin-New York, de Gruyter.

Kocadoru, Y. (1990): Die Türken. Studien zu ihrem Bild und seiner Geschichte in Österreich. Klagenfurt, Universität für Bildungswissenschaften. Dissertation.

Köhbach, M. (1992): Imperium terribile et admirale - die osmanische Expansion und Europa. In: Begegnung zwischen Okzident und Orient. Ptuj, pp. 1-10.

Kohnke, M. (1986): Merseburg. Az egykori Brandenburgi Választófejedelemség iratai. In: Buda Expugnata 1986. Europa et Hungaria 1683-1718. A török kiüzésének levéltári forrásai II. Budapest Fővárosi Levéltárának kiadványa, pp. 603-637.

Koller, W. (1998): Stereotypes und Stereotype. Sozialpsychologische und linguistische Aspekte. Muttersprache. Vierteljahresschrift für deutsche Sprache, Jahrgang 108, März, pp. 1-16.

Köpeczi, B. (1976): „,Magyarország a kereszténység ellensége”. A Thököly-felkelés az európai közvéleményben. Budapest, Akadémiai Kiadó.

Korpás, Z. (1999): A török-magyar küzdelmek megjelenítése Lope de Vega néhány mủvében. SIC ITUR AD ASTRA, 1, pp. 31-32.

Kovács, S. (1971): Magyar humanisták levelei. Budapest, Gondolat Könyvkiadó.

Linke, A. (1998): Sprache, Gesellschaft und Geschichte. Überlegungen zur symbolischen Funktion kommunikativer Praktiken der Distanz. Zeitschrift für Germanistische Linguistik. Deutsche Sprache in Gegenwart und Geschichte. Hrsg. von H. Henne, A. Linke, S. Wichter, H. E. Wiegand. Berlin-New York, de Gruyter.

Mandlmayer, C. M. - Vocelka, G. K. (1981): Vom Adelsaufgebot zum stehenden Herr. Bemerkungen zum Funktionswandel des Adels im Kriegswesen der frühen Neuzeit. In: Sozialforschung und "Gesamtgeschichte". Beispiele und Methodenfragen zur Geschichte der frühen Neuzeit. Hrsg. von G. Klingenstein und Heinrich Lutz. (= Wiener Beiträge zur Geschichte der Neuzeit, Band 8.) Wien, Verlag für Geschichte und Politik, pp. 112-125.

Matuz, J. (1986): Das Osmanische Reich. Grundlinien seiner Geschichte. Darmstadt.

Mayer, A. (1883): Wiens Buchdruckergeschichte 1482-1882. Band 1: 1482-1682. Wien.

Meid, V. (1986): Barocklyrik. Stuttgart, Metzler, pp. 9-10.

Mezler-Andelberg, H. J. (1986): Schutzheilige gegen Feindesgefahr. In: Die Steiermark. Brücke und Bollwerk. Graz, pp. 179-181.

McGinn, B. (1995): Antikrisztus. Az emberiség kétezer éve a gonosz büvöletében. Budapest. 
Miksch, A. (1986): Drezda. Az egykori Szász Választófejedelemség iratai. In: Buda Expugnata 1686. Europa et Hungaria 1683-1718. A török kiüzésének levéltári forrásai II. Budapest. Budapest Fővárosi Levéltárának kiadványa, pp. 581-600.

Mörke, O. (1995): Pamphlet und Propaganda. Politische Kommunikation und technische Innovation in Westeuropa in der Frühen Neuzeit. In: Kommunikationsrevolutionen. Die neuen Medien des 16. und 19. Jahrhunderts. Hrsg. von M. North. Köln-Weimar-Wien, Böhlau, pp. $15-32$.

Mraz, G. (1985): Prinz Eugen und seine Zeit. Ein Leben in Bildern und Dokumenten. München, Süddeutscher Verlag.

Nehring, K. (1986): Magyarország és a zsitvatorki békeszerződés (1605-1608). Századok, 1986/1, pp. $3-49$.

Németh, S. K. (1994): Fiktív német beszélgetések Magyarországról (Johann Georg Schielen írásai 1683). Irodalomtörténeti Közlemények, 1994/1, pp. 1-18.

Newald, R. (1951): Die deutsche Literatur vom Späthumanismus zur Empfindsamkeit 1570-1750. München.

Özyurt, S. (1972): Die Türkenlieder und das Türkenbild in der deutschen Volksüberlieferung vom 16. bis zum 20. Jahrhundert. Motive, Freiburger folkloristische Forschungen, Bd. 4. München, Wilhelm Fink Verlag.

Pálffy, G. (1996): A török elleni védelmi rendszer szervezetének története a kezdetektől a 18. század elejéig. Történelmi Szemle, 1996/2-3, pp. 163-217.

Pálffy, G. (1999): Hírszerzés és hírközlés a törökkori Magyarországon. In: Információáramlás a magyar és a török végvári rendszerben. Studia Agriensa 20. Eger, pp. 33-63.

Pannon Enciklopédia (1997): Pannon Enciklopédia. A magyarság története. Budapest.

Parker, G. (1992): The Military Revolution. Military Innovation and the Rise of the West. 15001800. Cambridge.

Pauser, J. (1996): »Ain guets exempl furzutragen.« Die steirisch-krainische Bruderschaft vom goldenen Kreuz (1558) im Kampf gegen das »teüffelhafftig lasster« des Saufens und Fressens. Mitteilungen des Steiermärkischen Landesarchivs, Folge 46. Graz, pp. 59-97.

Petzoldt, L. (1993): Sagen aus der Steiermark. München, Diederichs.

Pickl, O. (1977): Nachschub für den Großen Türkenkrieg. Der Anteil der Steiermark an den siegreichen Feldzügen der Jahre 1683 bis 1686. Sonderdruck aus der Zeitschrift des Historischen Vereines für Steiermark. Graz, pp. 105-136.

Pickl, O. (1990): Kriegsfinanzierung als Faktor der Wirtschaftsbelebung. Die Ausgaben für das »Drau-Corps« 1684-1687 als »Investitionsspritze« für die Wirtschaft Innerösterreichs. In: Geschichtsforschung in Graz. Hrsg. von H. Ebner, H. Haselsteiner. Graz, pp. 81-90.

Pickl, O. (1992): Der Beitrag der Steiermark zu den Siegen im Türkenkrieg 1684-1688. Zur Logistik der Operationen an Drau und Save. In: Sonderdruck aus 800 Jahre Steiermark und Österreich 1192-1992. Der Beitrag der Steiermark zu Österreichs Größe. Hrsg. von O. Pickl. Graz, pp. 296-342.

Pieper, R. (1995): Informationszentren im Vergleich. Die Stellung Venedigs und Antwerpens im 16. Jahrhundert. In: Kommunikationsrevolutionen. Die neuen Medien des 16. und 19. Jahrhunderts. Wien-Köln-Weimar, Böhlau, pp. 45-60.

Pokorny, J. (1989): Indogermanisches Etymologisches Wörterbuch. 1. Band. Bern-Stuttgart, Francke Verlag.

Prümm, K. (1996): In der Hölle - im Paradies der Bilder. Medienstreit und Mediengebrauch. Literaturwissenschaft und Linguistik. Band 26, pp. 52-69. 
Pukánszky, B. (1931): Geschichte des deutschen Schrifttums in Ungarn. Von der ältesten Zeit bis um die Mitte des 18. Jahrhunderts. Erster Band (= Deutschtum und Ausland. Studien zum Auslandsdeutschtum und Auslandkultur). Münster.

Reifenscheid, R. (1990): Die Habsburger in Lebensbildern von Rudolf I. bis Karl I. Graz, Verlag Styria.

Roessler, P. (1998): Text, Satz, Druck. Prolegomena zur Auswahl und Sprachanalyse von Wiener Drucken des 17. und frühen 18. Jahrhunderts. In: Deutsche Sprache in Raum und Zeit. Festschrift für Peter Wiesinger zum 60. Geburtstag. P. Ernst-F. Patocha. Wien, Edition Praesens, pp. 623-642.

Schmidt, P. (1995): Das spanische Weltreich in der Propaganda des Dreißigjährigen Krieges. Eichstätt. Habilitationsschrift.

Schröder, T. (1995): Die ersten Zeitungen. Textgestaltung und Nachrichtenauswahl. Tübingen, Gunter Narr Verlag.

Schulze, H. (1999): Staat und Nation in der europäischen Geschichte. München.

Schwertl, G. (1986): Bajor Szabadállam. In: Buda Expugnata 1686. Europa et Hungaria 16831718. A török kiüzésének levéltári forrásai II. Budapest, Budapest Fővárosi Levéltárának kiadványa, pp. 687-723.

Selinsek, P. (1996): Das Türkenbild in der bildenden Kunst unter besonderer Berücksichtigung der Slowenischen Steiermark. Graz.

Simoniti, V. (1991): Vojaska organizacija na slovenskem v 16. stoletju. Ljubljana, Slovenska Matica.

Smitek, Z. (1992): Zur Rezeption der außereuropäischen Kulturen in der slowenischsprachigen Welt vom 17. Jahrhundert bis zur ersten Hälfte des 19. Jahrhunderts. In: Begegnung zwischen Orient und Okzident. Ptuj, pp. 53-58.

Sporhan-Krempel, L. (1968): Nürnberg als Nachrichtenzentrum zwischen 1400 und 1700. Nürnberg.

Streitfeld, Th. (1973): Wer war der Autor des »Tractatus de ritu et moribus Turcorum«. In: Forschungen zur Volks- und Landeskunde. Bd. 16. Bucuresti.

Sudár, B.-Csörsz Rumen, I. (1996): „Trombita, rézdob, tárogató...”. A török hadizene és Magyarország. Enying.

Szakály, F. (1972): Das Bauerntum und die Kämpfe gegen die Türken bzw. gegen Habsburg in Ungarn im 16-17. Jahrhundert. In: Ostmitteleuropäische Bauernbewegungen. Budapest, pp. 251-266.

Szakály, F. (1979): Phases of Turco-Hungarian Warfare before the Battle of Mohács (1365-1526). Acta Orientalia Academiae Scientiarum Hung., Tomus XXXIII (1), pp. 65-111.

Szakály, F. (1986): Hungaria Eliberata. Budavár visszavétele és Magyarország felszabaditása a török uralom alól 1683-1718. Budapest, Corvina Könyvkiadó.

Szent Biblia (1995). Fordította: Károli Gáspár. Budapest.

Talkenberger, H. (1994): Von der Illustration zur Interpretation: Das Bild als historische Quelle. Methodische Überlegungen zur Historischen Bildkunde. Zeitschrift für Historische Forschung. Band 21, pp. 289-313.

Tardy, L. (1977): Rabok, követek, kalmárok az Oszmán Birodalomról. Budapest, Gondolat Könyvkiadó.

Teply, K. (1983a): Die Türkenkriege in der historischen Forschung. Forschungen und Beiträge zur Wiener Stadtgeschichte. Wien, Franz Deuticke, pp. 23-38.

Teply, K. (1983b): Das österreichische Türkenkriegszeitalter. Die Türkenkriege in der historischen Forschung. Wien, Deuticke. 
Vocelka, K. (1977): Die inneren Auswirkungen der Auseinandersetzung Österreichs mit den Osmanen. Südost-Forschungen. Internationale Zeitschrift für Geschichte, Kultur und Landeskunde Südosteuropas. Band XXXVI. Hrsg. von Bernath Mathias R., München, Oldenburg, pp. $13-34$.

Vocelka, K. (1981): Die politische Propaganda Kaiser Rudolfs II. Wien, Verlag der Österreichischen Akademie der Wissenschaften.

Vocelka, K. (1988): Das Türkenbild des christlichen Abendlandes in der Frühen Neuzeit. In: Österreich und die Osmanen - Prinz Eugen und seine Zeit. (= Schriften des Instituts für Österreichskunde. Band 51-52. Hrsg. von Erich Zöllner und Karl Gutkas.) Wien, pp. $20-31$.

Voje, I. (1992): Die Türkeneinfälle in das Pettauer Gebiet und deren Folgen. In: Begegnung zwischen Orient und Okzident. Ptuj.

Wagner, Norimberg, Johann Christoph (1685): DELINATIO PROVINCIARUM PANNONIAE ET IMPERII TURCII IN ORIENTE. Eine Grundrichtige Beschreibung deß ganzen Aufgangs / sonderlich aber deß Hochloblichen KÖNIGRECHS UNGARN und der ganzen TURCKEN, Augsburg, Gedruckt und verlegt durch Jacob Koppmayer / Anno M.DC.LXXXV. Universitätsbibliothek Graz, RARA 1, II. 26332.

Wenzel, A. (1978): Stereotype in gesprochener Sprache. Form, Vorkommen und Funktion in Dialogen. Heutiges Deutsch, pp. 38-50.

Wiesenberger, D. (1986): Türken, Pestilenz und Heuschrecken. In: Die Steiermark. Brücke und Bollwerk. Graz, pp. 181-185.

Wiesflecker, H. (1986): Kaiser Maximilian I. Das Reich. Österreich und Europa an der Wende der Neuzeit. München.

Wiesinger, P. (1985a): Die Diagliederung des Deutschen seit dem 17. Jahrhundert. In: Sprachgeschichte. Ein Handbuch: der Geschichte der deutschen Sprache und ihrer Forschung, 2. Halbbd. Hrsg. von W. Besch, O. Reichmann, S. Sondegger. Berlin-New York. (Handbücher zur Sprach- und Kommunikationswissenschaft 2.2), pp. 1633-1651.

Wiesinger, P. (1985b): Die Entwicklung des Verhältnisses von Mundart und Standardsprache in Österreich. In: Sprachgeschichte. Ein Handbuch der Geschichte der deutschen Sprache und ihrer Forschung. 2. Halbbd. Hrsg. von W. Besch, O. Reichmann, S. Sondegger. BerlinNew York. (Handbücher zur Sprach- und Kommunikationswissenschaft 2.2), pp. 19391949.

Wiesinger, P. (1987): Zur Frage lutherisch-ostmitteldeutscher Spracheinflüsse auf Österreich im 17. und in der ersten Hälfte des 18. Jahrhunderts. In: Beiträge zur Sprachwirkung Martin Luthers im 17/18. Jahrhundert. Hrsg. von M. Lemmer. Halle (= Wissenschaftliche Beiträge 1987/10), pp. 83-109.

Witzmann, R. (1983a): Der Wandel des Türkenbildes in der Volkskunst - vom Verlierer zum orientalischen Pascha. In: Die Türken vor Wien. Europa und die Entscheidung an der Donau. Wien, pp. 288-290.

Witzmann, R. (1983b): Spielkarten mit Türkendarstellungen. Flugblatt - Türkenmode - Historische Reminiszenzen. In: Die Türken vor Wien. Europa und die Entscheidung an der Donau 1683. Wien, pp. 282-285.

Wolter, M. (1992): Der Gegner als endzeitlicher Widersager. Die Darstellung des Feindes in der jüdischen und christlichen Apokalyptik. In: Feindbilder. Die Darstellung des Gegners in der politischen Publizistik des Mittelalters und der Neuzeit. Hrsg. von F. Bosbach (= Bayreuther Historische Kolloquien, Band 6). Köln-Weimar-Wien, Böhlau, pp. 23-39.

Wurth, R. (1985): Die Familie Paar und das habsburgisch-erbländische Postwesen. In: Zwei Jahrtausende Postwesen. Vom cursus publicus zum Satelliten. Halbturn. 